Estudo e definição de ontologias como apoio ao desenvolvimento de módulos educacionais

Joice Basílio Machado 

SERVIÇO DE PÓS-GRADUAÇÃO DO ICMC-USP

Data de Depósito: 23/03/2012

Assinatura:

\title{
Estudo e definição de ontologias como apoio ao desenvolvimento de módulos educacionais
}

\author{
Joice Basílio Machado
}

Orientadora: Prof ${ }^{\mathrm{a}}$. Dr ${ }^{\mathrm{a}}$. Ellen Francine Barbosa

Dissertação apresentada ao Instituto de Ciências Matemáticas e de Computação - ICMC-USP, como parte dos requisitos para obtenção do título de Mestre em Ciências - Ciências de Computação e Matemática Computacional. EXEMPLAR DE DEFESA 
Ficha catalográfica elaborada pela Biblioteca Prof. Achille Bassi e Seção Técnica de Informática, ICMC/USP, com os dados fornecidos pelo(a) autor(a)

Basílio Machado, Joice
Estudo e definição de ontologias como apoio ao
desenvolvimento de módulos Educacionais / Joice
Basílio Machado; orientador Ellen Francine Barbosa. --
São Carlos, 2012.
97 p.
Dissertação (Mestrado - Programa de Pós-Graduação en
Ciências de Computação e Matemática Computacional) --
Instituto de Ciências Matemáticas e de Computação,
Universidade de São Paulo, 2012.
1. Modelagem de conteúdo. 2. Ontologia. 3.
Personalização de conteúdo. 4. Objeto de
aprendizagem. 5. Módulo educacional. I. Barbosa,
Ellen Francine, orient. II. Título.


Agradeço ao Bom Deus por me permitir cursar o mestrado e por ter me concedido tantas graças e presentes ao longo destes dois anos!

Agradeço à Ellen, minha cara orientadora, que durante todo o mestrado foi uma excelente orientadora, ensinando e direcionando o caminho da pesquisa; sempre solícita e generosa, uma amiga, uma mãe!

Agradeço à minha mãe, à minha família, ao meu noivo Leandro, aos meus amigos por todo o apoio, compreensão, ajuda e paciência para comigo.

Agradeço aos amigos do laboratório de engenharia de software - LabES - pela convivência agradável e formativa. Em especial ao Marco Aurélio por sua ética, senso crítico e solicitude, e a todos os queridos da minha turma: Neiza, Rodolfo, Draylson, Harry, Eliana, Silvana e Eduardo.

A todos os funcionários do ICMC, pelos serviços prestados.

À Universidade de São Paulo.

Ao CNPq e CAPES pelo apoio Financeiro. 

$\mathrm{O}$

desenvolvimento de conteúdos educacionais e a adoção de mecanismos de modelagem representam fatores importantes a serem considerados no contexto de ensino e aprendizagem. Nesse cenário, a utilização de ontologias proporciona vantagens tais como definição formal do conhecimento, reusabilidade e interoperabilidade de informações. Além disso, facilidades como recuperação dos objetos de aprendizagem, reúso do conteúdo de aprendizagem e personalização do conteúdo a partir do desempenho do usuário também são observadas. Diante disso, diversas aplicações com base em ontologias têm sido utilizadas tanto para modelar domínios educacionais como para construir, organizar e atualizar objetos de aprendizagem e perfis de aluno. Ainda, associado ao uso de ontologias em sistemas educacionais, verifica-se um crescente interesse na construção da personalização do conteúdo, de acordo com as preferências e características do usuário envolvendo a utilização de ontologias. O presente projeto está inserido nesse contexto, em que um conjunto de ontologias foi desenvolvido para prover a personalização do conteúdo, com base no perfil do usuário. Foi construído um exemplo na ontologia global (que compõe o conjunto de ontologias), em que o domínio de análise de ponto de função foi instanciado para três usuários com diferentes níveis de conhecimento. A ideia é elicitar a granularidade distinta do conteúdo para cada usuário, em conformidade com suas preferências e nível de conhecimento no domínio, a partir das relações e das inferências estabelecidas nas ontologias. 
The development of didactic material and adoption of modeling mechanisms represent important factors to be considered in the context teaching and learning. In this scenario, the use of ontologies provides advantages such as a formal definition of knowledge, reusability and interoperability of information. Moreover, facilities such as retrieval of learning objects, learning content reuse and customization of content from the user's performance are also observed. Therefore, several applications based on ontologies have been used to model so educational domains and to build, organize and update learning objects and student profiles. Also associated with the use of ontologies educational systems, there is an increasing interest in the personalization of the content, according to the user preferences and characteristics, involving the use of ontologies. This project is inserted in this context, where a set of ontologies was developed to provide the personalization of content based on user profile. We constructed an example in the ontology global (which defines the set of ontologies) in the domain of function point analysis was instantiated to three users with different levels of knowledge. The idea is to elicit the distinct granularity of the content for each learner, in accordance with their preferences and level of knowledge in the domain, from the relationships and inferences in the ontologies.

keywords: ontologies; learning object; personalization; educational modeling. 
1 Introdução 1

1.1 Contexto e Motivação . . . . . . . . . . . . . . . . . . . 1

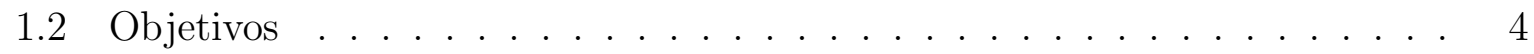

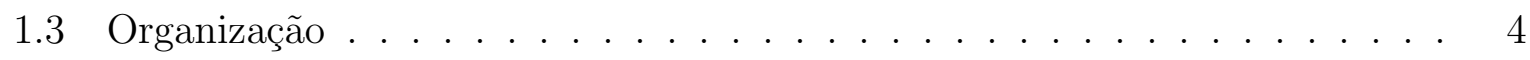

2 Revisão Bibliográfica $\quad 7$

2.1 Considerações Iniciais . . . . . . . . . . . . . . . . . . . . . . 7

2.2 Modelagem de Conteúdos Educacionais . . . . . . . . . . . . . . . . 8

2.2.1 Abordagem AIM-CID . . . . . . . . . . . . . . 8

2.2.1.1 Modelagem Conceitual . . . . . . . . . . . . . . . . . 9

2.2.1.2 Modelagem Instrucional . . . . . . . . . . . . . . . . . 10

2.2.1.3 Modelagem Didática . . . . . . . . . . . . . . 11

2.3 Ontologias . . . . . . . . . . . . . . . . . . . . . . . . 12

2.3.1 Conceitos Básicos . . . . . . . . . . . . . . . . . 14

2.3.1.1 Componentes . . . . . . . . . . . . . . . 14

2.3.1.2 Tipos de Ontologias . . . . . . . . . . . . . . . . 15

2.3.2 Processo de Desenvolvimento . . . . . . . . . . . . . . . . 16

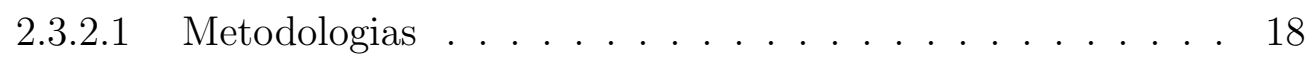

2.3.2.2 Linguagens . . . . . . . . . . . . . . . . . . . . 18

2.3.2.3 Ferramentas . . . . . . . . . . . . . . . . . . 19

2.3.3 Mapeamento de Ontologias . . . . . . . . . . . . . . . . 20

2.3 .4 Regras de Inferência . . . . . . . . . . . . . . . . . . . . . . . . . . . . . . . . . . . . . . . . . . . 22

2.4 Adaptação e Personalização . . . . . . . . . . . . . . . . . . 23

2.4.1 Adaptação: Conceitos Básicos . . . . . . . . . . . . . . . . . . . . . . . . . . . . . . . 23

2.4.2 Personalização: Conceitos Básicos . . . . . . . . . . . . 26

2.4.2.1 Modelo do Usuário . . . . . . . . . . . . . . . . . . . . . . 27

2.5 Personalização com base em Ontologias . . . . . . . . . . . . . . . . 30

2.5.1 Personalização do Conteúdo a partir de Anotação . . . . . . . . . . 31

2.5.2 Personalização a partir da Extração do Conteúdo da Ontologia . . . 34

2.5.3 Sistema de Gerenciamento de Ontologia para Personalização . . . . 35

2.5.4 Raciocínio com Base em Regras para Alteração da Navegação Padrão 36

2.6 Considerações Finais . . . . . . . . . . . . . . . . . . 38 
3 Um Conjunto de Ontologias para Personalização 39

3.1 Considerações Iniciais . . . . . . . . . . . . . . . . . . . . . . . . . 39

3.2 Proposta do Conjunto de Ontologias para Personalização . . . . . . . . . . 40

3.2.1 Onto-Imacid: Ontologia da IMA-CID . . . . . . . . . . . . . . . . 41

3.2.2 Onto-Domain: Ontologia de Domínio . . . . . . . . . . . . . 45

3.2.3 Onto-UserModel: Ontologia do Modelo do Usuário . . . . . . . . . 48

3.2.4 Onto-Navigation: Ontologia de Navegação . . . . . . . . . . . . . . 53

3.3 Considerações Finais . . . . . . . . . . . . . . . . . . . . 55

4 OntoToLearner - Uma Ontologia de Integração para Personalização 57

4.1 Considerações Iniciais . . . . . . . . . . . . . . . . . . 57

4.2 Processo de Composição da OntoToLearner . . . . . . . . . . . . . . . 58

4.3 Mapeamento e Instanciação das Ontologias . . . . . . . . . . . . . . . . . 60

4.3.1 Instanciação da Onto-Imacid . . . . . . . . . . . . . . . . . . . 61

4.3 .2 Instanciação da Onto-Domain . . . . . . . . . . . . . . . . . 62

4.3 .3 Instanciação da Onto-UserModel . . . . . . . . . . . . . . . . . . 64

4.3.4 Instanciação da Onto-Navigation . . . . . . . . . . . . . . 66

4.4 Exemplo de Instanciação . . . . . . . . . . . . . . . . . . . . . . . 68

4.4.1 Geração de Consultas e Visualização da Personalização . . . . . . . 69

4.5 Considerações Finais . . . . . . . . . . . . . . . . . 75

$\begin{array}{lll}5 & \text { Conclusão } & 77\end{array}$

5.1 Visão Geral . . . . . . . . . . . . . . . . . . . . . . . . . . . . . . . . . . . . . .

5.2 Contribuições . . . . . . . . . . . . . . . . . . . . . . 78

5.3 Trabalhos Futuros . . . . . . . . . . . . . . . . . . . . . . . 79

$\begin{array}{lr}\text { Referências Bibliográficas } & 86\end{array}$

$\begin{array}{ll}\text { A Questionário sobre o Usuário } & 87\end{array}$

B Questionário sobre Estilo de Aprendizagem $\quad 89$

$\begin{array}{ll}\text { C Questionário sobre APF } & 95\end{array}$ 
2.1 AIM-CID: Abordagem integrada para modelagem de conteúdos

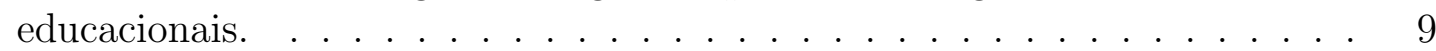

2.2 Elementos do modelo instrucional associados a ALOCoM-Ontology (Borges, 2010). . . . . . . . . . . . . . . . . . 11

2.3 Categorização das ontologias segundo Lassila e Mcguinness (2001). . . . . . 16

2.4 Processo de desenvolvimento de ontologias (Corcho et al., 2006). . . . . . . 17

2.5 Classificação das técnicas da hipermídia adaptativa (Adaptado de Knutov et al. (2009)). . . . . . . . . . . . . . . . . . . . 24

2.6 Tecnologias clássicas para AIWBES (Devedžic, 2006) . . . . . . . . . . 25

2.7 Correspondência entre os modelos IMS LIP e IEEE PAPI (Brusilovsky e Peylo, 2003). . . . . . . . . . . . . . . . . . 30

2.8 Ontologia do modelo do usuário (Jovanovic et al., 2006b) . . . . . . . . . . 33

2.9 Representação de uma ontologia (Capuano et al., 2009). . . . . . . . . . . . 34

3.1 Onto-IMACID: conceitos e relações. . . . . . . . . . . . . . . . . 42

3.2 Onto-IMACID: propriedades. . . . . . . . . . . . . . . . 43

3.3 Onto-Domain: ontologia de análise de ponto de função. . . . . . . . . . . 46

3.4 Onto-Domain: propriedades. . . . . . . . . . . . . 47

3.5 Exemplo da construção de um indivíduo na Protégé. . . . . . . . . . . . 48

3.6 Onto-UserModel: estrutura geral dos conceitos. . . . . . . . . . . . 50

3.7 Onto-UserModel: conceitos e relações. . . . . . . . . . . . . . . . 51

3.8 Onto-UserModel: propriedades. . . . . . . . . . . . . 53

3.9 Onto-Navigation: conceitos e propriedades. . . . . . . . . . . 54

3.10 Propriedades da Ontologia Onto-Navigation. . . . . . . . . . . . . 55

4.1 Composição da ontologia OntoTolearner. . . . . . . . . . . . . 58

4.2 Processo para a geração da ontologia de integração OntoToLEARnER. . . 59

4.3 Onto-Imacid: propriedades criadas na OnTOTOLEARneR. . . . . . . . . 61

4.4 Exemplo da instância d: processoAPF associada à OnTOTOLEARnER. . . 62

4.5 Possibilidades de apresentação do conteúdo para a Onto-Domain. . . . . 63

4.6 Exemplo de uma instância associada à OnTO-UserModel. . . . . . . . . 65

4.7 Exemplo de uma instância associada à Onto-Navigation. . . . . . . . . . . 67

4.8 Propriedades e suas instâncias para os usuários userA, userB e userC. . . . 68 
4.9 Consulta que retorna os usuários instanciados no curso. . . . . . . . . . . . 70

4.10 Consultas que retornam os usuários instanciados no curso de acordo com o perfil de usuário. . . . . . . . . . . . . . . . . . . . . . . 70 70

4.11 Instâncias que devem ser apresentadas para cada perfil de usuário. . . . . . 71

4.12 Consultas estabelecidas de acordo com os estilos de aprendizagem dos usuários. . . . . . . . . . . . . . . . . . . . 73

4.13 Instâncias dos conceitos para cada perfil de usuário de acordo com o estilo de aprendizagem. . . . . . . . . . . . . . . . . . . 73 


\section{Lista de Tabelas}

2.1 Comparação entre métodos de construção de ontologias. . . . . . . . . . . 18

2.2 Comparação entre linguagens de construção de ontologias (Corcho et al., 2006). . . . . . . . . . . . . . . . . . 19

2.3 Comparação entre as ferramentas para o desenvolvimento de ontologias. . . 20

3.1 Descrição dos conceitos da ontologia Onto-IMACID. . . . . . . . . . . . 43

3.2 Descrição das relações da ontologia OnTo-IMACID. . . . . . . . . . . . . . 44

3.3 Descrição dos conceitos da ontologia Onto-UserModel . . . . . . . . . . 49

3.4 Descrição das relações da ontologia UserModeL . . . . . . . . . . . . . . 52

3.5 Descrição das relações da ontologia Onto-Navigation . . . . . . . . . . . 55

4.1 Nível de conhecimento para o domínio dos usuários . . . . . . . . . . . . . 64 


\subsection{Contexto e Motivação}

No contexto de ensino e aprendizagem, o desenvolvimento de conteúdos educacionais e a adoção de mecanismos de modelagem representam importantes fatores a serem considerados. Tais mecanismos auxiliam o autor na definição e estruturação dos principais conceitos e relacionamentos associados ao domínio de conhecimento em questão, de forma a facilitar a padronização e reutilização do conteúdo.

Nessa perspectiva, foi proposta a abordagem $\mathcal{A} \mathcal{L} \mathcal{M}-\mathcal{C L D}$ (Abordagem Integrada de Modelagem - Conceitual, Instrucional e Didática) (Barbosa, 2004; Barbosa e Maldonado, 2006a, 2011a) - uma abordagem integrada de modelagem, composta por um conjunto de modelos, cada um deles tratando um aspecto específico da modelagem de conteúdos educacionais. O modelo conceitual consiste em uma descrição de alto nível do domínio de conhecimento que se deseja ensinar. Sua construção envolve a definição dos conceitos relevantes para a compreensão do domínio e a especificação da forma pela qual os mesmos se relacionam. O modelo instrucional visa a definir itens de informação e elementos instrucionais, associando-os aos conceitos já identificados. Por fim, o modelo didático é responsável por associar os objetos anteriormente modelados, estabelecendo uma sequência de apresentação entre eles.

Os mecanismos estabelecidos pela abordagem $\mathcal{A L M}-\mathcal{C I D}$ propiciaram tanto o desenvolvimento como a reestruturação de materiais didáticos a fim de facilitar o 
domínio e a disseminação de conhecimentos técnico-científicos em diversos contextos de conhecimento (Barbosa, 2004; Barbosa e Maldonado, 2006d; Borges, 2010; Corte et al., 2006).

Observa-se que, além da necessidade de modelar e desenvolver conteúdos educacionais de qualidade, a demanda por ensino e aprendizagem, com interações presenciais, à distância e/ou híbridas, tem resultado em um investimento significativo em pesquisa e desenvolvimento de ambientes virtuais de aprendizagem (Capuano et al., 2009). Aliado a esses fatores, nota-se o crescente interesse na construção e aplicação de ontologias no cenário educacional a fim de promover a interoperabilidade semântica e o compartilhamento do conhecimento (Gaeta et al., 2009).

Ontologia pode ser definida como uma especificação formal e explícita de uma conceituação, uma visão simplificada de um domínio de conhecimento (Gruber, 1995). Consiste de conceitos e relações, que definem um vocabulário específico usado para descrever um determinado domínio, e um conjunto de decisões explícitas (definições, propriedades e restrições), descritas na forma de axiomas, fixando de forma rigorosa o significado pretendido para o vocabulário.

Ontologias têm sido aplicadas em diversas áreas de conhecimento, tais como gestão do conhecimento, web semântica, recuperação da informação, inteligência artificial, processamento de linguagem natural, e-commerce, integração inteligente da informação, projeto e integração de banco de dados, bioinformática e educação (Corcho et al., 2006; Gomez-Perez et al., 2004; Heiyanthuduwage e Karunaratne, 2007). Entre os aspectos responsáveis pela crescente utilização de ontologias destacam-se: maior interoperabilidade, coerência e heterogeneidade semântica, alto nível de reúso, padronização e formalização do conhecimento, personalização de conteúdo de forma automatizada, entre outras.

No cenário educacional, várias pesquisas e aplicações baseadas em ontologias têm sido utilizadas. Entre razões para que as ontologias sejam incorporadas em ambientes educacionais tem-se (Heiyanthuduwage e Karunaratne, 2007): (i) prover o compartilhamento do entendimento comum de um dado domínio entre as pessoas e/ou agentes de software; (ii) permitir a reutilização do conhecimento do domínio; (iii) fazer suposições explícitas sobre o domínio; (iv) separar conhecimento do domínio de conhecimento operacional; e (v) analisar o conhecimento do domínio.

Outra linha de pesquisa associada envolve a aplicação de ontologias à adaptação e personalização de conteúdo, promovendo assim a criação de ambientes educacionais interoperáveis, compartilhados e personalizados para os alunos. Em síntese, a principal ideia da adaptação é baseada na suposição de que as características de diferentes usuários devem influenciar as funcionalidades oferecidas pelo serviço ou ambiente, apresentando a informação de maneira individual para os alunos ou usuários (Sosnovsky e Dicheva, 2010). 
A personalização é uma consequência da adaptação (Brusilovsky et al., 2009). Personalizar significa uniformizar as informações relevantes para cada usuário em particular (Chi e Lee, 2006). Segundo Gasparini et al. (2009), a personalização é o processo de adaptação de uma aplicação para as necessidades de usuários específicos, beneficiando-se da aquisição de conhecimento sobre eles. O uso de técnicas de personalização visa melhorar a usabilidade dos sistemas educacionais, personalizando a interface do usuário, conforme o seu perfil, e permitindo que cada usuário tenha uma percepção de que o sistema foi projetado especificamente para ele (Brusilovsky e Peylo, 2003).

Além disso, um conceito-chave no campo da personalização refere-se ao modelo do usuário ou perfil do usuário, que pode ser definido como a representação das características e preferências sobre o usuário, tratadas de maneira individual em um ambiente e/ou aplicação. Nesse contexto, existem diversas abordagens ontológicas que tratam a representação de modelos de usuário, das quais podem-se citar duas principais (Sosnovsky e Dicheva, 2010): (i) o emprego de ontologias para a modelagem da estrutura do domínio e representação das características do usuário, e (ii) a estrutura da modelagem do perfil do usuário. Vale ressaltar que, uma ontologia baseada em perfis de usuário é especialmente importante para sistemas com vários perfis ou para sistemas que podem se beneficiar de inferência em múltiplas ontologias, representando assim diferentes conhecimentos.

Consequentemente, o uso de técnicas de personalização aliado ao desenvolvimento de ontologias tem o objetivo de melhorar a interação dos usuários com os sistemas educacionais. Ao personalizar a apresentação do conteúdo para o usuário, considerando suas preferências e características, este tem a percepção de que o sistema foi projetado especificamente para ele. Associado aos benefícios da personalização, com base no modelo do usuário, a inserção de ontologias nas aplicações favorece o compartilhamento, a padronização, o reúso e a apresentação personalizada do conhecimento.

Apesar das vantagens observadas, nota-se que a maioria dos ambientes de aprendizagem não dispõem de mecanismos de adaptação. Em decorrência disso, algumas desvantagens podem ser evidenciadas: (i) dificuldade em instanciar as diferentes granularidades de conhecimento para os usuários; (ii) pouco (ou nenhum) estímulo ao envolvimento do usuário com o curso; e (iii) pouca (ou nenhuma) consideração do feedback do usuário para gerenciar próximas atividades ou até mesmo para criar novos materiais ou cursos.

O presente trabalho insere-se nesse cenário, sendo seus objetivos detalhados a seguir. 


\subsection{Objetivos}

Este trabalho tem como principal objetivo explorar o desenvolvimento e a utilização de ontologias, e associado a aspectos de modelagem educacional, na personalização de conteúdos. Nesse sentido, é proposto um conjunto de ontologias que apoia a personalização de conteúdo, de acordo com o perfil do usuário, organizando o conteúdo com base na abordagem $\mathcal{A} \mathcal{L} \mathcal{M}-\mathcal{C} \mathcal{L} D$.

O conjunto de ontologias para gerar a personalização do conteúdo é formado por quatro ontologias: (i) uma ontologia educacional com base nos modelos da $\mathcal{A L M}-\mathcal{C L D}$; (ii) uma ontologia do modelo do usuário, para estabelecer as características do usuário;

(iii) uma ontologia de navegação, a fim de dissociar as regras de apresentação do domínio do conteúdo; e (iv) uma ontologia de domínio, para instanciar a ontologia da $\mathcal{A} \mathcal{L} M-\mathcal{C L D}$ e associar as demais ontologias, a fim de visualizar os resultados projetados.

A partir das ontologias estabelecidas fez-se necessário o desenvolvimento de uma quinta ontologia, a ontologia de integração, com o objetivo de facilitar a manutenibilidade, reusabilidade e interoperabilidade das ontologias. Nesta ontologia foram elaboradas a construção do mapeamento entre as propriedades das ontologias, as regras de inferência para gerar a personalização de forma automática, as consultas para visualizar a personalização, e a instanciação dos indivíduos das ontologias.

Por fim, ainda como parte dos objetivos deste trabalho, os aspectos investigados são explorados em um exemplo de instanciação na ontologia de integração, considerando-se o domínio de Análise de Ponto de Função. Neste exemplo são criadas as propriedades, as instâncias dos conceitos e as consultas que exibem as inferências e os relacionamentos entre as ontologias. Dessa forma, o conteúdo é visualizado de acordo com o perfil do usuário, sendo estruturado em conformidade com a abordagem $\mathcal{A} \mathcal{I M}$ - CID e com as características de navegação estabelecidas entre as classes e instâncias na ontologia de integração.

\subsection{Organização}

Neste capítulo foram apresentados o contexto, a motivação e os objetivos da presente pesquisa. No Capítulo 2 é dada uma visão geral sobre modelagem educacional, em especial sobre os modelos da abordagem $\mathcal{A} \mathcal{L} \mathcal{M}-\mathcal{C L D}$. Ontologias, abordando definições, bem como seus aspectos de desenvolvimento, mapeamento e regras de inferência, também são sintetizadas. Além disso, os conceitos referentes à adaptação e personalização, assim como questões relacionadas à personalização construída a partir de ontologias também, são vistos. 
No Capítulo 3 são descritas as ontologias propostas neste projeto. Para cada ontologia conceitos, propriedades e instâncias são desenvolvidos e sumarizados.

No Capítulo 4 é apresentada a ontologia global - responsável para integrar as ontologias propostas. É descrito a composição da ontologia, seu processo de integração e a instanciação das ontologias desenvolvidas. Além disso, é ilustrado um exemplo de instanciação em que são exibidos os resultados de personalização segundo o perfil de três usuários.

Por fim, no Capítulo 5 é feita uma síntese dos principais resultados, contribuições da pesquisa realizada e perspectivas para a condução de trabalhos futuros. 
CAPÍTULO 1. INTRODUÇÃO 


\subsection{Considerações Iniciais}

A modelagem de conteúdos educacionais pode ser considerada um dos fatores primordiais para a criação de material de qualidade, que possa ser reutilizado e padronizado. Nesse contexto foi proposta a abordagem de modelagem de conteúdo educacional $\mathcal{A} \mathcal{L} M-\mathcal{C I D}$ (Barbosa, 2004), que é formada pelos modelos conceitual, instrucional e didático. Nesses modelos são estruturados e definidos os objetos de aprendizagem e/ou módulos educacionais para o domínio.

Aliado aos fatores, no campo de ensino e aprendizagem diversas abordagens utilizam ontologias para promover a formalização, o compartilhamento e a interoperabilidade dos conceitos. Agregando, ainda, aspectos de personalização do usuário, com a finalidade de construir aplicações que proporcionem uma maior interação entre o usuário e o material.

Neste capítulo são apresentados os principais conceitos envolvidos neste projeto. $\mathrm{Na}$ Seção 2.2 são apresentados os conceitos relacionados à modelagem educacional e à abordagem $\mathcal{A} \mathcal{I} M-\mathcal{C L D}$. Na Seção 2.3 são sumarizados os conceitos básicos, questões referentes ao processo de desenvolvimento, mapeamento e regras de inferência entre ontologias. Na Seção 2.4 são vistos os conceitos sobre adaptação e personalização. Por fim, na Seção 2.5 são descritos alguns trabalhos relacionados que aplicam a personalização por meio de ontologias. 


\subsection{Modelagem de Conteúdos Educacionais}

A preocupação com ensino e aprendizagem exige que vários aspectos sejam investigados, tais como (Barbosa, 2004): (i) a autoria de material didático; (ii) a apresentação do material, de maneira controlada, aos aprendizes; e (iii) o apoio à interação e à colaboração entre os atores do processo. Diante disso, diversos trabalhos têm sido desenvolvidos com o intuito de abordar tais aspectos, considerando especialmente a ideia de que o material gerado deve ter qualidade, deve ser reutilizado e compartilhado por várias aplicações e deve estar em conformidade com o perfil dos alunos ou aprendizes envolvidos.

Nesse contexto, uma das linhas de pesquisa investigada refere-se à construção de módulos educacionais - unidades concisas de estudo, compostas por conteúdos teóricos integrados a atividades práticas e avaliações, cuja disponibilização aos aprendizes é apoiada por recursos tecnológicos e computacionais (Barbosa, 2004; Barbosa e Maldonado, 2006a, 2011a,b).

Considerando o desenvolvimento de módulos educacionais, a modelagem dos conteúdos associados representa uma atividade essencial para a estruturação do conhecimento, apoiando a identificação e a definição de conceitos e informações pertinentes e possibilitando, em última análise, que os mesmos sejam disponibilizados de modo coerente e ordenado, com base em teorias e princípios educacionais previamente definidos. Portanto, a qualidade do material didático utilizado também constitui um fator determinante nessa perspectiva e, com isso, a modelagem de conteúdos torna-se um aspecto fundamental.

Diante disso, foi proposta a $\mathcal{A L M}$-CID uma abordagem para a modelagem e representação de conteúdos, embasada em teorias e princípios educacionais (Barbosa, 2004; Barbosa e Maldonado, 2006b, 2011a).

\subsubsection{Abordagem AIM-CID}

A abordagem $\mathcal{A} \mathcal{L}$ M - CID (Abordagem Integrada de Modelagem - Conceitual, Instrucional e Didática) (Barbosa, 2004; Barbosa e Maldonado, 2006b, 2011a) visa a reunir, em uma única proposta, diferentes visões de modelagem, caracterizando assim um conjunto de modelos genéricos para a representação de conteúdos educacionais. A abordagem foi proposta em 2004 e vem sendo adaptada e evoluída recentemente a fim de incorporar aspectos de desenvolvimento e aplicação distribuída e colaborativa aos conteúdos educacionais resultantes. A Figura 2.1 sintetiza os principais aspectos da abordagem.

Os modelos associados, já considerando algumas das extensões propostas em relação à abordagem original, são discutidos a seguir. 


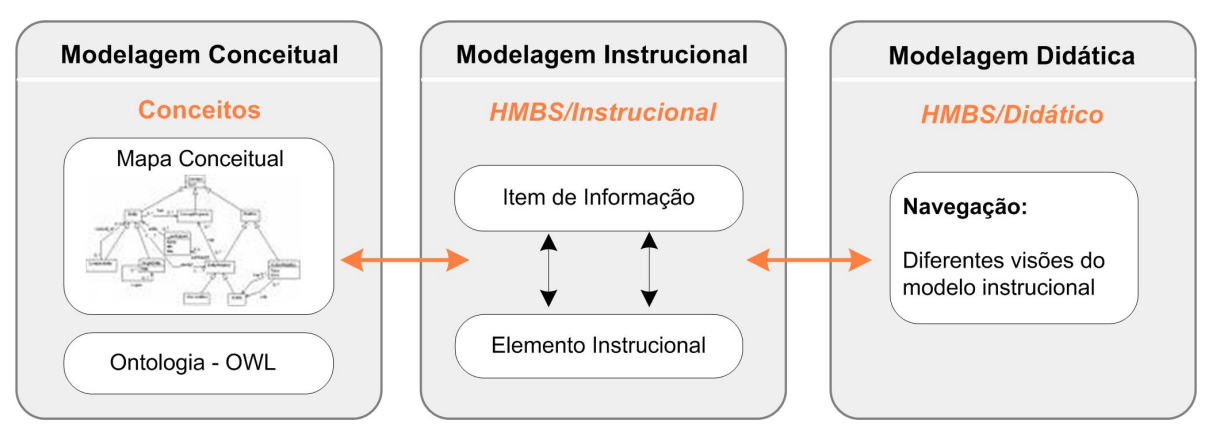

Figura 2.1: $\mathcal{A L M}$-CLD: Abordagem integrada para modelagem de conteúdos educacionais.

\subsubsection{Modelagem Conceitual}

O modelo conceitual consiste em uma descrição em alto nível do domínio que se deseja ensinar. Sua construção envolve a definição dos conceitos relevantes para a compreensão do domínio, a especificação de como tais conceitos se relacionam e o estabelecimento de uma estrutura para sua representação. Para a construção do modelo conceitual foi utilizada a técnica de mapas conceituais (Novak, 1990). Tal técnica foi selecionada por possibilitar uma representação gráfica adequada do domínio de conhecimento e, além disso, por se tratar de uma abordagem intuitiva mesmo para usuários não familiarizados. Ressalta-se, entretanto, o caráter subjetivo da utilização de mapas conceituais - sua construção, ainda que considerando um mesmo domínio de conhecimento, pode variar significativamente em função da perspectiva observada pelo desenvolvedor.

Como uma extensão à caracterização de conceitos foi investigada, na etapa de modelagem conceitual da abordagem $\mathcal{A} \mathcal{I} M-\mathcal{C} \mathcal{L} D$, a possibilidade de utilização de termos definidos em uma ontologia, mais especificamente, arquivos no formato OWL (Web Ontology Language) (Dean e Schreiber, 2004). A entrada por ontologias foi escolhida, sobretudo, devido ao fato de uma ontologia descrever um vocabulário comum de um dado domínio de conhecimento, por meio da definição do significado de termos e suas relações (Gruber, 1995). Este vocabulário, disponível no formato OWL, é capaz de representar integralmente as informações necessárias à modelagem conceitual.

A adoção de ontologias no nível conceitual pode gerar um melhor entendimento e, consequentemente, compartilhamento e reúso dos conceitos e relacionamentos representados. Como estudo preliminar, em trabalhos anteriores uma ontologia no domínio de Teste de Software - Onto Test (Barbosa e Maldonado, 2011b; Borges, 2009, 2010) foi utilizada como base para o desenvolvimento e evolução de um módulo educacional neste domínio. 


\subsubsection{Modelagem Instrucional}

O modelo instrucional é responsável pela definição de informações adicionais relativas aos conceitos previamente identificados. Nessa etapa são definidos e modelados itens de informação e elementos instrucionais. Por itens de informação compreende-se, além dos conceitos já identificados, todas as demais informações significativas do domínio de conhecimento as quais também devem ser representadas e incorporadas ao conteúdo educacional (Barbosa e Maldonado, 2006c).

Várias teorias e técnicas podem ser utilizadas a fim de apoiar a categorização de informações. No caso da abordagem $\mathcal{A} \mathcal{L} \mathcal{M}-\mathcal{C L D}$ foi considerada a teoria proposta por Merrill (Merrill, 1983), sendo especificados no modelo instrucional os seguintes itens de informação: conceitos (já representados no modelo conceitual), fatos, procedimentos e princípios.

Os elementos instrucionais, por sua vez, são informações adicionais que complementam os conceitos e demais itens de informação definidos. Tais elementos são representados a fim de melhor compreender e assimilar o domínio de conhecimento em questão. Como elementos instrucionais destacam-se (Barbosa e Maldonado, 2006c): exemplos, exercícios, dicas, sugestões de estudo, ferramentas, simulações, entre outros.

O modelo instrucional definido na abordagem $\mathcal{A} \mathcal{L}$ M - CID utiliza como base o HMBS (Hyperdocument Model Based on Statecharts) (Turine et al., 1997) - modelo para a especificação da estrutura semântica de hiperdocumentos, baseado na técnica de Statecharts - como modelo de especificação formal subjacente. Neste caso, o HMBS original foi desvinculado da representação de transições, eventos e mecanismos de história, e estendido para a representação de diferentes categorias de conhecimento (itens de informação e elementos instrucionais).

Como extensão ao modelo instrucional, foram caracterizadas as mídias que representam os itens de informação e elementos instrucionais (Borges, 2010). Tal caracterização teve como base a ALOCoM-Ontology (Abstract Learning Object Content Model - Ontology) (Verbert et al., 2004), discutida na Seção 2.5.1.

Para definir as mídias adequadas aos itens de informação e elementos instrucionais na abordagem $\mathcal{A L M}$ - CID foi utilizado o "conjunto fragmentos" de conteúdo, que agrega dois sub-conjuntos (Borges, 2010): (1) contínuo - caracterizado por animações, vídeos, áudios e simulações; e (2) descontínuo - caracterizado por textos, gráficos, links e imagens. A Figura 2.2 ilustra as mídias definidas para os elementos do modelo instrucional da abordagem $\mathcal{A} \mathcal{L} M-\mathcal{C L D}$, em conformidade com a ALOCoM-Ontology.

É importante observar que a representação adotada possibilita o uso do framework ALOCoM. O framework possui suporte a esquemas XML, permitindo a importação e 


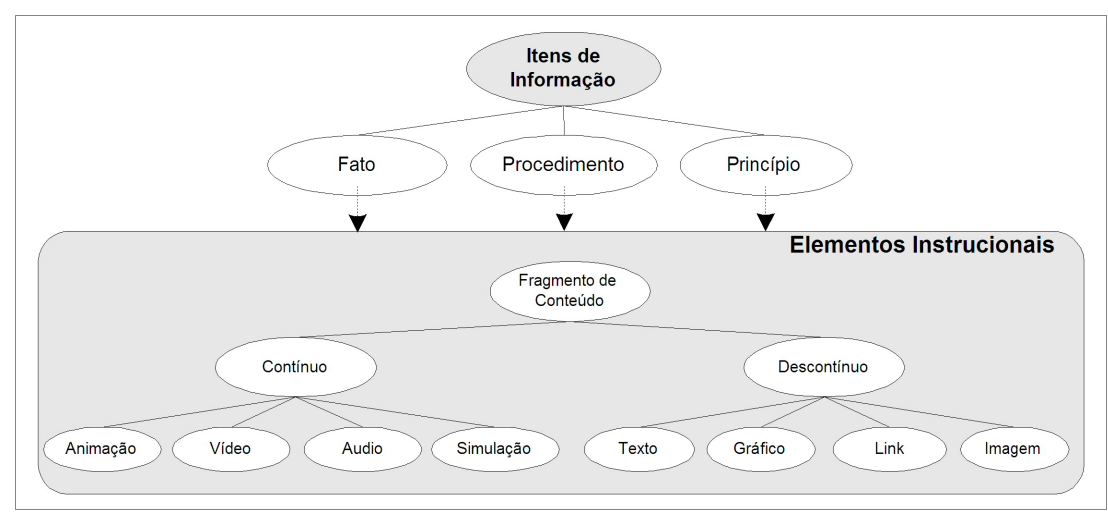

Figura 2.2: Elementos do modelo instrucional associados a ALOCoM-Ontology (Borges, 2010).

exportação para diferentes modelos como, por exemplo, o SCORM (Shareable Content Object Reference Model) (ADL, 2006). Tal aspecto vem sendo explorado com o objetivo de permitir que a $\mathcal{A L M}-\mathcal{C L D}$ apoie a geração automática de conteúdos segundo diferentes modelos e padronizações (LOM e SCORM). Nessa perspectiva, a padronização obtida por meio da utilização da ALOCoM-Ontology procura garantir a interoperabilidade, o compartilhamento e o reúso dos objetos de aprendizagem, ou seja, dos conteúdos educacionais desenvolvidos segundo a abordagem $\mathcal{A L M}-\mathcal{C L D}$ (Borges, 2010).

Por fim, ressalta-se que a especificação de mídias no nível instrucional da $\mathcal{A} \mathcal{L} M-\mathcal{C L D}$, em especial das mídias contínuas, constitui um fator relevante no desenvolvimento de conteúdos educacionais interativos, capazes de despertar no aprendiz o interesse pelos tópicos abordados, transformando-os em agentes no processo de construção do conhecimento.

\subsubsection{Modelagem Didática}

O modelo didático é responsável por associar os objetos anteriormente modelados, estabelecendo uma sequência de apresentação entre eles. A partir de um mesmo modelo instrucional é possível derivar diferentes modelos didáticos, ou seja, diferentes visões de um modelo instrucional. Desse modo, diferentes maneiras de utilização e disponibilização de conteúdo educacional, estabelecidas segundo os objetivos do curso, a estratégia pedagógica do professor e o perfil de cada aprendiz podem ser representadas por meio de modelos didáticos distintos (Barbosa e Maldonado, 2006c).

A construção do modelo didático também utiliza como base o HMBS. Nesse nível, além dos aspectos tratado no $\mathcal{H} \mathcal{M B S} /$ Instrucional, elementos associados à navegação e à especificação de aspectos comportamentais são representados, incorporando a ele a noção de especificação aberta dos aspectos de navegação. 
A especificação aberta apoia, em nível de modelagem e projeto, o estabelecimento de contextos de aprendizagem diferenciados. Além disso, quando fisicamente implementada no módulo educacional (implementação aberta), possibilita que a navegação seja definida pelo próprio usuário, em tempo de execução. Em outras palavras, o usuário tem total liberdade para decidir, dinamicamente, quais tópicos devem ser abordados e em que ordem os mesmos devem ser apresentados.

Portanto, pode-se afirmar que a abordagem $\mathcal{A L M}$ - CLD compõe os passos necessários para estruturar o conteúdo de acordo com os modelos conceitual, instrucional e didático, facilitando a padronização e a geração de material de qualidade.

Ressalta-se que, neste trabalho, a $\mathcal{A} \mathcal{L} M-\mathcal{C I D}$ foi utilizada como base para o estabelecimento de uma ontologia educacional, com o objetivo de desenvolver a personalização do conteúdo para o aluno com base em suas preferências e estruturando o conteúdo de acordo com a abordagem.

\subsection{Ontologias}

Neches et al. (1991) define ontologia como termos básicos e relações compreendendo o vocabulário de um tópico de uma área, bem como as regras para a combinação dos termos e das relações para definir as extensões do vocabulário. Uma definição mais simples e muito conhecida na comunidade é a de Gruber (Gruber, 1995), que definiu ontologia como uma especificação explícita de uma conceituação.

Já Uschold e Gruninger (1996) definem ontologia como o termo usado para se referir ao entendimento compartilhado de algum domínio de interesse que pode ser usado como uma estrutura unificadora para resolver problemas de interoperabilidade e falta de comunicação, por exemplo. Borst (1997) modificou alguns aspectos da definição de Gruber (1995), afirmando que ontologias são definidas como uma especificação formal de uma conceituação compartilhada.

Diante das definições apresentadas, pode-se observar que as ontologias necessariamente incluem um vocabulário de termos e alguma especificação de seu significado. Isto compreende a definição e a indicação de como os conceitos estão inter relacionados e, coletivamente, impõe uma estrutura sobre o domínio e restringe as possíveis interpretações dos termos (Corcho et al., 2006).

Neste trabalho, será utilizada a definição de Borst (1997) que, sucintamente, descreve os pontos fundamentais da abordagem ontológica: formalização e compartilhamento do conhecimento. Além desses fatores, outros benefícios são identificados por Guarino (1998): (i) capacitam o ambiente para a prática do alto nível de reúso, usando um vocabulário comum por meio de plataformas de softwares heterogêneos; e (ii) capacitam 
o ambiente para se concentrar na estrutura do domínio e na tarefa manual, protegendo-o de preocupações iniciais e da implementação de detalhes.

Marietto et al. (2002) também identificam algumas vantagens para o uso de ontologias, complementando os pontos anteriores:

i. Propiciam uma melhor compreensão do domínio abordado.

ii. Possibilitam o compartilhamento do conhecimento, considerando termos de um determinado domínio.

iii. Oferecem apoio à interoperabilidade entre sistemas computacionais, considerando o relacionamento de diferentes paradigmas, métodos, linguagens, etc.

iv. Possibilitam a troca de informações e o reúso do conhecimento.

v. Auxiliam na manutenção e documentação de sistemas computacionais.

No entanto, uma desvantagem que está presente na maioria das aplicações ontológicas refere-se à complexidade na construção de ontologias que tenham um grande número de conceitos, em que o domínio é considerado complexo e, que portanto, exigem um alto consumo de tempo. Situações como essa podem gerar erros relacionados tanto à compreensão do domínio quanto à implementação da ontologia (Capuano et al., 2009).

Pode-se afirmar, com base nas pesquisas recentes, que ontologias têm sido inseridas como forma de proporcionar interoperabilidade entre sistemas, coerência semântica, personalização de ambientes e perfis de alunos, entre outras especificidades. Ainda, segundo Wang e Hsu (2006), a motivação dessa variedade de aplicações e áreas, deve-se ao fato de que a ontologia é uma parte fundamental na estruturação da web semântica, atuando na transformação e no compartilhamento do conhecimento, e em sua reutilização no desenvolvimento de diferentes aplicações.

Nas últimas décadas, ontologias têm sido estudadas, desenvolvidas e aplicadas por diferentes grupos de pesquisas em áreas de conhecimento distintas. Em engenharia de software, ontologias relacionadas a métricas de software, gerência de riscos, teste de software e qualidade de software, entre outras sub-áreas, podem ser encontradas facilmente na literatura (Corcho et al., 2006; Costa e Gusmão, 2008; Moro e Falbo, 2009).

No campo de ensino e aprendizagem, diversas aplicações baseadas em ontologias também têm sido utilizadas tanto para modelar domínios educacionais como para construir, organizar e atualizar recursos específicos de aprendizagem (ou seja, objetos de aprendizagem, perfis de alunos, caminhos de aprendizagem, entre outros) (Gaeta et al., 2009). Portanto, as aplicações que envolvem ontologias podem favorecer, diretamente, a gerência e as competências na engenharia do conhecimento. 


\subsubsection{Conceitos Básicos}

Além das definições apresentadas, existem outros conceitos associados às ontologias e que são necessários para seu desenvolvimento. Entre eles destacam-se os componentes e os tipos de ontologias, descritos nas próximas seções.

\subsubsection{Componentes}

Ontologias, sejam de alto nível ou de baixo nível, são modeladas com diferentes técnicas, que podem ser: (1) altamente informais, (2) semi-informais, (3) semi-formais e (4) rigorosamente formais. As ontologias altamente informais expressam linguagem natural; as semi-informais expressam uma linguagem natural, de forma restrita e estruturada; as semi-formais expressam uma linguagem artificial, formalmente definida; e as rigorosamente formais prevêem termos meticulosamente definidos com semânticas formais, teoremas e provas de propriedades como solidez e completude (Gomez-Perez et al., 2004).

Independentemente do nível de formalismo da ontologia, existem diversos componentes para a formalização e implementação na representação do conhecimento. Cada representação fornece diferentes componentes que podem ser usados para a construção de suas tarefas. Embora exista uma ampla variedade de representações, há um conjunto mínimo de componentes que estão inclusos e são essenciais, a saber (Corcho et al., 2006): Classe, Relação, Axioma Formal e Instância.

- Classes: representam conceitos que são retirados de um domínio amplo e são organizados em taxonomias por meio de herança.

- Relações: representam um tipo de associação entre os conceitos do domínio. Elas são formalmente definidas como um subconjunto de um produto de $n$ conjuntos. As ontologias contêm relações binárias que são usadas para expressar atributos de conceitos. Atributos são usualmente diferenciados das relações pois suas extensões são tipos de dados, enquanto a extensão da relação é o próprio conceito.

- Axiomas formais: servem para modelar sentenças que são sempre verdade (Gruber, 1995). São usados, normalmente, para representar o conhecimento que não pode ser definido formalmente por outros componentes. Axiomas formais também são usados para verificar a consistência da própria ontologia ou a consistência do conhecimento armazenado. Além disso, são utilizados para a criação de inferências.

- Instâncias: são usadas para representar elementos ou indivíduos em uma ontologia. 
De acordo com a ontologia a ser definida e dependendo do nível de formalidade exigido e do conhecimento e experiência da equipe, pode-se escolher um paradigma de desenvolvimento que modele os componentes necessários em conformidade com a aplicação. Há diversos modelos de construção com seus respectivos componentes de modelagem. Entre eles, destacam-se (Gomez-Perez et al., 2004):

- Frames e Lógica de Primeira Ordem: classes, relacionamentos, funções, axiomas formais e instâncias.

- Lógica de Descrição: conceitos, regras e indivíduos.

- UML (Unified Modeling Language): conceitos, relações binárias e axiomas formais.

- Banco de Dados: classes, atributos e axiomas representados por restrições (constraints).

É importante observar que, independentemente do paradigma usado para modelar os conceitos do domínio, a ontologia deve ser um modelo de conhecimento compartilhado e consensual, acordado por uma comunidade. Dessa forma, espera-se que os objetivos sejam alcançados, que o conhecimento extraído seja coerente com o domínio, e que a formalização esteja de acordo com o nível exigido da aplicação. Na próxima seção serão apresentados alguns tipos de ontologias e suas classificações.

\subsubsection{Tipos de Ontologias}

Algumas categorizações ontológicas podem ser encontradas na literatura. Mizoguchi et al. (1995) caracterizam quatro tipos de ontologias: Ontologias de Conteúdo, Ontologias de Tarefa e de Comunicação, Ontologias de Indexação e Meta-Ontologias.

1. Ontologias de conteúdo: usadas para reúso de conhecimento.

(a) Ontologias de domínio: são reusáveis em um domínio específico (médico, farmacêutico, automobilístico). Essas ontologias fornecem vocabulários sobre conceitos dentro do domínio e de seus relacionamentos, sobre as atividades e teorias desenvolvidas e os princípios elementares que governam o domínio.

(b) Ontologias de tarefa: fornecem um vocabulário sistemático dos termos usados para resolver os problemas associados às tarefas que podem ou não pertencer ao mesmo domínio.

(c) Ontologias gerais ou comuns: usadas para representar conhecimento reusável de senso comum para vários domínios. 
2. Ontologias de comunicação: usadas para conhecimento compartilhado.

3. Ontologias de indexação: usadas em casos de recuperação.

4. Meta-ontologias: são equivalentes às ontologias de representação do conhecimento.

Outra classificação foi feita por Lassila e Mcguinness (2001), na qual as ontologias foram categorizadas de acordo com a informação necessária para expressar e enriquecer suas estruturas internas, apontando as seguintes categorias: vocabulários controlados, glossários, hierarquia informal do tipo é-um, instâncias formais, frames, restrição de valores e restrições de lógica geral. Na Figura 2.3 a ideia proposta é sumarizada.

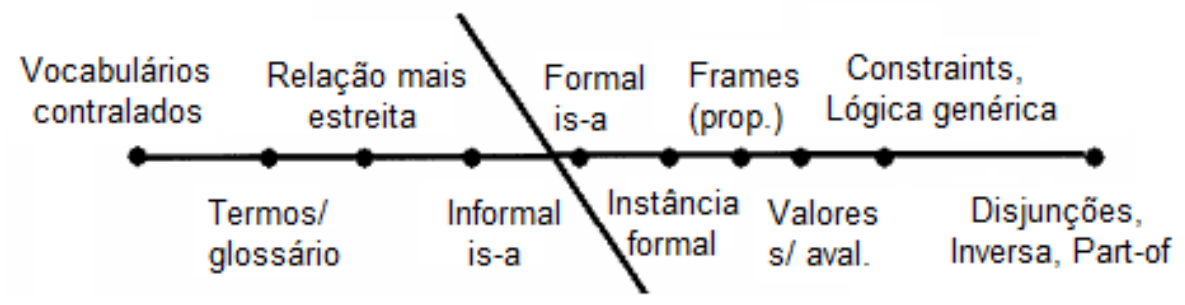

Figura 2.3: Categorização das ontologias segundo Lassila e Mcguinness (2001).

As ontologias ainda podem ser classificadas de acordo com suas estruturas internas, por exemplo (Corcho et al., 2006): ontologias de representação do conhecimento, ontologias de alto-nível, ontologias de domínio, ontologias de tarefa, ontologias de tarefa de domínio, ontologias de métodos e ontologias de aplicação.

As classificações sintetizadas são importantes para orientar o desenvolvimento ontológico, pois apontam as características e particularidades atribuídas a cada categoria e, portanto ao domínio. Dessa forma, a categorização direciona alguns aspectos relevantes no processo de construção, como o nível de restrições e de formalidade, colaborando de forma direta na definição da ontologia e de suas especificidades.

\subsubsection{Processo de Desenvolvimento}

Assim como a Engenharia de Software, a Engenharia Ontológica estabelece um processo e diretrizes, indicando e descrevendo os passos do ciclo de vida e de desenvolvimento para a construção das ontologias. O processo de desenvolvimento de ontologias proposto por Corcho et al. (2006) incorpora as atividades referentes à construção da ontologia, classificadas em três categorias - Gerenciamento, Desenvolvimento e Apoio - conforme ilustrado na Figura 2.4.

A proposta foi baseada no padrão de desenvolvimento de software da IEEE (1996). As fases e suas respectivas atividades do processo de desenvolvimento são definidas resumidamente (Corcho et al., 2006): 

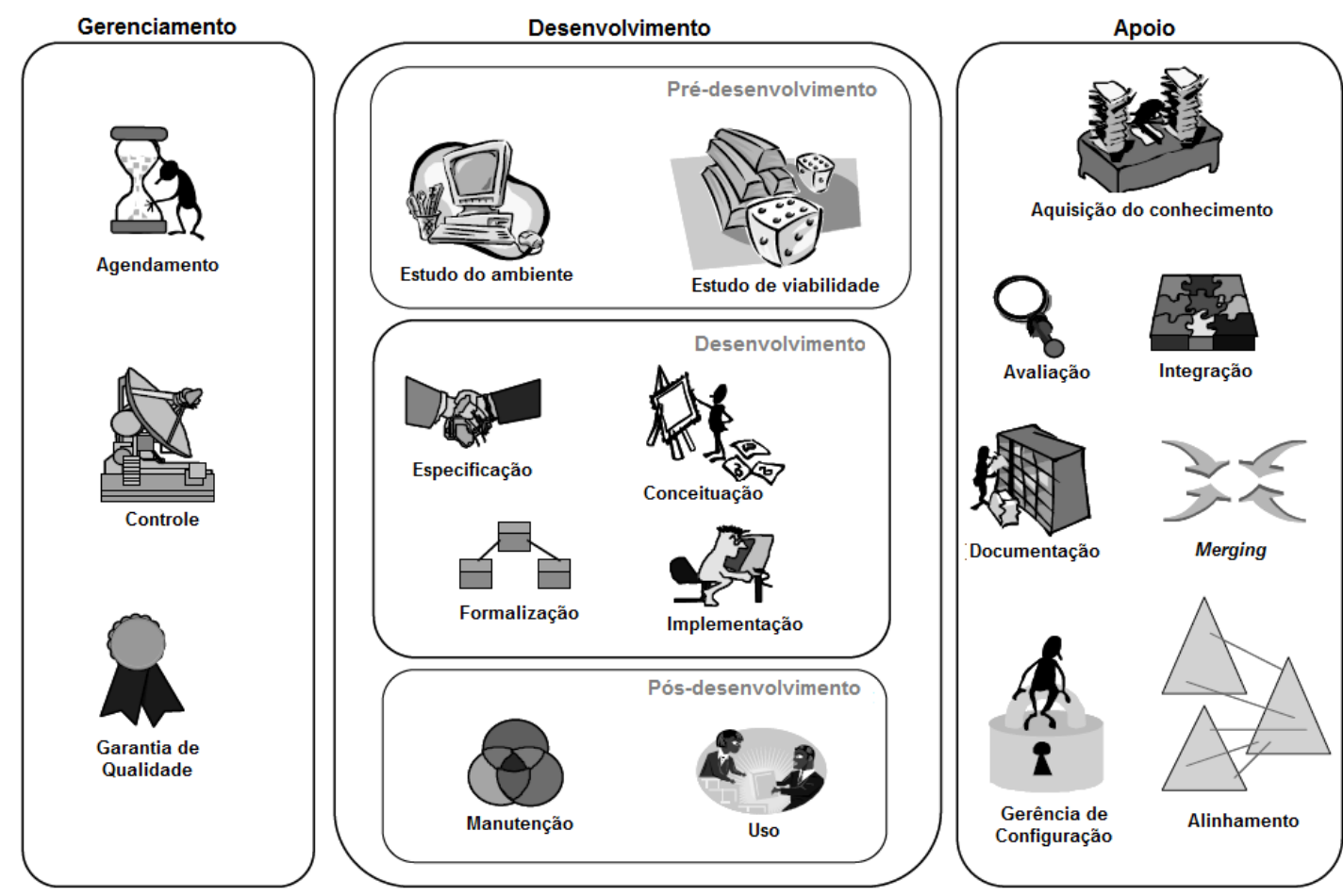

Figura 2.4: Processo de desenvolvimento de ontologias (Corcho et al., 2006).

- Atividades de gerenciamento da ontologia: incluem atividades de listagem, controle e de garantia de qualidade.

- Atividades orientadas ao desenvolvimento da ontologia: são um grupo de atividades que englobam o pré-desenvolvimento (estudo do ambiente e possibilidades), o desenvolvimento (especificação, conceituação, formalização e implementação) e o pós-desenvolvimento (manutenção e uso).

- Atividades de apoio à ontologia: incluem uma série de atividades que podem ser desempenhadas durante a fase das atividades orientadas ao desenvolvimento sem que a ontologia esteja construída. São elas: aquisição do conhecimento, avaliação, integração, documentação, união, gerenciamento de configuração e alinhamento.

No entanto, o processo de desenvolvimento ontológico não estabelece uma ordem para a execução das atividades. Essa é considerada uma regra do ciclo de vida da ontologia, na qual as atividades podem ser executadas a partir do conjunto de estágios envolvidos na aplicação específica. Dessa forma, prováveis mudanças são administradas, seja durante a descrição ou execução das atividades, no decorrer da construção ontológica (Corcho et al., 2006).

A escolha dos cenários, da metodologia, da linguagem e da ferramenta é dependente do escopo do projeto envolvido e é inerente ao processo de desenvolvimento das ontologias. A seguir é apresentado uma descrição sumarizada dessas características. 


\subsubsection{Metodologias}

As metodologias propostas na literatura têm a finalidade de orientar o desenvolvimento ontológico. Em linhas gerais, tais metodologias propõem um conjunto de atividades que devem ser executadas visando a construção de uma ontologia de qualidade. Um fato observado nas pesquisas atuais é que grande parte dos pesquisadores desenvolvem suas próprias metodologias, conforme as necessidades de suas aplicações. Na Tabela 2.1 é apresentada uma comparação sumarizando as principais contribuições e limitações das metologias mais utilizadas na literatura.

\begin{tabular}{|c|c|c|}
\hline Metodologia & Vantagem & Desvantagem \\
\hline $\begin{array}{l}\text { Uschold \& King } \\
\text { (Uschold e King, 1995) }\end{array}$ & $\begin{array}{l}\text { Recomendada para a construção de ontologia de } \\
\text { alto nivel. }\end{array}$ & $\begin{array}{l}\text { Existe uma lacuna no processo de } \\
\text { conceituação. }\end{array}$ \\
\hline $\begin{array}{l}\text { Grüninger \& Fox } \\
\text { (Gruninger e Fox, 1995) }\end{array}$ & $\begin{array}{l}\text { Construção da ontologia utilizando lógica de } \\
\text { primeira ordem. }\end{array}$ & $\begin{array}{l}\text { Não indica atividades de gerenciamento e } \\
\text { avaliação. }\end{array}$ \\
\hline $\begin{array}{l}\text { On-To-Knowledge } \\
\text { (Staab et. al., 2001) }\end{array}$ & Apresenta fases bem definidas. & $\begin{array}{l}\text { Não indica as atividades para evolução das } \\
\text { ontologias. }\end{array}$ \\
\hline $\begin{array}{l}\text { AFM } \\
\text { (Mizoguchi, 1995) }\end{array}$ & $\begin{array}{l}\text { Desenvolvimento de ontologias de tarefas e para } \\
\text { inicio de processos. }\end{array}$ & $\begin{array}{l}\text { Não indicada para o desenvolvimento de } \\
\text { ontologia em larga-escala. }\end{array}$ \\
\hline $\begin{array}{l}\text { Ontology } 101 \\
\text { (Noy e McGuinness, 2001) }\end{array}$ & Abordagem iterativa para desenvolver ontologias. & $\begin{array}{l}\text { Não indica atividades de gerenciamento da } \\
\text { manutenção e de avaliação. }\end{array}$ \\
\hline $\begin{array}{l}\text { Methontology } \\
\text { (Fernandez-Lopez, 1997) }\end{array}$ & $\begin{array}{l}\text { Proporciona construção, reúso e reengenharia de } \\
\text { ontologias. }\end{array}$ & $\begin{array}{l}\text { O processo proposto pelo método pode ser } \\
\text { considerado extenso. }\end{array}$ \\
\hline
\end{tabular}

Tabela 2.1: Comparação entre métodos de construção de ontologias.

Analisando a Tabela 2.1 percebe-se que: (i) a maioria das metodologias enfatiza atividades de desenvolvimento, especialmente em conceituação e implementação de ontologias. Por outro lado, aspectos importantes como gestão, aprendizagem, integração, evolução e avaliação de ontologias ainda são pouco explorados; (ii) a maioria das abordagens não são utilizadas por grupos externos e, em alguns casos, são aplicadas em um único domínio; e (iii) a maioria das abordagens não dispõe de uma ferramenta específica.

\subsubsection{Linguagens}

No início dos anos 90, ontologias eram construídas usando principalmente técnicas de modelagem baseadas em frames e lógica de primeira ordem, consideradas como a evolução das linguagens de representação do conhecimento. Nos últimos anos, outras técnicas de representação de conhecimento baseadas em lógica de descrição têm sido usadas para construir ontologias e novas linguagens lógicas de descrição, tais como OIL, DAML+OIL e OWL, têm sido propostas no contexto da web semântica (Corcho et al., 2006). Na Tabela 2.2 é apresentada uma comparação sumarizando as principais contribuições e limitações das linguagens ontológicas mais utilizadas na literatura.

Ao analisar a Tabela 2.2 percebe-se que: (i) todas as linguagens possuem conceitos como instâncias, recursos de restrições, relações e funções binárias; (ii) as linguagens 


\begin{tabular}{|c|c|c|c|c|c|c|c|c|c|}
\hline Conceitos & Ontolíngua & Loom & OCML & Flogic & SHOE & RDF(S) & OIL & $\mathrm{DAML}+\mathrm{OIL}$ & OWL \\
\hline \multicolumn{10}{|l|}{ Atributos } \\
\hline Instâncias & + & + & + & + & + & + & + & + & + \\
\hline Classes & + & - & + & + & - & $w$ & - & $\therefore$ & - \\
\hline \multicolumn{10}{|l|}{ Aspectos Particulares } \\
\hline Restricões & + & + & + & + & + & + & + & + & + \\
\hline Cardinalidade & + & + & + & $w$ & - & - & + & + & + \\
\hline Procedimento & - & + & + & - & - & - & - & - & - \\
\hline \multicolumn{10}{|l|}{ Taxonomias } \\
\hline Subclass-of & + & + & + & + & + & + & + & + & + \\
\hline Decomposição disjunta & + & + & + & $w$ & 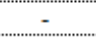 & - & + & + & + \\
\hline Decomposição exaustiva & + & - & $w$ & $w$ & - & - & $w$ & $w$ & $w$ \\
\hline Particionamento & + & + & + & $w$ & - & - & + & + & $w$ \\
\hline \multicolumn{10}{|l|}{ Relaçôes } \\
\hline Binária & + & + & + & + & + & + & + & + & + \\
\hline N-ária & + & + & + & w & + & $\mathrm{w}$ & $w$ & $w$ & $w$ \\
\hline Hierarquia & + & + & + & $w$ & - & + & + & + & + \\
\hline Integridade & + & + & + & + & - & - & - & - & - \\
\hline \multicolumn{10}{|l|}{ Funções } \\
\hline Binária & + & + & + & + & - & - & + & + & + \\
\hline $\mathrm{N}$-ária & + & + & + & + & - & - & - & - & $\therefore$ \\
\hline \multicolumn{10}{|l|}{ Outros Componentes } \\
\hline Axiomas formais & + & + & + & + & - & - & - & - & - \\
\hline Procedimento & + & + & + & - & - & - & - & - & - \\
\hline Regras & - & + & + & - & + & - & - & - & - \\
\hline
\end{tabular}

Tabela 2.2: Comparação entre linguagens de construção de ontologias (Corcho et al., 2006).

mais recentes não possuem recursos para a construção das regras em suas sintaxes; e (iii) as linguagens OIL, DAML+OIL e OWL são muito parecidas em sua estrutura e possuem características como cardinalidade, decomposição disjunta e exaustiva.

\subsubsection{Ferramentas}

Segundo Gómez-Pérez et al. (2004), desenvolver ontologias é algo complexo e demanda tempo, principalmente se os desenvolvedores tiverem que implementá-las diretamente em uma linguagem ontológica sem o apoio de ferramentas automatizadas. Dessa forma, a partir da metade dos anos 90, foram criados ambientes para desenvolvimento de ontologias a fim de auxiliar os usuários em algumas das principais atividades do processo de desenvolvimento, tais como conceituação, implementação, checagem de restrições e documentação das ontologias.

As ferramentas, segundo Corcho et al. (2006) e Mizoguchi (2003), possibilitam a criação e integração de ontologias, apoiando a maioria das atividades do ciclo de vida de desenvolvimento. De modo geral, são ferramentas extensíveis com arquitetura baseada em componentes, permitindo que novos módulos sejam facilmente adicionados. Além disso, permitem modelar o conhecimento independentemente da linguagem utilizada. Na Tabela 2.3 são apresentadas as ferramentas mais utilizadas para a construção de ontologias. 
CAPÍTULO 2. REVISÃO BIBLIOGRÁFICA

\begin{tabular}{|c|c|c|c|}
\hline Características & Protégé & OntoEdit & WebODE \\
\hline \multicolumn{4}{|l|}{ Informações } \\
\hline Metodologia & - & On-To-Knowledge & METHONTOLOGY \\
\hline Avaliação & Open Source & Freeware & Livre \\
\hline \multicolumn{4}{|l|}{ Arquitetura } \\
\hline Extensibilidade & Plug-in & Plug-in & Servidor \\
\hline Armazenamento & DBMS & Arquivos & DBMS \\
\hline \multicolumn{4}{|c|}{ Modelagem do conhecimento } \\
\hline Formalismo & Frames & Frames & Frames \\
\hline Linguagem & - & OXML & - \\
\hline Axiomas formais & $\mathrm{PAL}$ & FLogic & WAB \\
\hline \multicolumn{4}{|l|}{ Interoperabilidade } \\
\hline Importação & $\begin{array}{c}\text { XML, RDF(S) } \\
\text { XML Schema, XMI }\end{array}$ & $\begin{array}{c}\text { OXML, RDF(S) } \\
\text { DAML+OIL, Flogic }\end{array}$ & $\begin{array}{c}\text { XML, RDF(S) } \\
\text { DAML+OIL, OWL }\end{array}$ \\
\hline Exportação & $\begin{array}{c}\text { XML, RDF }(\mathrm{S}) \\
\text { XML Schema, Flogic } \\
\text { CLIPS, Java, XMI } \\
\end{array}$ & $\begin{array}{c}\text { OXML, RDF(S) } \\
\text { DAML+OIL, Flogic }\end{array}$ & $\begin{array}{c}\text { XML, RDF(S), OIL } \\
\text { DAML+OIL, OWL } \\
\text { Flogic, Prolog, Jess, Java }\end{array}$ \\
\hline \multicolumn{4}{|l|}{ Construção das ontologias } \\
\hline Edição de conceito gráfica & Sim & Sim & Sim \\
\hline Editor de axioma formal & Sim & Não & Sim \\
\hline Classificação automática & Não & Não & Não \\
\hline
\end{tabular}

Tabela 2.3: Comparação entre as ferramentas para o desenvolvimento de ontologias.

Ao analisar as ferramentas da Figura 2.3 pode-se observar, entre outros pontos, que (i) a Protégé é independente da metodologia de desenvolvimento; e (ii) as três ferramentas são extensíveis, tendo a possibilidade de importar/exportar várias linguagens.

\subsubsection{Mapeamento de Ontologias}

O mapeamento de ontologias é um dos principais pontos para possibilitar a interoperabilidade entre as ontologias, seja para vários sistemas ou para várias ontologias. O processo de mapeamento inclui usualmente duas principais partes (Xu e Xu, 2010): (i) a descoberta e a (ii) a seleção do que deve ser mapeado. Complementando esta definição, segundo Zheng et al. (2010), o mapeamento é um processo para encontrar a relação semântica entre ontologias heterogêneas e expressar seus relacionamentos, bem como alcançar interoperabilidade entre diferentes ontologias.

Outra definição para mapeamento de ontologias é dada por Zheng et al. (2010), que exemplifica: dadas duas ontologias $\mathrm{O}_{1}$ e $\mathrm{O}_{2}$, o mapeamento de uma ontologia para outra significa que para cada entidade (conceito $\mathbf{C}$, relação $\mathbf{R}$, instância $\mathbf{I}$ ) na ontologia $O_{1}$, tenta-se encontrar uma entidade correspondente, ou seja, que tem o mesmo significado pretendido na ontologia $\mathrm{O}_{2}$.

Atualmente, muitas áreas de investigação propõem métodos para realizar o mapeamento. Zheng et al. (2010) descrevem quatro tipos, a saber: (i) biblioteca de ontologia geral superior baseada em mapas conceituais; (ii) mapeamento de ontologia com 
base na similaridade do conceito; (iii) mapeamento de ontologias baseado em estrutura de conceito; e (iv) mapeamento de ontologia baseado em instância.

Uma outra categorização é feita por Choi et al. (2006), em que três tipos de mapeamento são definidos. Essa classificação será utilizada neste projeto, devido às similaridades das definições do mapeamento e do contexto deste trabalho. O tipo do mapeamento e a sua descrição são detalhados a seguir (Choi et al., 2006):

- Mapeamento entre ontologia global integrada e ontologias locais: usado para mapear conceitos encontrados em uma ontologia, a partir de uma visão ou uma consulta em outras ontologias.

- Mapeamento entre ontologias locais: é o processo que transforma as entidades da ontologia de origem para as entidades da ontologia alvo com base na relação semântica.

- Mapeamento durante o merging e alinhamento da ontologia: estabelece a correspondência entre a ontologia de origem e as ontologias locais e determina o conjunto de conceitos que se sobrepõem, sejam os sinônimos ou os conceitos únicos para essas fontes.

Uma diferença entre as três categorias está na maneira em que o mapeamento é construído e mantido. Cada categoria apresenta diferentes vantagens e desvantagens (Choi et al., 2006). Neste caso, no primeiro tipo de mapeamento pode ser considerado fácil a definição do mapeamento em si e das regras de mapeamento entre ontologias locais, pois uma ontologia global integrada fornece um vocabulário compartilhado e todas as ontologias locais são relacionadas à ontologia global. Por outro lado, pode ser mais complexo para comparar diferentes ontologias locais porque não existem mapeamentos diretos entre as ontologias locais (Choi et al., 2006).

Deve-se notar também que o mapeamento de ontologias é requerido para combinação de ontologias distribuídas e heterogêneas. Além disso, é importante observar que mapeamentos entre ontologias podem criar resultados que variam em função do agente de integração ou da técnica de mapeamento. O mapeamento pode, então, ser considerado subjetivo, pois para cada pessoa que define um conjunto de mapeamento entre duas ou mais ontologias, haverá a possibilidade de discrepância (Hooijmaijers e Stumptner, 2008).

Neste projeto foi utilizado o mapeamento das relações semânticas com base em uma ontologia global que se comunica com as outras ontologias (locais). Dessa maneira, a ideia é garantir que exista consistência entre as ontologias e as relações não alterem as ontologias originais, uma vez que estas são construídas e instanciadas na ontologia global ou de integração. Tais aspectos serão detalhados no Capítulo 4. 


\subsubsection{Regras de Inferência}

No contexto de ambientes de ensino e aprendizagem, as ontologias podem ser associadas aos mecanismos de raciocínio e regras de inferência para aplicar uma determinada estratégia pedagógica em sistemas de adaptação, a fim de alcançar objetivos pedagógicos específicos (Vesin et al., 2011). Ontologias são tipicamente baseadas na lógica de descrição, a qual tem um conjunto de mecanismos básicos de raciocínio implícitos (como classificação, relações, verificação de exemplos, etc.). No entanto, são necessárias regras adicionais para fazer inferências maiores e para expressar relações que não podem ser representadas de forma direta pelo raciocínio ontológico (Vesin et al., 2011).

Nesse sentido, a inferência é importante no contexto do desenvolvimento de ontologias. A máquina de consulta da ontologia coopera com o reasoner, resolve a consulta e retorna não somente resultados explícitos mas também implícitos. Após a primeira consulta, o modelo de inferência é usado para calcular as demais (Jing et al., 2008).

As consultas originam as regras que devem compor a ontologia para gerar o resultado da personalização. Diversas linguagens são utilizadas para escrever as regras de inferência. Atualmente a SWRL (Semantic Web Rule Language) (Horrocks et al., 2004) é uma das mais populares formas de representação do conhecimento devido à sua simplicidade, compreensão e expressividade. A SWRL tem uma forte capacidade de expressar a lógica por causa de regras envolvidas na ontologia escrita em OWL (Web Ontology Language). Além disso, pode ser descrita não apenas em XML (Extensible Markup Language), mas também em RDF (Resource Description Frame) (Wang et al., 2009).

Vale destacar que existem diferentes tipos de regras, implementadas de acordo com o tipo do conhecimento a ser armazenado. Algumas classificações para as regras são: regras de decisão, regras de associação, regras de classificação, regras de predição, regras causais e regras de otimização. As regras de decisão e de classificação são as mais utilizadas. As regras de decisão são usadas para a apresentação de objetos de aprendizagem, enquanto as regras de classificação ajudam na categorização dos objetos de aprendizagem (Vesin et al., 2011).

Neste trabalho, as consultas são implementadas na ferramenta Protégé, como regras de decisão e classificação. O objetivo é classificar e apresentar os objetos de aprendizagem e/ou o conteúdo de acordo com o modelo do usuário. Como trabalho futuro, estas regras deverão ser escritas em SWRL. 


\subsection{Adaptação e Personalização}

Atualmente, o acesso à informação de forma personalizada é um dos pontos mais importantes para a satisfação do usuário nos mais variados ambientes e sistemas de informação. Vários serviços de informação e aplicações estão produzindo novas informações a cada segundo e torna-se cada vez mais complicado o acesso a itens relevantes e conexos em tempo real (Ahn e Brusilovsky, 2010).

Aliados à personalização estão os sistemas de hipermídia adaptativa que têm como objetivo refletir características dos usuários a partir do modelo do usuário e aplicar este modelo para adaptar vários aspectos visíveis do sistema para o usuário (Brusilovsky, 1996). É importante observar, que os termos adaptação e personalização estão tão intrinsecamente relacionados e que nem todos os trabalhos fazem uma distinção clara e precisa entre eles.

Neste projeto, adota-se a definição com base no trabalho de Brusilovsky (1996), na qual pode-se dizer que a ênfase da adaptação está no ambiente ou no sistema, enquanto a ênfase da personalização está no usuário. Assim, pode-se afirmar que a construção da ontologia do modelo do usuário é um meio de prover a adaptação do conteúdo como forma de proporcionar a personalização da apresentação ao usuário, em conformidade com o modelo do usuário instanciado. Nas próximas seções serão apresentadas características que compõem a adaptação e a personalização.

\subsubsection{Adaptação: Conceitos Básicos}

A ideia central da adaptação é baseada na suposição de que as características de diferentes usuários devem influenciar a funcionalidade oferecida pelo serviço ou a informação de maneira individual. Pode-se considerar, então, que se o comportamento do sistema é adaptado de acordo com estas características, o sistema será melhor (Sosnovsky e Dicheva, 2010).

Segundo Brusilovsky (1996) e Knutov et al. (2009), o núcleo da adaptação pode ser definido pela proposição e resposta a seis questões: (i) "O que adaptar?"; (ii) "Para que adaptar?"; (iii) "Por que adaptar?"; (iv) "Onde aplicar a adaptação?"; (v) "Quem deve aplicar a adaptação?"; e (vi) "Como adaptar?". Essas questões, ao serem solucionadas, guiam e auxiliam o processo de construção da adaptação, como é apresentado na Figura 2.5 .

De acordo com Knutov et al. (2009), o processo para a construção da adaptação depende das técnicas aplicadas, porém o fluxo deste pode ser considerado genérico segundo a definição de Brusilovsky (1996). Em um alto nível de abstração, na Figura 2.5 pode-se 


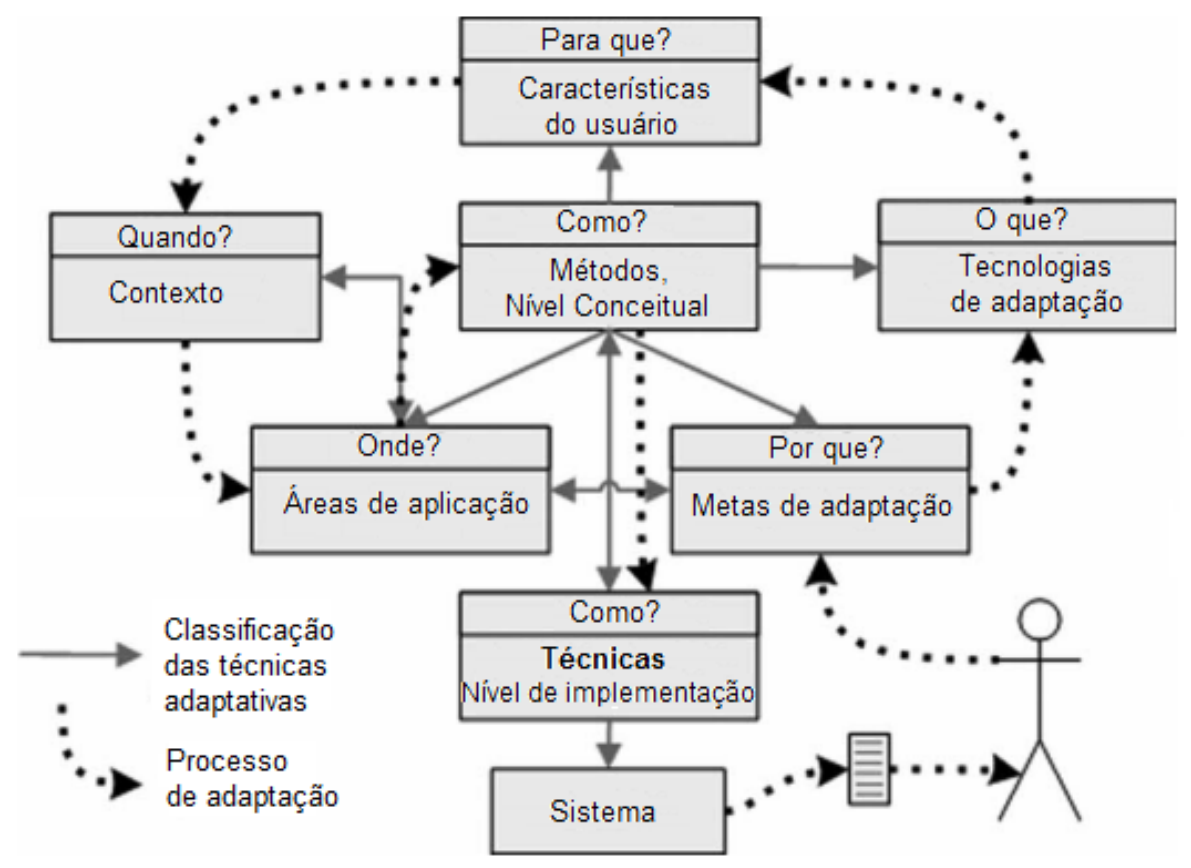

Figura 2.5: Classificação das técnicas da hipermídia adaptativa (Adaptado de Knutov et al. (2009)).

inferir que as tecnologias de adaptação, as características dos usuários, o contexto, as metas e as áreas de aplicação são fatores que devem ser observados e são necessários ao desenvolvimento de um sistema adaptativo, por isso a generalização do processo.

Para identificar se um sistema é adaptativo, Devedžic (2006) descreve alguns fatores que podem ser considerados e servem como base tanto para a identificação como para a construção de ambientes adaptativos, são eles:

- Permitir o uso de paradigmas de ensino um-para-um (um aluno para um professor) ou muitos-para-um (muitos professores para um aluno), diferentemente do ambiente tradicional de ensino.

- Não deve impor restrições quanto ao tempo e localização.

- Reconhecer a grande variedade de características e preferências dos alunos, em termos de estilo de aprendizagem, mídia, interesses, etc.

- Fornecer "instrução sob medida" para atender aos requisitos do aluno.

Várias classificações para sistemas adaptativos podem ser encontradas na literatura. A categorização feita por Devedžic (2006) descreve: (i) Sistemas Tutores Inteligentes (ITS - Intelligent Tutoring Systems); (ii) Sistemas de Hipermídia Adaptativa Educacionais (AEHS - Adaptive Educational Hypermedia Systems); e (iii) Educação Baseada em Web (WBE - Web-based Education). 
Outra classificação é feita por Brusilovsky e Peylo (2003), na qual foram identificadas as cinco principais tecnologias usadas para dois grandes grupos de sistemas educacionais baseados em web - inteligentes e adaptativos (Adaptive and Intelligent Web-Based Educational Systems - AIWBES). Essas tecnologias têm raízes em dois campos de pesquisa que foram estabelecidos antes da era da internet - Hipermídia Adaptativa e Sistemas Tutores Inteligentes (Devedžic, 2006), como é exibido na Figura 2.6.

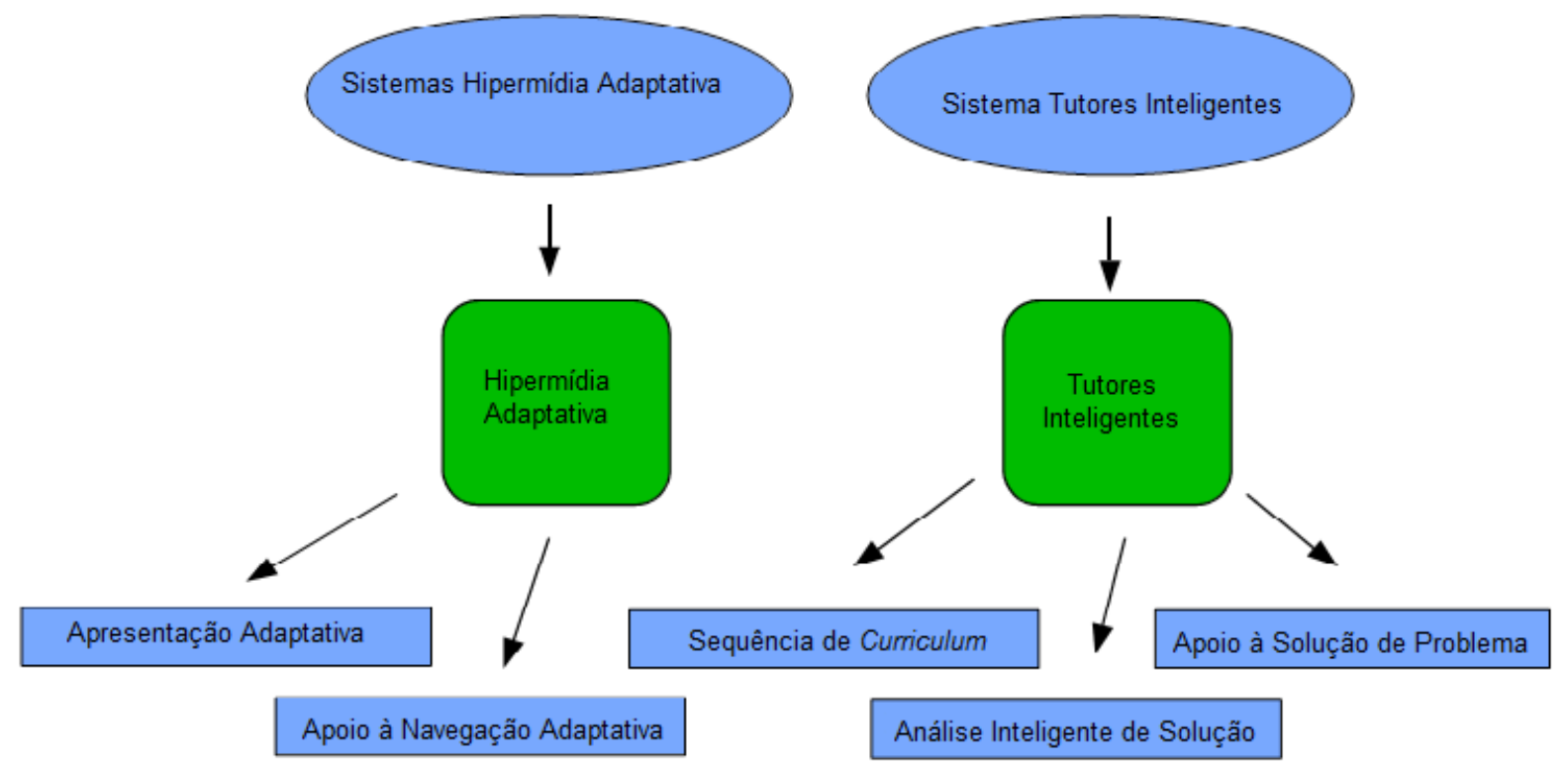

Figura 2.6: Tecnologias clássicas para AIWBES (Devedžic, 2006).

Segundo Brusilovsky e Peylo (2003), as principais tecnologias ligadas aos sistemas de hipermídia adaptativa referem-se à apresentação e ao apoio à navegação adaptativas. Já para os sistemas tutores inteligentes destacam-se o sequenciamento de currículo, o apoio à solução de problemas e a análise de solução inteligente.

Existem diversas classificações para os sistemas adaptativos. As classificações de Brusilovsky e Peylo (2003) e Devedžic (2006), apresentadas nesta seção, se completam mas também divergem principalmente quanto ao grau de fragmentação das áreas ou dos tipos de sistemas.

Das tecnologias citadas, o apoio à apresentação e à navegação adaptativas são as duas mais exploradas por sistemas de hipermídia e de hipertexto adaptativo (Devedžic, 2006). A meta da apresentação adaptativa é adaptar o conteúdo apresentado em cada nó ou página de hipermídia para as metas, conhecimento e outras informações armazenadas no modelo do usuário. Em um sistema com apresentação adaptativa, as páginas não são estáticas, mas geradas de forma adaptável ou elaboradas para cada usuário. Já o objetivo do apoio à navegação adaptativa é auxiliar o estudante na orientação e navegação para escolher a aparência da visibilidade dos links (Devedžic, 2006). 
Segundo Ahn e Brusilovsky (2010), a visualização adaptativa é uma tentativa de melhorar a visualização de informação a partir da adição de um componente de adaptação. Por meio da adaptação, os usuários podem modificar a maneira em que o sistema visualiza uma coleção de documentos, por exemplo.

Além disso, Brusilovsky e Peylo (2003) fazem uma classificação de cinco grandes grupos de tecnologias atuais de AIWBES, fragmentando um pouco mais os grupos apresentados anteriormente. Essas tecnologias são: (i) hipermídia adaptativa; (ii) filtro de informação adaptativo; (iii) monitoramento inteligente; (iv) ensino colaborativo e inteligente, e (v) tutor inteligente.

\subsubsection{Personalização: Conceitos Básicos}

A personalização tem como objetivo fornecer respostas personalizadas de modo a cumprir requisitos específicos, bem como dar significado às informações que muitas vezes são desconexas (Baldoni et al., 2005). Esta pode ser aplicada de várias formas, por exemplo, no conteúdo, no feedback apresentado para o usuário ou na navegação do conteúdo. Em todos os casos, objetiva dar indicativos a respeito do desempenho e progresso do usuário (Devedžic, 2006).

Nesse contexto, um benefício da personalização a ser ressaltado é que o ambiente personalizado tem a capacidade de propor uma sequência de estudo fácil ou complexa para um determinado aluno, de acordo com as suas necessidades e preferências, ou com seus objetivos de aprendizagem. Em outras palavras, um ambiente que apoia a personalização disponibiliza somente a informação que é realmente relevante para o aluno, de maneira e em tempo apropriados. Cada vez que o aluno interage com o ambiente, este é capaz de aprender e armazenar um pouco mais sobre o conjunto de características únicas do aluno, conforme a abordagem de adaptação utilizada (Devedžic, 2006).

Outro conceito relevante associado à personalização e que deve ser mencionado, pois está ligado ao projeto do modelo do usuário, refere-se às propriedades dependentes e independentes do domínio, que fazem parte da modelagem do perfil do usuário. Exemplos de propriedades dependentes são: conhecimento do usuário, resultados de testes, objetivos de aprendizagem, tarefas, resolução de problemas ou objetivos conjunturais. Exemplos de propriedades independentes são (Brusilovsky e Peylo, 2003): credenciais dos usuários, preferências, estilos cognitivos e de aprendizagem, ambiente do usuário (tempo, espaço, equipamento, etc.) e do grupo.

Quanto à forma para construir a personalização, podem-se indicar os filtros de informação, que incluem desde o material de aprendizagem, atividades e processos, até as preferências e metas de acordo com o contexto dos aprendizes (Devedžic, 2006). O filtro 
pode ser adaptativo (automaticamente ensinado e ajustado pelo sistema durante as sessões de aprendizagem) e/ou adaptável (configurado e ajustado pelo aprendiz) (Sosnovsky e Dicheva, 2010). Além disso, o filtro adaptativo é uma tecnologia clássica no campo da recuperação da informação. Sua meta é encontrar poucos itens que são relevantes para os interesses dos usuários em vastos documentos (baseados em texto, por exemplo) (Devedžic, 2006).

A partir da classificação dos sistemas adaptativos e da definição de personalização, é importante, também, considerar os tipos de personalização que podem ser desenvolvidos. Devedžic (2006) propõe cinco métodos para aplicar a personalização:

1. Personalização com base no reconhecimento de nome: mostra o nome do aluno com os objetos de aprendizagem associados ou com os problemas resolvidos e seus resultados.

2. Personalização auto-descritiva: usa questionários, testes iniciais, surveys, preferências e atributos comuns descritos pelos alunos, bem como para identificar a visão geral e as experiências prévias.

3. Personalização segmentada: estabelece grupos menores de alunos, que são identificáveis e gerenciáveis, com base em outros atributos comuns. Partes das instruções são adaptadas aos grupos e aplicadas em algum momento para todos os membros do grupo.

4. Personalização baseada em cognição: adapta e entrega o conteúdo e instrui os tipos específicos de alunos, definidos de acordo com as informações sobre seus processo cognitivo, estratégias, capacidades e preferências.

5. Personalização da pessoa como um todo: combina personalização cognitiva com um conjunto psicológico complexo, impactando no ensino e desempenho.

Neste trabalho será utilizada a personalização auto-descritiva, pois serão usados questionários para instanciar os perfis dos usuários.

\subsubsection{Modelo do Usuário}

Um recurso que distingue um sistema adaptativo é o modelo do usuário, que pode ser definido como a representação da informação sobre um usuário de maneira individual, fator que é essencial para um sistema adaptativo fornecer o efeito de adaptação, isto é, comportar-se diferentemente para usuários diferentes (Knutov et al., 2009). 
Tradicionalmente, em trabalhos sobre personalização, a adaptação ocorre no nível de seleção da informação e, principalmente, na apresentação (Baldoni et al., 2005). É importante observar que existem muitas definições para modelo ou perfil de usuário. O termo "perfil de usuário" tem sido usado tradicionalmente para se referir à estrutura composta de conhecimento, refletindo várias informações estáticas sobre um usuário (tais como a demografia do usuário, background, estilo cognitivo, etc.). Diferentemente de "modelo do usuário", que normalmente representa um aspecto instantâneo, dinâmico de um único de um usuário (conhecimento conceitual, interesses, preferências, etc.), essa distinção é relativa, pois depende do contexto de sua aplicação (Sosnovsky e Dicheva, 2010).

Observa-se que o perfil do usuário e modelo do usuário têm sido frequentemente utilizados como sinônimos na literatura. Às vezes, modelos de usuário podem ter uma estrutura composta e armazenar informações estáticas do usuário, bem como os perfis de usuário podem incluir um componente dinâmico que representa estado atual de uma determinada característica do usuário (Sosnovsky e Dicheva, 2010).

Há diversidade de definições também na construção do perfil do usuário, que pode ser feita de maneira implícita (com o uso de agentes) ou explícita (por meio da intervenção do usuário). Além disso, perfis podem ser modificados em tempo de execução e são considerados dinâmicos, assim como existem perfis estáticos, os quais mantêm informação ao longo do tempo. No entanto, a meta do perfil do usuário é coletar informações a respeito dos interesses do usuário, bem como a duração do tempo durante a execução das atividades e o grau de interesse demonstrado (Knutov et al., 2009).

Quanto às características que devem formar o modelo do usuário, Brusilovsky e Peylo (2003) estabelecem o seguinte conjunto para definir um usuário como um indivíduo: conhecimento, interesses, metas, background e traços individuais. Em sistemas educacionais, o conhecimento é frequentemente usado como uma característica do usuário que está sendo modelado; por outro lado, em sistemas adaptativos, ele é usado para dar apoio à navegação e à apresentação adaptativa. Os interesses do usuário são considerados essenciais para a recuperação da informação adaptada do usuário; as metas são relacionadas ao que o usuário quer alcançar; o background é relacionado às experiências; e os traços individuais são relativos à personalidade e aos estilos cognitivos e de aprendizagem.

Além do modelo proposto por Brusilovsky e Peylo (2003), outros dois padrões são muito utilizados na construção de modelo do usuário: (i) o padrão IMS LIP (Learner Information Package Specification) (IMS, 2001); e (ii) o padrão IEEE PAPI (Public and Private Information) (IEEE-LTSC, 2001). 
Segundo o padrão IEEE PAPI (IEEE-LTSC, 2001), as características do perfil do aluno são:

- Informações pessoais: contêm informação demográfica;

- Relações: especificam relações dos alunos com outros sujeitos do processo educacional (pares, alunos);

- Segurança: indica credenciais de aluno e direitos de acesso;

- Preferências: indicam quais objetos um aluno pode e gostaria de trabalhar;

- Desempenho: armazena os resultados das avaliações dos alunos;

- Portifólio: contém informação sobre experiências prévias dos alunos.

As características para o perfil do usuário, segundo a especificação IMS LIP (IMS, 2001) são:

- Identificação: dados individuais como: nome, endereço, informação de contato;

- Metas: objetivos pessoais;

- QCL: qualificações, certificações, licenças;

- Atividades: registros sobre educação, trabalho e serviços (militar, comunidade);

- Competências: descrições das habilidades que o aluno adquiriu;

- Acessibilidade: preferências cognitivas, técnicas e físicas do aluno;

- Transcrição: o desempenho acadêmico do aluno no que diz respeito a uma instituição particular;

- Filiação: uma descrição das afiliações associados com o aluno;

- Chaves de segurança: descrições de senhas, certificados, PINs, etc.;

- Relacionamentos: definição das relações entre as estruturas de dados do núcleo.

As definições dos padrões apresentam similaridades entre os conceitos, os quais podem ser equivalentes entre si, como é exibido na Figura 2.7.

Tratando-se ainda da construção do perfil do usuário, outro conceito importante refere-se a forma de modelagem do perfil do usuário. Existem duas principais formas de modelagem na literatura (Sosnovsky e Dicheva, 2010): (i) sobreposição e (ii) esteriótipos. 


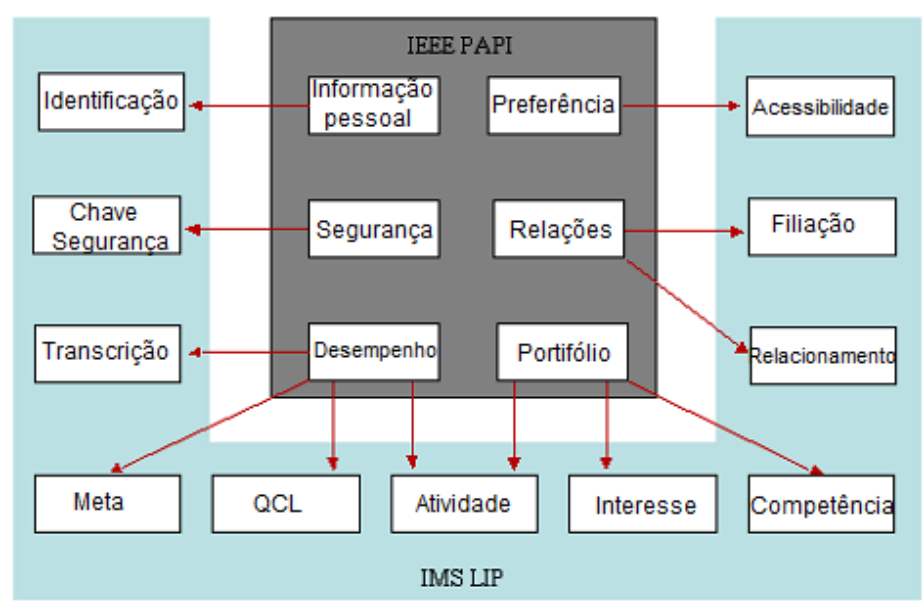

Figura 2.7: Correspondência entre os modelos IMS LIP e IEEE PAPI (Brusilovsky e Peylo, 2003).

A modelagem do usuário por sobreposição é a mais antiga e é empregada em diversos tipos de sistemas para modelar o conhecimento como um subconjunto do conhecimento do especialista do domínio (Sosnovsky e Dicheva, 2010). Já a modelagem com base em esteriótipos procura agrupar todos os possíveis usuários de um sistema adaptativo dentro de diversos grupos, com o objetivo de fornecer o mapeamento a partir de uma combinação específica de características do usuário para um dos esteriótipos. Depois disso, somente o esteriótipo do usuário corrente é usado para adaptação (Sosnovsky e Dicheva, 2010).

Neste trabalho, foi desenvolvida uma ontologia para o modelo do usuário com base nas características apresentadas, seguindo parte dos padrões abordados e de ontologias que foram reutilizadas, aproveitando-se os conceitos que são pertinentes ao escopo atual. A seguir, serão apresentados alguns trabalhos que empregam ontologias como apoio à personalização e atuam na modelagem do perfil do usuário.

\subsection{Personalização com base em Ontologias}

Entre as razões para que as ontologias sejam incorporadas em sistemas educacionais destacam-se (Heiyanthuduwage e Karunaratne, 2007): (i) prover o compartilhamento do entendimento comum de um dado domínio entre as pessoas e/ou agentes de software; (ii) permitir a reutilização do conhecimento do domínio, (iii) fazer suposições explícitas sobre o domínio, (iv) separar conhecimento do domínio de conhecimento operacional; e (v) analisar o conhecimento do domínio.

Existem, também, diversas abordagens ontológicas para representação de modelos de usuário, contribuindo para o desenvolvimento de sistemas adaptativos. Podem-se identificar duas direções principais: (i) um sistema adaptativo pode empregar ontologias para a modelagem da estrutura do domínio e representação atômica das características 
do usuário com base nos elementos da ontologia; e (ii) a estruturação de um perfil de modelagem do usuário que tenha várias dimensões do estado do usuário como uma ontologia (Sosnovsky e Dicheva, 2010).

O uso de técnicas de personalização visa melhorar a usabilidade dos sistemas educacionais, personalizando a interface do usuário, considerando o seu perfil e permitindo que cada usuário tenha uma percepção de que o sistema foi projetado especificamente para ele. Nesse sentido, diversas aplicações baseadas em ontologias têm sido utilizadas tanto para modelar domínios educacionais como para construir, organizar e atualizar recursos específicos de aprendizagem (ou seja, objetos de aprendizagem, perfis de alunos, caminhos de aprendizagem, entre outros) (Gaeta et al., 2009). A seguir são apresentadas algumas aplicações que utilizam ontologias educacionais e personalização do conteúdo.

\subsubsection{Personalização do Conteúdo a partir de Anotação}

Jovanovic et al. (2006b) apresentam uma abordagem para a anotação automática de unidades de conteúdo de objetos de aprendizagem (LOs - Learning Objects), que podem ser reunidos posteriormente formando novos LOs, personalizados de acordo com o conhecimento, preferências e estilos de aprendizagem dos usuários.

A abordagem especifica a geração de metadados que são usados para descreverem o sujeito baseado no domínio da ontologia e a regra pedagógica baseada nas regras pedagógicas da ontologia para a unidade de conteúdo. O mecanismo de construção da ontologia utilizado foi o padrão LOM do IEEE, na linguagem RDF (Jovanovic et al., 2006b).

O trabalho utiliza várias ontologias para a construção da abordagem, as quais são estendidas com base na ontologia ALOCoM (Abstract Learning Object Content Model) (Verbert et al., 2004). A partir da ALOCoM são estendidas as seguintes sub-ontologias (Jovanovic et al., 2006b):

- ALOCoM CS (Content Structure): identifica o conceito do domínio da ontologia que: (i) descreve a semântica da melhor unidade de conteúdo; (ii) infere a regra educacional das unidades de conteúdo com a respectiva regra pedagógica da ontologia; e (iii) gera título de unidades de conteúdo e a descrição de outros metadados. Existem três partes ou definições para a ALOCoM CS:

- Fragmentos de conteúdo (content fragments - CF): são unidades de conteúdo na sua forma mais básica (por exemplo, texto, áudio, vídeo).

- Objeto de conteúdo (content objects - CO): representam as instâncias da classe do objeto de conteúdo, agregam outros CFs, COs e adicionam navegação. 
- Objeto de aprendizagem (learning objects - LO): é um agregado de COs orientado a cumprir um único objetivo de aprendizagem.

- ALOCoM CT (Content Type): a ontologia foi inspirada no padrão SCORM (ADL, 2006) e os elementos do modelo são os mesmos da ALOCoM CS, mas são considerados a partir da perspectiva das regras pedagógicas ou instrucionais. Os conceitos definidos nesta ontologia são usados para anotar os objetos de aprendizagem e seus componentes com regras instrucionais e pedagógicas.

- Ontologia de domínio: o núcleo da ontologia é definido usando SKos (Simple Knowledge Organization System $)^{1}$ em que cada conceito do domínio é representado como uma instância e para um conceito podem ser atribuídos termos alternativos de acordo com o uso na literatura.

- Ontologia LP (Learning Paths): define as trajetórias de aprendizagem por meio de tópicos a partir da ontologia de domínio, relacionando as instâncias por meio de conjuntos adicionais de relacionamentos que refletem uma abordagem instrucional específica para ensino/aprendizagem.

Para o processo de anotação automática foi definida uma sequência de passos para que os LOs, quando inseridos no repositório pelos autores, sejam atualizados conforme os caminhos usados pelo aluno durante a aprendizagem. A ontologia de domínio é consultada por conceitos que são relacionados semanticamente; a partir do padrão aplicam-se algumas heurísticas para determinar as regras instrucionais (Jovanovic et al., 2006b). Quanto à personalização e modelagem do usuário, desenvolveu-se uma ontologia que representa as informações relevantes do usuário conforme as funcionalidades do sistema TANGRAM, a qual é apresentada na Figura 2.8.

O sistema TANGRAM é um ambiente educacional adaptativo baseado na web, tendo como características o dinamismo, a criação em tempo de execução e a personalização de conteúdo de aprendizagem fora das unidades de conteúdo existentes. Suas funcionalidades são baseadas em duas perspectivas (Jovanovic et al., 2006b): (i) disposição do conteúdo adaptado do aluno; e (ii) acesso rápido ao conteúdo do tópico de interesse.

No trabalho de Jovanovic et al. (2006b), o estilo de aprendizagem do aluno é determinado inicialmente por um questionário, que aponta o conhecimento inicial do aluno sobre o sistema de informação inteligente. Dessa forma, o sistema constrói o conteúdo personalizado com base nos tópicos selecionados pelo aluno. Vale destacar que, parte da ontologia desenvolvida foi utilizada para a construção da ontologia do modelo do usuário neste trabalho. Algumas contribuições a serem destacadas:

\footnotetext{
${ }^{1}$ http://www.w3.org/2004/02/skos/core/
} 


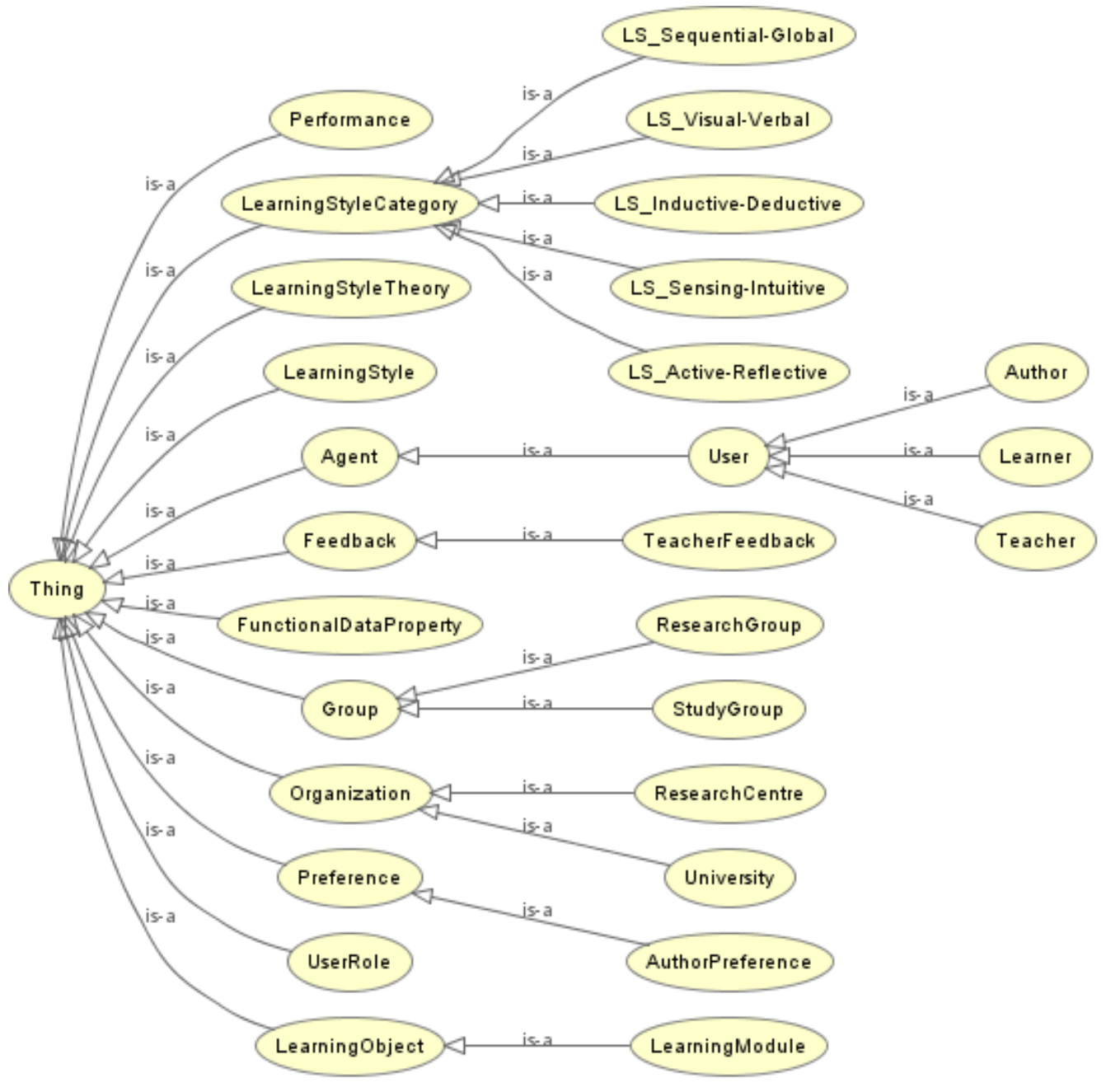

Figura 2.8: Ontologia do modelo do usuário (Jovanovic et al., 2006b).

- O uso de ontologias facilita a adaptação do objeto de aprendizagem, permite o acesso direto de seus componentes e a adaptação às características específicas da autoria do estudante/conteúdo.

- O modelo de domínio dissociado da aplicação gera a reutilização da ontologia de domínio - mesmo que se apliquem mudanças na abordagem instrucional, a ontologia de domínio permanece intacta.

- A abordagem explora o processo de estruturar dinamicamente unidades de conteúdos a partir de cursos/códigos diferentes.

Por fim, entre as limitações referentes à personalização de conteúdo, Jovanovic et al. (2006b) destacam a inflexibilidade de padrões de termos na variação dos metadados e a recuperação e reúso dos objetos de aprendizagem. 


\subsubsection{Personalização a partir da Extração do Conteúdo da Ontologia}

Capuano et al. (2009) apresentam um processo semi-automático baseado na extração de conhecimento, a partir de conteúdo educacional existente no padrão SCORM, para tornar rápido e facilitar o desenvolvimento de ontologias de domínio, especialmente para usuários sem habilidades em engenharia do conhecimento.

O padrão SCORM é um conjunto de padrões e especificações desenvolvido pela ADL (Advanced Distributed Learning). Os elementos básicos são (ADL, 2006):

- Assets (ativos): conteúdo na forma mais básica (texto, imagem, som).

- SCO (Sharable Content Objects - conteúdo de objetos compartilháveis): coleção de um ou mais assets.

A ontologia é modelada usando um grafo, no qual os nós representam conceitos relevantes e as arestas são relações binárias entre dois conceitos. As relações são: HasPart (HP), IsRequiredBy (IRB) e SuggestedOrder (SO). A ontologia modela os conceitos subjacentes e os termos mais representativos; os documentos educacionais são pacotes SCORM ou conteúdos produzidos como slides ou documento de texto.

Um exemplo de ontologia modelada usando grafo com as relações definidas

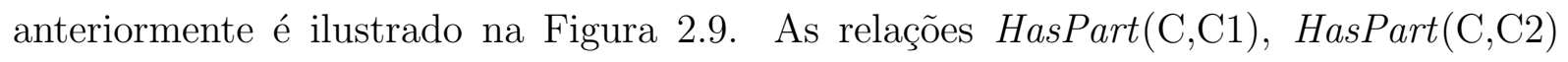
e HasPart(C,C3) (Figura 2.9.a) significam que os conceitos C1, C2 e C3 podem ser ensinados sem uma ordem específica determinada. Já na Figura 2.9.b, as relações IsRequiredBy $(\mathrm{C} 1 ; \mathrm{C} 2)$ e IsRequiredBy $(\mathrm{C} 2 ; \mathrm{C} 3)$ expressam a obrigatoriedade de uma ordem de precedência de ensino, em que o conceito $\mathrm{C} 1$ deve ser ensinado antes do conceito $\mathrm{C} 2 \mathrm{e}$ que o conceito $\mathrm{C} 2$ deve ser ensinado antes do conceito C3.

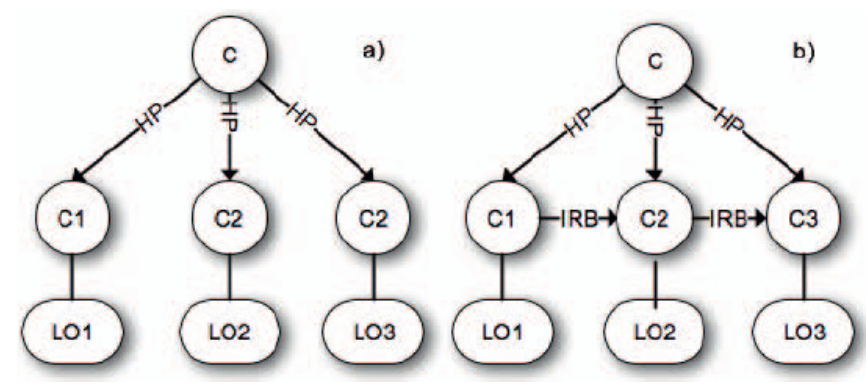

Figura 2.9: Representação de uma ontologia (Capuano et al., 2009).

O processo de construção proposto (Capuano et al., 2009) é semi-automático e alguns passos de iteração são requeridos pelo usuário. A vantagem do processo é que os conhecimentos implícitos e explícitos são estruturados como um pacote de conteúdo do 
padrão utilizado. São necessários quatro passos (Capuano et al., 2009): (1) projeto de criação da ontologia; (2) análise de recursos; (3) divisão de recursos; e (4) resolução da análise.

Com base nas ontologias extraídas, foi desenvolvido o sistema IWT (Intelligent Web Teacher). O sistema define a sequência de conceitos necessários (por aluno) para adquirir um conhecimento satisfatório dos objetivos de aprendizagem identificados (pelo professor), como os conceitos-alvo das ontologias (Capuano et al., 2009). As principais contribuições e/ou vantagens do trabalho são:

- O software desenvolvido extrai uma série de elementos úteis para a construção de uma experiência de ensino e aprendizagem personalizada, de forma simples a partir de um pacote SCORM.

- O sistema IWT requer pouca interação com o usuário e não requer competências de engenharia do conhecimento.

- O sistema IWT facilita o acesso às funcionalidades de personalização para todos os tipos de usuários e gera uma ontologia de domínio que pode ser refinada com outras ferramentas avançadas de edição fornecidas durante a navegação.

Entre as limitações identificadas trabalho destacam-se (Capuano et al., 2009): (i) a importância de ontologias vem com o desafio de seu processo de construção, citando o tempo consumido e a inclinação ao erro; e (ii) a maior parte dos usuários de ambientes de ensino tendem a não aproveitar a personalização devido ao trabalho preliminar necessário pela falta de competências na engenharia do conhecimento.

\subsubsection{Sistema de Gerenciamento de Ontologia para Personalização}

Gaeta et al. (2009) apresentam uma abordagem integrada para gerenciar o ciclo de vida de ontologias, utilizada para definir experiências personalizadas de e-Learning, sem a necessidade de qualquer experiência específica em engenharia do conhecimento.

Os princípios fundamentais da abordagem são (Gaeta et al., 2009): (i) modelagem de domínios educacionais por meio de ontologias e-Learning; (ii) modelagem do estado cognitivo e das preferências do aluno; (iii) anotação de objetos de aprendizagem com metadados e conexões semânticas entre objetos de aprendizagem e os elementos de ontologias; e (iv) modelagem de experiências de ensino e aprendizagem.

O foco da abordagem está na construção e manutenção da ontologia, enfatizando dois pontos: (1) definição de modelos para representar e explorar ontologias de e-Learning; e (2) definição de um conjunto de ferramentas para representar e gerenciar ontologias 
e-Learning. Para modelar a ontologia é utilizado um grafo (da mesma maneira em que foi desenvolvido no trabalho de Capuano et al. (2009), como foi exibido na Figura 2.9) em que os nós são os conceitos relevantes e as arestas são as relações.

Existem três modelos para construir a personalização da experiência de aprendizagem: modelo do estudante, modelos do objeto de aprendizagem e modelo de experiência de aprendizagem. Estes se comunicam por meio de algoritmos que automatizam o processo, que é feito para o aluno em cada fase de um determinado aprendizagem, considerando seu estado cognitivo (Gaeta et al., 2009).

Depois que uma ontologia é construída e validada, por meio do sistema AOMS, esta é anotada com metadados, indexada e arquivada. O formato de troca de ontologia é a linguagem OWL, que também promove a interoperabilidade dos AOMS com ferramentas de terceiros, e representação do conhecimento com a Protégé.

O AOMS é composto por vários componentes (Gaeta et al., 2009): Visual Ontology Editor (constrói uma camada de abstração antes da ontologia); Ontology Merging Tool (auxilia os usuários na harmonização da modelagem de duas ou mais ontologias do mesmo domínio educativo); e o Semantic Wiki Engine (implementa um consenso sobre uma ontologia construída de forma colaborativa). Entre as contribuições do desenvolvimento do sistema destacam-se (Gaeta et al., 2009):

- Existem inconsistências inerentes relacionadas à evolução do conhecimento. Nesse sentido, a harmonização, o versionamento e o controle de alterações da ontologia são aspectos importantes e são definidos como parte da abordagem.

- A abordagem é totalmente implementada em uma plataforma comercial de aprendizagem, utilizando o IWT.

- A abordagem provê colaboração, avaliação e validação da ontologia construída.

Por fim, algumas dificuldades foram encontradas ao longo do trabalho, entre elas: (i) a gestão da engenharia do conhecimento e competências dos atores; e (ii) o uso de ferramentas complexas.

\subsubsection{Raciocínio com Base em Regras para Alteração da Navegação Padrão}

O trabalho de Vesin et al. (2011) propõe a adaptação nos níveis de apresentação e navegação do conteúdo, por meio da construção de uma arquitetura baseada em ontologias. A partir deste objetivo, o grupo desenvolveu o sistema Protus (PRogramming 
TUtoring System) que é usado para ensinar conceitos básicos de programação Java e utiliza os princípios básicos de hipermídia adaptativa e recomendação de conteúdo para personalização.

A adaptação no Protus utiliza princípios de hipermídia adaptativa e recomendação de conteúdo pra a personalização do curso. Uma das características mais importantes do sistema é a adaptação do material de ensino e a navegação no curso com base no conhecimento de um aluno particular (Vesin et al., 2011).

O sistema tutor foi projetado para apoiar o processo de aprendizagem em diferentes cursos e domínios mas com intenção de ser usado para linguagens de programação. Apresenta cinco módulos principais: aplicação, adaptação, modelo do aluno, monitor de sessão, e módulo de domínio. Dando ênfase ao módulo de adaptação utilizado, vale ressaltar que no sistema Protus para a construção de recomendações automáticas existem três grupos de regras (Vesin et al., 2011):

- Regras de interação entre sistema e aluno: pré-processam os dados para construir os modelos dos alunos. A interação representa alguma tipo de ação desenvolvida pelo aluno em um objeto de aprendizagem específico (página visitada, testes submetidos e resultados de tarefas, busca no navegador, etc.). Os dados sobre as atividades dos alunos são coletados com estas regras. Dessa forma, quando o aluno completa a sequência de material de aprendizagem, o sistema avalia o conhecimento do aluno para cada lição.

- Regras off-line: usam modelo do aluno em tempo de execução para reconhecer as metas dos alunos e perfis de conteúdos.

- Regras de recomendação: produzem uma lista de recomendações ou de objetos de aprendizagem.

Ao longo do trabalho demonstrou-se que a lógica da adaptação pode ser capturada de maneira explícita com base no modelo de regras. Tendo o objetivo de aumentar a interoperabilidade, reusabilidade e extensibilidade por meio do uso de regras em SWRL.

No sistema Protus o padrão comportamental é descoberto para cada aluno por meio do algoritmo AprioriAll. Depois é criada uma lista de recomendação de acordo com a sequência fornecida pelo sistema. Por fim, como resultado da execução das regras, são geradas recomendações na forma da apresentação do conteúdo, em que cada uma pode ser usada para implementar os conceitos de navegação adaptada (Vesin et al., 2011).

Verifica-se uma semelhança do trabalho de Vesin et al. (2011) em relação ao presente projeto. No entanto a abordagem e a construção da personalização diferem em muitos sentidos, a começar pela utilização da abordagem de modelagem $\mathcal{A} \mathcal{L} M-\mathcal{C L D}$ e pela generalidade de conteúdo na instanciação da ontologia de domínio. 


\subsection{Considerações Finais}

Neste capítulo foram apresentadas definições e características sobre as principais áreas de pesquisas que compõem este projeto: (i) modelagem de conteúdos educacionais; (ii) definições de ontologias; (iii) adaptação e personalização. Também foram vistos trabalhos relacionados que aplicam a personalização de conteúdo a partir do desenvolvimento de ontologias.

A partir dos conceitos estudados, um conjunto de ontologias para personalização foi proposto. No próximo capítulo serão descritas as ontologias desenvolvidas e suas características para alcançar os objetivos para a personalização do conteúdo. 


\subsection{Considerações Iniciais}

Independentemente do domínio em questão, a representação do conhecimento utilizando ontologias proporciona vantagens tais como definição formal do conhecimento, reusabilidade e interoperabilidade de informações. Além disso, no contexto educacional, facilidades como recuperação dos objetos de aprendizagem e personalização de conteúdo a partir do desempenho e das preferências do usuário também podem ser identificadas na literatura (Arapi et al., 2008; Capuano et al., 2009; Gaeta et al., 2009; Jain e Pareek, 2010; Keleberda et al., 2006).

Aliadas às abordagens de personalização, as ontologias podem contribuir para que a definição formal e o compartilhamento do conhecimento aconteçam em paralelo com a adaptação e personalização do conteúdo, segundo as características dos usuários. Promove-se, dessa forma, uma maior interação entre o usuário e o conteúdo, além de possibilitar o conhecimento das preferências e das necessidades dos alunos.

Este trabalho envolve o desenvolvimento e a integração de um conjunto de ontologias para apoiar a personalização do conteúdo com base no perfil do usuário. As ontologias são: ONTO-IMACID - ontologia desenvolvida a partir da abordagem $\mathcal{I M A}-\mathcal{C} \mathcal{L D}$ descrita na Seção 3.2.1; Onto-Domain - ontologia referente ao domínio do conhecimento 
apresentada na 3.2.2; ONTO-USERMODEL - ontologia que descreve as características que compõem o modelo do usuário descrita na 3.2.3; e ONTO-NAVIGATION - ontologia que aborda as características de apresentação e navegação do conteúdo, descrita na Seção 3.2 .4 .

\subsection{Proposta do Conjunto de Ontologias para Personalização}

Em linhas gerais, o presente trabalho tem como objetivos investigar a adoção de ontologias como mecanismos de apoio à personalização de conteúdos. Nesse contexto, foram identificados quatro elementos fundamentais: (i) a abordagem $\mathcal{A L M}-\mathcal{C L D}$; (ii) a generalização do domínio de conhecimento; (iii) a modelagem do perfil do usuário; e (iv) a estrutura de navegação do conteúdo. Esses elementos combinados proporcionam a personalização e apoiam a generalização do conteúdo.

A modelagem de informações heterogêneas, mas conexas implicitamente, é feita por meio de ontologias, que construídas de acordo com as características de cada elemento proporcionam interoperabilidade, facilitam a correlação semântica e auxiliam na otimização e automatização do desenvolvimento da personalização do conteúdo, de acordo com os perfis dos usuários (Corcho et al., 2006; Jovanovic et al., 2006b; Vesin et al., 2011; Wang e Hsu, 2006).

Neste cenário, um conjunto de quatro ontologias foi estabelecido: (i) ONTO-IMACID, (ii) Onto-Domain, (iii) Onto-UserModel e (iv) Onto-Navigation. As ontologias foram construídas na ferramenta Protégé, utilizando a linguagem OWL, com a finalidade de promover a estruturação de um determinado domínio de conhecimento de acordo com a abordagem IMA-CID e com as características dos usuários.

Ressalta-se que, essas ontologias, integradas formam uma quinta ontologia - a ontologia global ou de integração OnTOTOLEARNER, na qual são importadas as quatro ontologias, são construídos o mapeamento entre as relações e são definidas as regras de inferência para gerar o modelo do usuário de acordo com as características explícitas e implícitas nas ontologias. A OntoToLeARner será descrita no Capítulo 4.

Nas próximas seções serão apresentadas as ontologias desenvolvidas e suas principais características. Observa-se que os conceitos nas ontologias possuem prefixos, os quais indicam o tipo da ontologia. Para a ontologia da IMA-CID foi utilizado o prefixo imacid:; para a ontologia de domínio o prefixo d:; para a ontologia do modelo do usuário o prefixo usermodel:; e para a ontologia de navegação o prefixo nav:. Essa medida foi necessária devido ao mapeamento que é feito entre as relações das ontologias, como maneira para 
facilitar a criação das regras e auxiliar o entendimento das inferências feitas na visão do autor do conteúdo.

\subsubsection{Onto-Imacid: Ontologia da IMA-CID}

Para apresentar a ontologia construída para a abordagem $\mathcal{I M A}-\mathcal{C D D}$ serão retomados alguns dos conceitos dos modelos que compõem a abordagem (Barbosa e Maldonado, 2011a), vistos na Seção 3.2.1:

- O modelo conceitual consiste em uma descrição em alto nível do domínio que se deseja ensinar. Sua construção envolve a definição dos conceitos relevantes para a compreensão do domínio, a especificação de como tais conceitos se relacionam e o estabelecimento de uma estrutura para sua representação.

- O modelo instrucional é responsável pela definição de informações adicionais relativas aos conceitos previamente identificados. Nessa etapa são definidos e modelados itens de informação e elementos instrucionais.

- O modelo didático é responsável por associar os objetos anteriormente modelados, estabelecendo uma sequência de apresentação entre eles. A partir de um mesmo modelo instrucional é possível derivar diferentes modelos didáticos, ou seja, modelos didáticos correspondem a diferentes visões de um modelo instrucional.

Com base nos modelos conceitual e instrucional, em que os conceitos e relacionamentos entre eles são identificados, foi definida a ontologia da $\mathcal{A} \mathcal{L} M-\mathcal{C L D}$, denominada ONTO-IMACID. Para seu desenvolvimento foram utilizadas as definições da abordagem (Barbosa, 2004), criando e validando relações entre conceitos de acordo com os modelos da $\mathcal{A} \mathcal{I} \mathcal{M}-\mathcal{C L D}$. Também foram considerados aspectos de generalização para proporcionar a modelagem de qualquer domínio de conteúdo na ontologia.

A partir das características da $\mathcal{A L M}$ - $\mathcal{C} \mathcal{D}$ foram definidas as propriedades semânticas para relacionar os conceitos e formalizar as relações. Uma visão completa da estrutura dos conceitos e das relações da ontologia é apresentada na Figura 3.1. As linhas contínuas representam a relação do tipo is-a; as linhas tracejadas são as relações definidas por propriedades, os retângulos com um círculo na cor amarela simbolizam os conceitos da ontologia; e os retângulos com um losango na cor rocha indicam os indivíduos (ou objetos instanciados).

Como pode ser visto na Figura 3.1, os conceitos que compõem a abordagem $\mathcal{A L M}-\mathcal{C L D}$ formam a ONTO-IMACID. Por exemplo, os sub-conceitos imacid:ExplanatoryElement, imacid:ExploratoryElement e imacid:EvaluationElement são tipos de elementos 


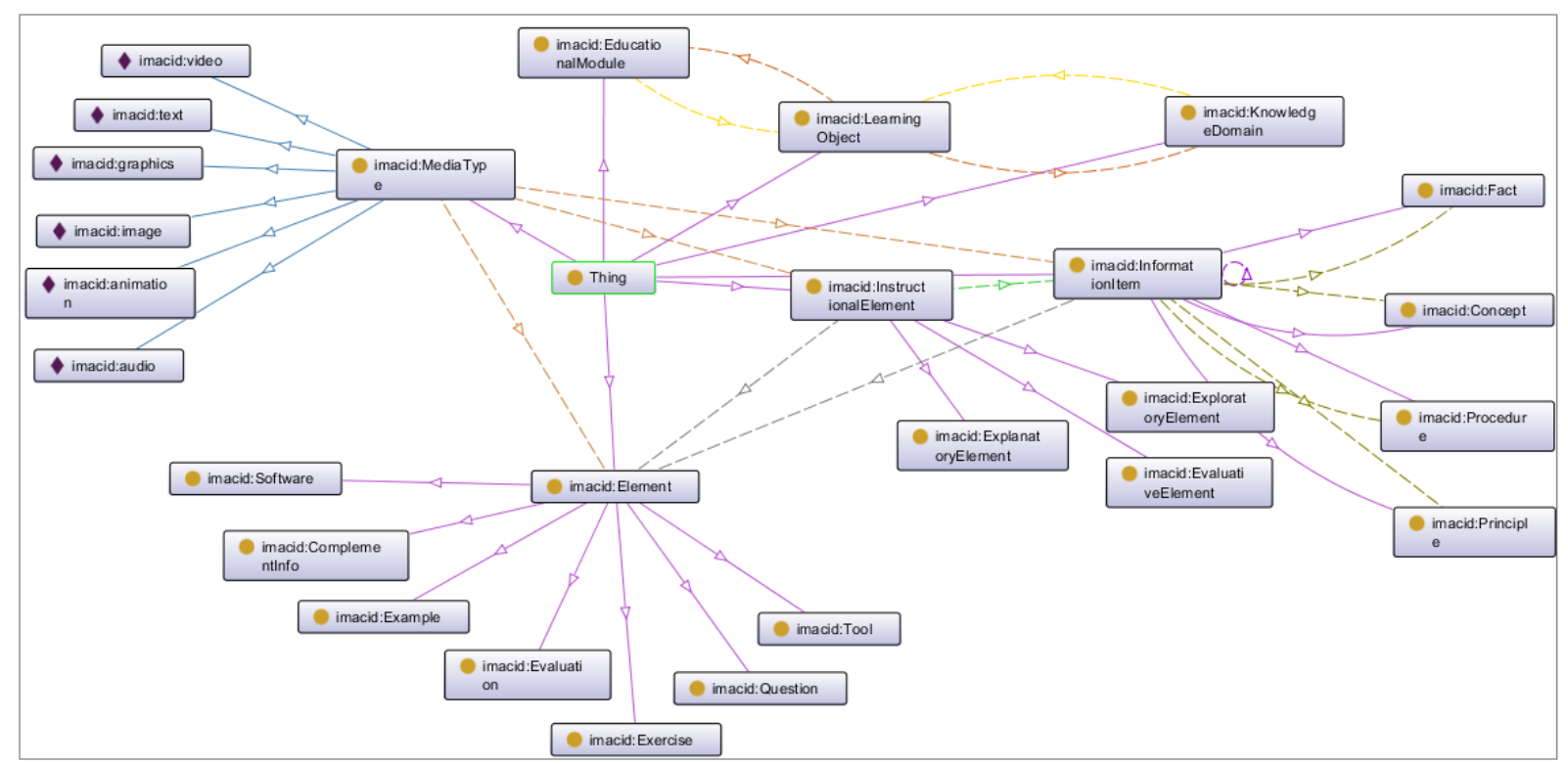

Figura 3.1: ONTO-IMACID: conceitos e relações.

instrucionais (imacid:InstructionalElement), os quais se relacionam por meio da propriedade imacid:complements com os tipos de mídia imacid:MediaType. Ainda sobre a relação imacid:complements, pode-se dizer: um determinado tipo de mídia (imacid:MediaType) complementa (imacid:complements) um elemento instrucional (imacid:InstructionalElement) e atinge os sub-conceitos por inferência.

Esses conceitos foram definidos de maneira a permitir, na integração das ontologias, a estruturação de vários domínios de conhecimento segundo a abordagem $\mathcal{I M A}-\mathcal{C L D}$. Desse modo, a ontologia proposta procura traduzir a abordagem e permitir a estruturação do conteúdo de forma genérica. A definição dos principais conceitos da ONTO-IMACID é apresentada na Tabela 3.1.

Na Figura 3.2, a título de ilustração, são exibidas as relações que compõem a ontologia. Na Figura 3.2.a são apresentadas as relações da ONTO-IMACID e na Figura 3.2.b, são exibidas as características da relação imacid:isAssociated. A relação isAssociated indica que o conceito imacid:MediaType é associado aos conceitos imacid:Element, imacid:InstructionalElement e imacid: InformationItem.

Na ferramenta Protégé as propriedades são definidas na aba Object Properties, na qual se devem inserir o domínio (Domain) principal da relação e os seus intervalos (Ranges), estabelecendo as conexões entre os conceitos. Na Tabela 3.2 são apresentadas as especificidades das relações da ONTO-IMACID. Para um melhor entendimento de como esses relacionamentos são inferidos pela ontologia considere a Figura 3.1. Na figura é possível visualizar as conexões estabelecidas por meio da construção das propriedades entre os conceitos. Ao visualizar as linhas entre os conceitos - algumas tracejadas, outras 
Tabela 3.1: Descrição dos conceitos da ontologia OnTO-IMACID.

\begin{tabular}{|c|c|c|}
\hline Conceito & Descrição & Sub-conceitos \\
\hline $\begin{array}{l}\text { Módulo } \\
\text { Educacional }\end{array}$ & $\begin{array}{l}\text { Unidades de estudo compostas por conteúdos } \\
\text { teóricos e práticos, integrados e disponibilizados } \\
\text { por meio de recursos tecnológicos e } \\
\text { computacionais. }\end{array}$ & - \\
\hline Elemento & $\begin{array}{l}\text { Elementos relacionados aos itens de informação e } \\
\text { elementos instrucionais. }\end{array}$ & $\begin{array}{l}\text { Complementar Info, Evaluation, } \\
\text { Example, Exercise, Tool, } \\
\text { Question, Software }\end{array}$ \\
\hline $\begin{array}{l}\text { Item de } \\
\text { Informação }\end{array}$ & $\begin{array}{l}\text { Conceitos e informações significativas a respeito } \\
\text { do domínio de conhecimento. }\end{array}$ & $\begin{array}{l}\text { Concept, Fact, Procedure, } \\
\text { Principle }\end{array}$ \\
\hline $\begin{array}{l}\text { Elemento } \\
\text { Instrucional }\end{array}$ & $\begin{array}{l}\text { Informações complementares aos conceitos e itens } \\
\text { de informação já definidos. }\end{array}$ & $\begin{array}{ll}\text { Evaluation } & \text { Element, } \\
\text { Explanatory } & \text { Element, } \\
\text { Exploratory Element } & \\
\end{array}$ \\
\hline $\begin{array}{l}\text { Dominio do } \\
\text { conhecimento }\end{array}$ & $\begin{array}{l}\text { Domínio do conhecimento associado ao curso em } \\
\text { questão. }\end{array}$ & - \\
\hline $\begin{array}{lc}\text { Objeto } \quad \text { de } \\
\text { Aprendizagem }\end{array}$ & $\begin{array}{l}\text { Entidades digitais ou não digitais, que podem } \\
\text { ser usadas, reusadas ou referenciadas durante } \\
\text { a aprendizagem com apoio a tecnologia (Wiley, } \\
2009 \text { ). }\end{array}$ & - \\
\hline $\begin{array}{l}\text { Tipo } \\
\text { Mídia }\end{array}$ & $\begin{array}{l}\text { Tipos de mídias associadas ao conteúdo } \\
\text { educacional. }\end{array}$ & $\begin{array}{l}\text { Animation, Audio, } \\
\text { Graphics, Text, Video }\end{array}$ \\
\hline
\end{tabular}

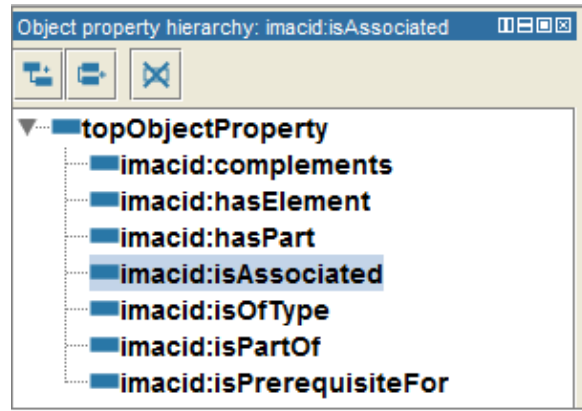

(a) Propriedades da Onto-IMACID

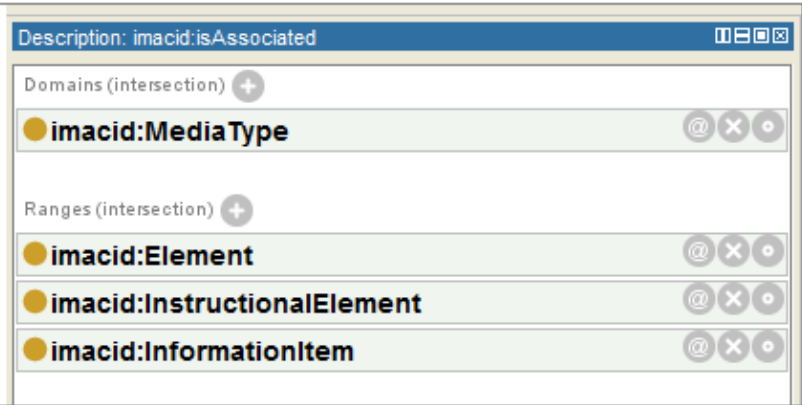

(b) Exemplo da propriedade isAssociated

Figura 3.2: ONTO-IMACID: propriedades.

contínuas e de várias cores - deve-se entender que cada uma destas refere-se a uma propriedade definida.

Essas propriedades, ou relações entre conceitos, estabelecem a correlação entre os conceitos e auxiliam na criação do mapeamento e das regras de inferência para que a ONTO-IMACID se comunique com as demais ontologias. A descrição das propriedades é feita a seguir:

- complements - O conceito X complementa o conceito Y.

- hasElement - O conceito X tem elemento(s) do conceito Y.

- hasPart - O conceito X tem parte do conceito Y, ou seja, o conceito Y é formado por X. 
CAPÍTULO 3. UM CONJUNTO DE ONTOLOGIAS PARA PERSONALIZAÇÃO

Tabela 3.2: Descrição das relações da ontologia ONTO-IMACID.

\begin{tabular}{l|l|l}
\hline \hline Relação & Domínio (Domain) & Intervalos (Range) \\
\hline complements & InstructionalElement & InformationItem \\
\hline hasElement & $\begin{array}{l}\text { InformationItem, } \\
\text { InstructionalElement }\end{array}$ & Element \\
\hline EasPart & $\begin{array}{l}\text { KducationalModule, } \\
\text { KnowledgeDomain }\end{array}$ & LearningObject \\
\hline isAssociated & MediaType & Element, InstructionalElement, InformationItem \\
\hline isPartOf & LearningObject & EducationalModule, KnowledgeDomain \\
\hline isPrerequisiteFor & InformationItem & InformationItem \\
\hline IsOfType & InformationItem & Concept, Fact, Principle, Procedure \\
\hline \hline
\end{tabular}

- isAssociated - O conceito X está associado ao conceito Y.

- isPartOf - O conceito X é parte de Y, ou seja, o conceito Y forma X.

- isPrerequisiteFor - O conceito $\mathrm{X}$ tem parte do conceito $\mathrm{Y}$, ou seja, o conceito Y é formado por X.

- IsOfType - O conceito X é do tipo do conceito Y.

O diferencial da ontologia ONTO-IMACID em relação à abordagem $\mathcal{A L M}$-CLD está no fato de que os tipos de mídia do conteúdo podem ser instanciados livremente, de acordo com as mídias existentes no domínio de conhecimento em questão. Na abordagem IMA-CID esses elementos estavam fixados como parte dos elementos instrucionais (ora como elementos explanatórios, exploratórios ou de avaliação). Portanto, a ONTO-IMACID permite a inserção de novos conceitos na abordagem, ou seja, o conceito imacid:Element pode ter novos tipos além dos que já estão na ontologia (imacid:Sofware, imacid:ComplementarInfo, imacid:Evaluation, imacid:Exercise, imacid:Question, imacid:Tool).

A ONTO-IMACID tem a finalidade de estruturar qualquer domínio de conteúdo de acordo com a abordagem IMA-CID, por meio das relações que devem ser associadas ao domínio pelo autor do conteúdo. A partir da associação das relações entre a ONTO-IMACID e a ontologia de domínio o conteúdo será instanciado segundo as características dos modelos que compõem a abordagem.

A instanciação dos conceitos é feita pela máquina de inferência que realiza além do raciocínio explícito (com base nas propriedades), o raciocínio implícito das propriedades que se relacionam nas ontologias. Desse modo, além do compartilhamento e formalização de acordo com a IMA-CID, o poder computacional propiciado pelas inferências e pelo mapeamento entre as ontologias agrega à aplicação interoperabilidade, desempenho, automatização e agilidade na associação dos conceitos. 
A Onto-Imacid garante que o conteúdo seja estruturado e organizado de acordo com a abordagem $\mathcal{A L M}$ - CID. Além disso, a ontologia provê a flexibilidade com relação ao domínio de conhecimento. Sendo assim, tanto as relações definidas pelo autor do conteúdo bem como as propriedades intrínsecas à abordagem podem ser instanciadas em qualquer domínio de conhecimento na ontologia. Um exemplo de aplicação é demonstrado no Capítulo 4.

\subsubsection{Onto-Domain: Ontologia de Domínio}

A ontologia de domínio, denominada OnTo-Domain, é fundamental para que as demais ontologias sejam instanciadas e associadas entre si, de modo a disponibilizar conteúdo estruturado e personalizado para o aluno. Para prover a flexibilidade do domínio, a construção da OnTo-Domain é dependente do especialista que a faz, ou seja, apresenta características referentes ao background e experiência de quem a elaborou. Assim, é importante ressaltar que não se pode afirmar quais conceitos estarão presentes ou não a partir de um determinado domínio de conhecimento, devido à liberdade na criação e desenvolvimento da ontologia.

Neste trabalho, a ONTO-DomAIn é inserida pelo autor do conteúdo para que o domínio seja instanciado em conformidade com a $\mathcal{A} \mathcal{I} M-\mathcal{C L D}$. No entanto, fica a cargo do autor do conteúdo fazer a associação entre os conceitos do domínio aos conceitos da $\mathcal{A} \mathcal{L} M-\mathcal{C L D}$, bem como conhecer os modelos da abordagem para que o conteúdo seja modelado. Isso será feito em conjunto com a máquina de inferência de acordo com o mapeamento feito na ONTO-IMACID.

A título de ilustração, foi construída uma ontologia no domínio de Análise de Pontos de Função (APF), que aborda os principais conceitos encontrados na literatura referentes a essa métrica. Como base para o estabelecimento da ontologia, foi utilizado o livro de Análise de Pontos de Função (Carlos Eduardo Vazquez, 2003). Desse modo, procurou-se considerar os principais conceitos deste domínio na ONTO-DOMAIN, os quais são instanciados na ferramenta Protégé.

A ontologia da APF tem cerca de 120 objetos (ou indivíduos). Além de instanciar a ontologia de domínio, foram construídas algumas propriedades para relacionar os conceitos entre si, as quais serão utilizadas no mapeamento para instanciar a ONTO-IMACID e demais ontologias propostas. A ontologia do domínio de APF é exibida na Figura 3.3.

$\mathrm{Na}$ Figura 3.3 são apresentados os principais conceitos para calcular os pontos de função em um sistema. Os passos necessários para obter o número de pontos de função são ligados aos conceitos de determinação da contagem d:DeterminacaoContagem), delimitação da fronteira (d:DelimitacaoFronteira), cálculo 
CAPÍTULO 3. UM CONJUNTO DE ONTOLOGIAS PARA PERSONALIZAÇÃO

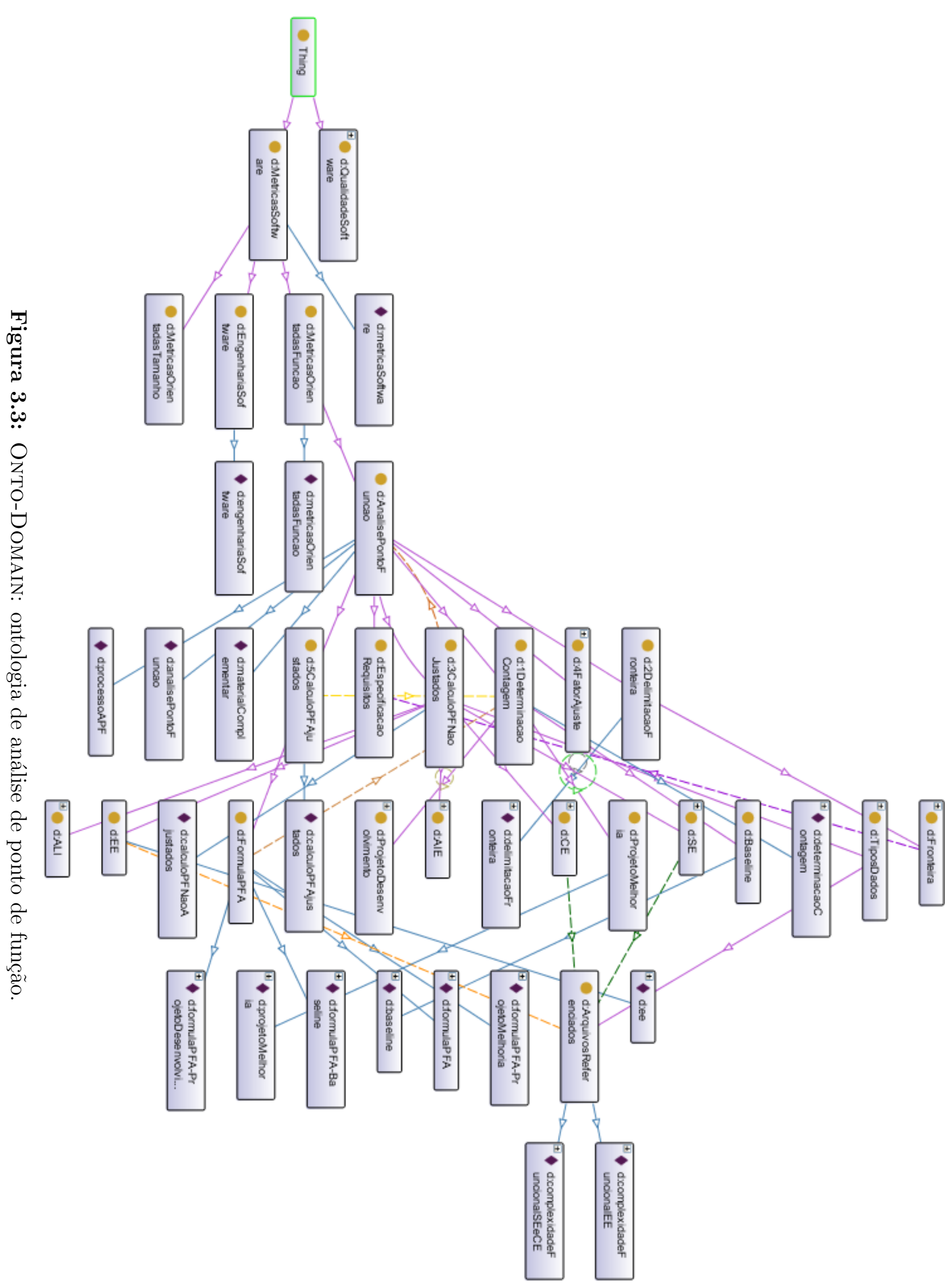


dos pontos de função não ajustados (d:CalculoPFNaoAjustados), especificação dos requisitos (d:EspecificacaoRequisitos) e cálculo dos pontos de função ajustados (d:CalculoPfAjustados). Esses conceitos são formados por sub-conceitos e indivíduos. Os conceitos foram instanciados na ferramenta Protégé, por meio do autor da ontologia, que inseriu a descrição e as características de cada nó conceitual.

Além da definição dos conceitos, também foram criadas propriedades que se referem às principais características que interligam os pontos-chaves do domínio e que são necessárias para estabelecer o vínculo de dependência entre os conceitos. Tais conceitos serão mapeados e apresentados para os usuários de acordo com a execução dos mapeamentos e das consultas. As propriedades da OnTO-DomAIN são apresentadas na Figura 3.4.

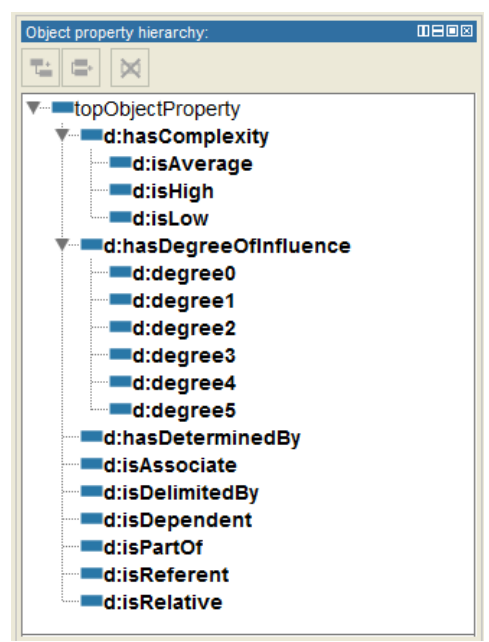

Figura 3.4: ONTO-DomaIn: propriedades.

A instanciação, o mapeamento e as inferências são feitos utilizando as funcionalidades e o reasoner (máquina de raciocínio e/ou inferência) da ferramenta Protégé. Um exemplo de indivíduo instanciado, bem como suas propriedades e usos associados é apresentado na Figura 3.5. Na figura são ilustradas as características relacionadas ao indivíduo d: projetoDesenvolvimento que é uma instância do conceito d:ProjetoDesenvolvimento que, por sua vez é um sub-conceito de $\mathrm{d}$ :DeterminacaoContagem. Pode-se perceber que o objeto $d:$ projetoDesenvolvimento é obrigatoriamente diferente dos indivíduos d:projetoMelhoria e d:baseline, por questões de definição sobre a forma com que cada conceito é calculado na Análise de Ponto de Função. Além disso, a classe a qual o indivíduo pertence está relacionada à propriedade d:projetoDesenvolvimento; portanto, o indivíduo, que é uma instância da classe d:ProjetoDesenvolvimento, herda a relação da classe-pai.

A Onto-Domain é genérica, ou seja, cada conteúdo instanciado pode ter o seu domínio de conhecimento definido por meio da ontologia inserida de acordo com o especialista do domínio ou o autor da ontologia. Independentemente do domínio, da 


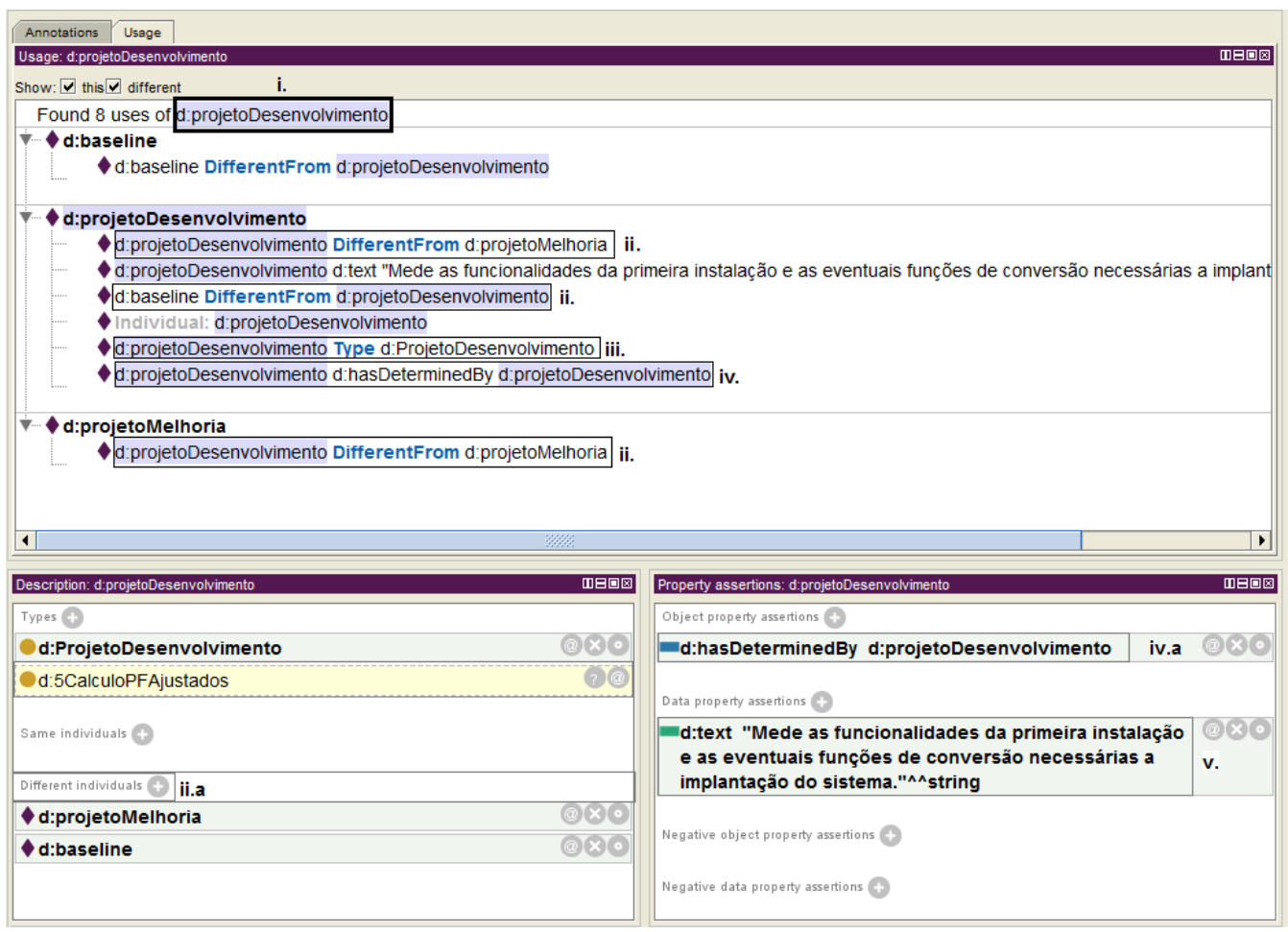

Figura 3.5: Exemplo da construção de um indivíduo na Protégé.

formalidade ou das diferentes ontologias para um mesmo domínio, a associação dos conceitos será feita pelo autor do conteúdo, que deve completar as propriedades ou relações na ontologia de integração. Dessa forma, a ontologia de integração provê a generalização do conteúdo por meio da inserção de outras ontologias de domínio, que podem ser abordadas e instanciadas, tendo o conhecimento estruturado segundo a abordagem $\mathcal{I M A}-\mathcal{C} \mathcal{L D}$.

\subsubsection{Onto-UserModel: Ontologia do Modelo do Usuário}

Como visto na Seção 2.4, a modelagem do perfil do usuário é um dos pontos fundamentais para a aplicação da personalização. A ONTO-UserModel, ontologia do modelo do usuário definida neste trabalho, foi construída buscando semelhanças nas ontologias existentes, a fim de reutilizar uma especificação já definida. Foi feita uma combinação de abordagens, considerando as vantagens e características mais importantes para este contexto. A partir da pesquisa em trabalhos relacionados e em ambientes de busca de ontologias, como Swoogle ${ }^{1}$ e Watson ${ }^{2}$, várias ontologias foram encontradas. Destas 10 ontologias foram analisadas.

Basicamente, a ONTO-UsERMODEL aborda as cinco pospostas por Brusilovsky e Peylo (2003) (conhecimento, interesse, meta, background e traços individuais) apresentadas

\footnotetext{
${ }^{1}$ http://swoogle.umbc.edu/

${ }^{2}$ http://watson.kmi.open.ac.uk/WatsonWUI/
} 
por na Seção 2.4 e reutiliza parte da ontologia definida por Jovanovic et al. (2006b), apresentada na Seção 2.5.1. A modelagem do perfil do usuário utilizada foi a modelagem por sobreposição, que modela o conhecimento como um subconjunto do conhecimento do especialista do domínio (Sosnovsky e Dicheva, 2010).

A estrutura da ontologia ONTO-UserModel é apresentada na Figura 3.6. Os conceitos user:Performance, user:Preference, user:Role, user:Feedback, user: LearningStyle são extraídos da ontologia do modelo do usuário da Jovanovic et al. (2006b). Já os conceitos user:Goal, user:knowledge, user:IndividualTraits, user:Competency, user:Activity, user:Background, user:ContextOfWork, user:Identification foram inseridos com base nas definições de Brusilovsky e Peylo (2003). Ainda, os conceitos user: Preference, user: Competency, user: Interest e user: Activity compõem os padrões IMS LIP (IMS, 2001) e IEEE PAPI (IEEE-LTSC, 2001), indicados na Seção 2.4.2.1.

A Onto-UserModel é composta de características que modelam o perfil do usuário e possibilitam a extração de dados como interesses, experiências anteriores, áreas de conhecimento, estilo de aprendizagem, estado afetivo, competências e objetivos do usuário. Na Tabela 3.3 são descritos os principais conceitos da ONTO-UsERModEL.

Tabela 3.3: Descrição dos conceitos da ontologia OnTO-UserModel

\begin{tabular}{ll}
\hline \hline Conceito & Descrição \\
\hline Atividades & Definidas de acordo com o curso e as unidades de estudo associadas. \\
\hline Interesses & $\begin{array}{l}\text { Relacionados ao que o usuário deseja adquirir no curso, suas metas pessoais } \\
\text { durante a aprendizagem. }\end{array}$ \\
\hline Preferências & $\begin{array}{l}\text { Referem-se ao tipo de mídia (áudio, imagem, vídeo, texto, gráfico e animação) } \\
\text { e à linguagem em que o usuário prefere estudar/aprender. }\end{array}$ \\
\hline Background & Associado às experiências anteriores do usuário. \\
\hline Competência & Associada ao usuário e incrementada de acordo com seu desempenho no curso. \\
\hline Estado afetivo & Refere-se às características sobre o humor e estado afetivo do usuário. \\
\hline $\begin{array}{l}\text { Contexto } \\
\text { trabalho }\end{array}$ & Consiste no ambiente externo ao qual o usuário está inserido. \\
\hline Feedback & Representa a finalidade imediata para o trabalho de um usuário. \\
\hline Meta & Representa a finalidade imediata para a atividade de um aluno. \\
\hline Identificação & representa os dados pessoais do usuário. \\
\hline Papel & Identificados pelo sistema, sendo do tipo autor, aluno, professor ou instrutor. \\
\hline $\begin{array}{l}\text { Traços } \\
\text { individuais }\end{array}$ & $\begin{array}{l}\text { Referem-se ao comportamento do usuário e aos seus estilos cognitivo e de } \\
\text { aprendizagem. }\end{array}$ \\
\hline $\begin{array}{l}\text { Estilo } \\
\text { aprendizagem }\end{array}$ & Refere-se às características de aprendizagem do aluno. \\
\hline Desempenho & Refere-se aos resultados das avaliações dos alunos em suas atividades. \\
\hline Conhecimento & Refere-se ao que o usuário conhece a respeito de um determinado domínio. \\
\hline \hline
\end{tabular}

No contexto deste trabalho, a personalização foi feita para cada usuário, com base em suas características, e os conceitos poderão ser instanciados: (i) por meio de questionários; (ii) pelo sistema; e/ou (iii) pelo autor do conteúdo. O processo de construção é variável, 


\section{CAPÍTULO 3. UM CONJUNTO DE ONTOLOGIAS PARA PERSONALIZAÇÃO}

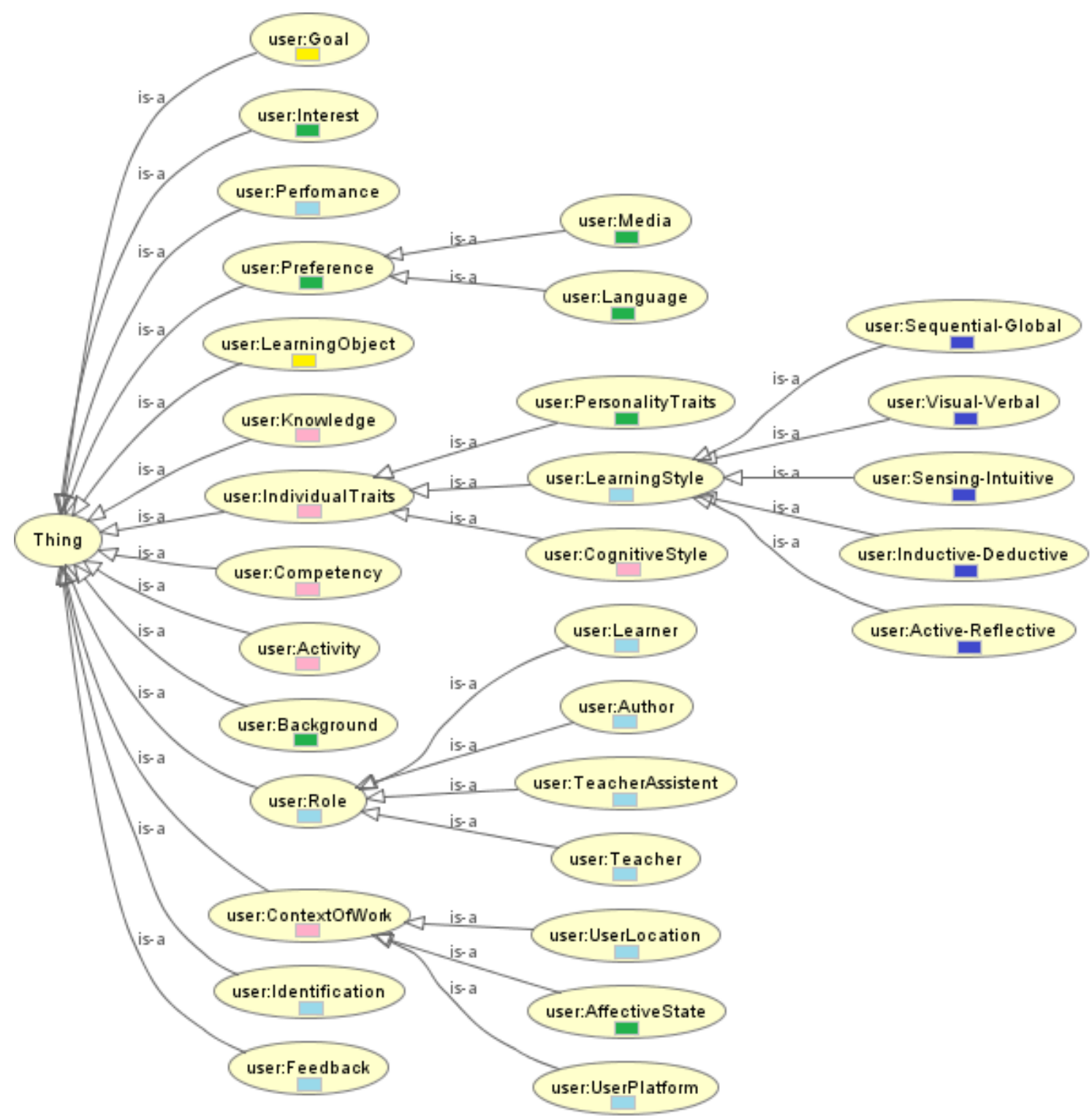

Figura 3.6: Onto-UserModel: estrutura geral dos conceitos.

por exemplo, enquanto algumas informações são extraídas pelo sistema na hora do cadastro do usuário, outras são inseridas pelo usuário ao preencher os questionários. Além disso, existem alguns conceitos que são mantidos ou atualizados durante o processo de ensino e aprendizagem.

Na Figura 3.6 os conceitos possuem indicadores coloridos que correspondem às especificidades de instanciação, ou seja, as cores representam os papéis dos atores que instanciam os conceitos, sendo respectivamente:

- Verde: conceito instanciado pelo usuário.

- Azul claro: conceito instanciado pelo sistema.

- Rosa: conceito instanciado pelo usuário e/ou sistema. 
- Azul escuro: conceito instanciado pelo questionário de Soloman e Felder (2001).

- Amarelo: conceito instanciado pelo instrutor ou autor do conteúdo.

Outro fator importante da ONTO-USERMODEL refere-se ao fato de que um conceito pode ser alterado ou atualizado durante a execução da aplicação (uma aula ou um curso, por exemplo), mesmo que esta não seja dinâmica. Há a possibilidade de que as consultas internas (via regras de inferência) tenham resultados que auxiliem e permitam a alteração ou atualização de conceitos da ontologia como atividades (user:Activity), interesses (user:Interest), background (user:Background), competência (user:Competency), feedback (user:Feedback), desempenho (user:Performance) e o conhecimento (user:Knowledge) do usuário.

Além dos conceitos apresentados, na ONTO-UsERMOdEL também foram implementadas propriedades, ou seja, foram definidas na ontologia as relações entre os conceitos para a criação de axiomas, mapeamento e regras de inferência. As relações envolvem conceitos e relacionamentos específicos, os quais não são alcançados somente com a relação do tipo é-um (is-a). As propriedades foram criadas de acordo com as definições dos conceitos, com as observações do contexto e com os inter-relacionamentos para gerar o modelo do usuário. Por exemplo, o desempenho (conceito user:Performance) é necessário para analisar a competência (conceito user: competency) e o retorno (conceito user:Feedback) do aluno em uma determinada atividade (conceito user:activity). Essa observação do contexto gerou a construção da propriedade user: isNecessaryFor. Na Figura 3.7 é exibido um grafo com todas as propriedades e como essas são relacionadas aos conceitos da ontologia.

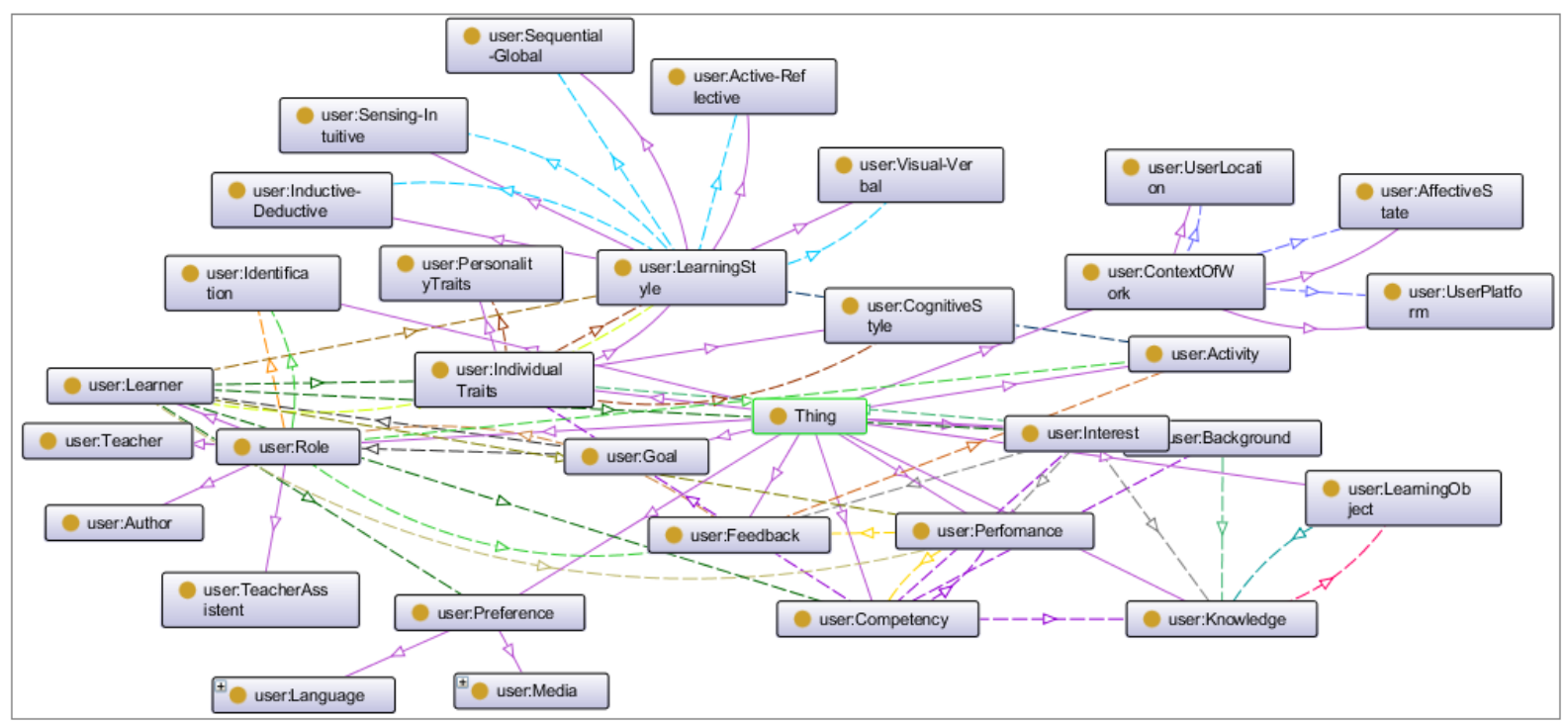

Figura 3.7: ONTO-UserModel: conceitos e relações. 
As linhas entre os conceitos (retângulos) representam as propriedades específicas entre os conceitos. No grafo construído pela ferramenta Protégé, cada cor indica uma propriedade. Além disso, após iniciar a máquina de inferência, outras propriedades podem ser criadas por meio da inferência. Na Tabela 3.4 são mostradas as relações criadas para a ONTO-UserModel e como os conceitos são associados.

Tabela 3.4: Descrição das relações da ontologia UsERMoDEL

\begin{tabular}{l|l|l}
\hline \hline Relação & Domain & Range \\
\hline user:isFormedBy & ContextWork & AffectiveState, UserLocation, UserPlatform \\
\hline user:isPresent & Role & Activity, Feedback, Identification \\
\hline user:isResult & Feedback & Activity \\
\hline user:isPrerequisiteFor & Activity & LearningStyle \\
\hline user:isNecessaryFor & Performance & Competency, Feedback \\
\hline user:has & Learner & Preference, IndividualTraits, Interest, Competency \\
\hline user:hasLearningStyle & Learner & LearningStyle \\
\hline user:hasPerformance & Learner & Performance \\
\hline user:isAchievedBy & Competency & $\begin{array}{l}\text { Performance, Background, Interest, Knowledge, } \\
\text { IndividualTraits }\end{array}$ \\
\hline user:isRelated & Background & Knowledge, IndividualTraits \\
\hline user:isBuilt & Interest & Feedback, Knowledge, Performance, Background \\
\hline user:isAssociated & Feedback & Role \\
\hline user:isPartOf & LearningObject & Knowledge \\
\hline user:hasPartOf & Knowledge & LearningObject \\
\hline user:isReached & Goal & Learner, Teacher \\
\hline user:isOfType & LearningStyle & $\begin{array}{l}\text { Active-Reflective, } \\
\text { Sensing-Global, Visual-Verbal }\end{array}$ \\
\hline user:isDeterminedBy & IndividualTraits & Cognitive-Style, LearningStyle, PersonalityTraits \\
\hline \hline
\end{tabular}

Outra forma de apresentar as propriedades da ontologia, utilizando o ambiente da ferramenta Protégé é ilustrada na Figura 3.8. Na Figura 3.8.a são mostradas todas as relações da ontologia, na Figura 3.8.b é ilustrado um exemplo da propriedade isAchievedBy. A propriedade isAchievedBy está ligada ao conceito competência Competency e aos demais conceitos exibidos na figura, o que significa que a competência (Competency) do aluno é alcançada por meio (user:isAchievedBy) do interesse (user:Interests), desempenho (user:Performance), conhecimento (user:Knowledge), background (user:Background) e traços individuais (user: IndividualTraits).

A ONTO-UserModel é instanciada inicialmente por meio de dois questionários: o primeiro com base no modelo proposto Felder ${ }^{3}$, em que as características de estilo de aprendizagem são extraídas; e o segundo é formado por questões básicas e pessoais a respeito do usuário. Essas questões podem ser vistas nos apêndices A e B respectivamente, bem como as respostas de acordo com o nível de conhecimento dos três usuários instanciados no exemplo de uso na integração das ontologias, apresentadas no Capítulo 4.

\footnotetext{
${ }^{3}$ http://www.engr.ncsu.edu/learningstyles/ilsweb.html
} 


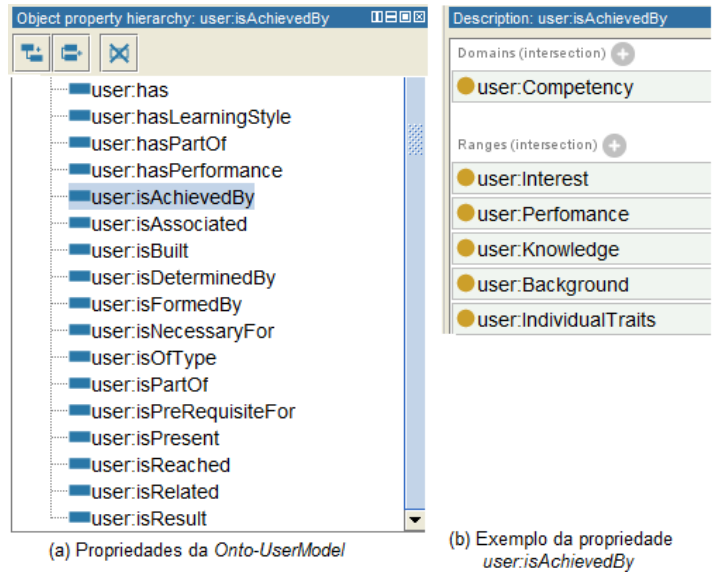

Figura 3.8: ONTO-USERMODEL: propriedades.

\subsubsection{Onto-Navigation: Ontologia de Navegação}

Assim como no trabalho de Jovanovic et al. (2006b), a ontologia de navegação proposta neste trabalho, foi construída com o intuito de facilitar a apresentação do conteúdo e dissociar o conhecimento do domínio das características de navegação. Essa prática proporciona o reúso tanto da ontologia de domínio e do modelo do usuário, quanto da ontologia de navegação.

O estabelecimento de uma ontologia de navegação, denominada ONTO-NAVIGATION, possibilita a criação de diversos níveis de granularidade para a visualização do domínio do conhecimento, em conformidade com as preferências do usuário. Isso ocorre por meio do mapeamento das relações de precedência entre as ontologias e entre os conceitos, fornecendo características da sequência e das mídias do conteúdo para o usuário.

Vale destacar, ainda, que a Onto-NAVigation aborda o modelo didático da abordagem $\mathcal{I M A}-\mathcal{C} \mathcal{I D}$, apresentado na Seção 3.2.1. O modelo didático prevê a criação de especificações abertas ou fechadas para a apresentação do conteúdo para o usuário, ou seja, navegação pelo conteúdo com pré-requisitos estabelecidos entre os conceitos ou sem restrições de ordem de apresentação. Com o desenvolvimento da Onto-Navigation a especificação é feita de forma personalizada, de acordo com as preferências e conhecimento do usuário sobre um determinado domínio. Dessa maneira, para cada usuário, a navegação é fechada e em conformidade suas características; havendo assim a possibilidade de várias formas de apresentação de um mesmo conteúdo para diversos usuários.

Apesar da Onto-NAvigation apresentar uma estrutura menor em termos de quantidade de conceitos, ela apresenta propriedades (ou relações) que são extremamente importantes para que os resultados sejam alcançados na ontologia de integração. Em conjunto com as demais ontologias, a ontologia de navegação oferece informações sobre a apresentação e o nível do conteúdo, de forma personalizada para cada usuário. O grafo da ontologia e suas relações entre os conceitos são exibidos na Figura 3.9. 


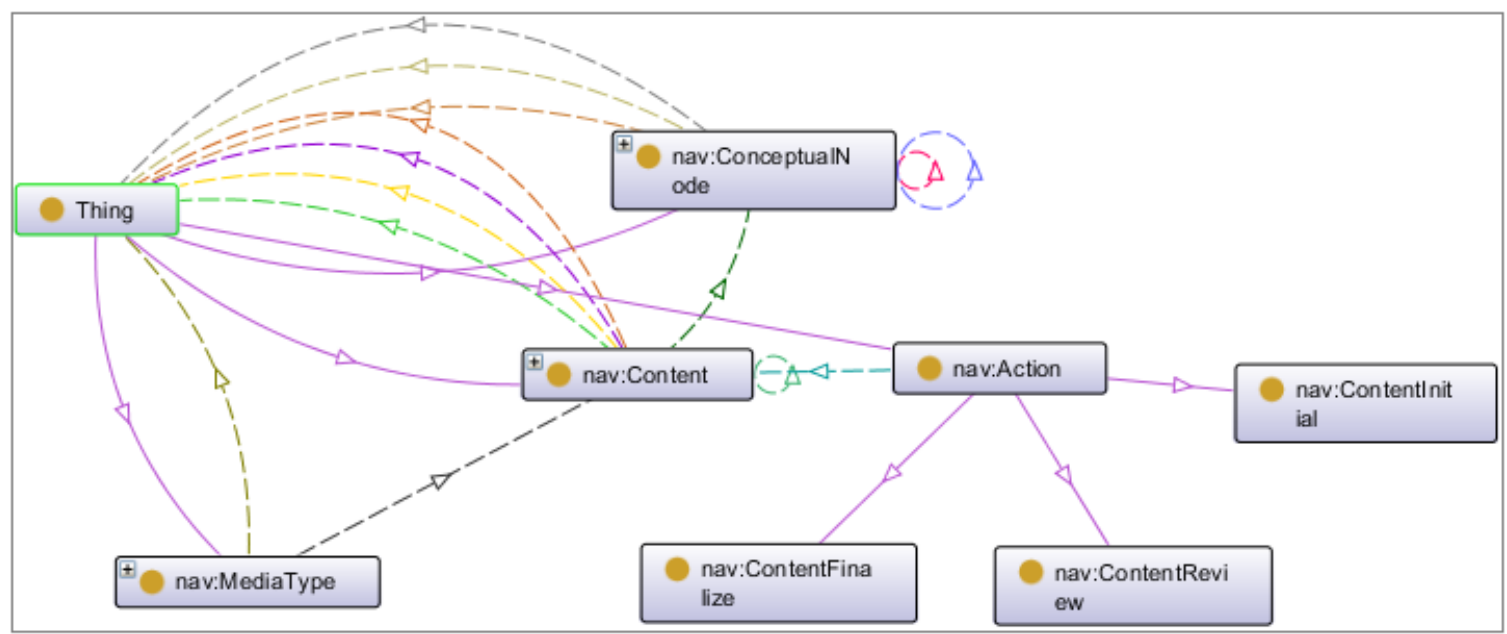

Figura 3.9: Onto-NAVigation: conceitos e propriedades.

De acordo com a Figura 3.9, tem-se: (i) o conceito nav:Action refere-se às ações possíveis para um determinado conteúdo; (ii) os sub-conceitos nav:ContentInicial, nav:ContentReview nav:ContentFinalize indicam o estado para o conteúdo em um objeto de aprendizagem ou em um módulo educacional, por exemplo; (iii) o conceito nav: Content refere-se ao conteúdo diretamente; (iv) o conceito nav: ContentNode indica a posição do conteúdo (primeiro, último, próximo ou anterior); e o conceito nav:MediaType refere-se ao tipo de mídia do conteúdo.

Quanto às propriedades estabelecidas, especificamente as propriedades nav:semanticRelation, nav:narrower, nav:broader e nav:related foram extraídas do padrão SKOS (Simple Knowledge Organization System) (Isaac et al., 2007) da W3C. Tais propriedades referem-se à relação semântica entre os conceitos, isto é, se um conceito está mais próximo ou mais distante de outro e/ou se são relacionados. Na Figura 3.10 são apresentadas as propriedades construídas para a ONTO-NAVIGATION.

Além das propriedades extraídas do modelo SKOS, outras três propriedades foram reutilizadas da ontologia de Learning Path da Jovanovic et al. (2006a): nav:hasKnowledgePonder, nav:isPrerequisteFor e nav:requiresKnowledge0f. Na Tabela 3.5 são exibidos os conceitos envolvidos nas relações.

A Onto-Navigation é instanciada em dois momentos: (i) manualmente pelo autor do conteúdo, de acordo com as regras estabelecidas para o domínio; e (ii) automaticamente, pela máquina de inferência, após a execução do mapeamento e das regras. O resultado é o conteúdo em conformidade com as preferências do usuário, o conteúdo estruturado segundo a ONTO-IMACID e com a sequência de apresentação e navegação do conteúdo definidas de forma personalizada para o usuário. Tais aspectos são explorados com mais detalhes no Capítulo 4 


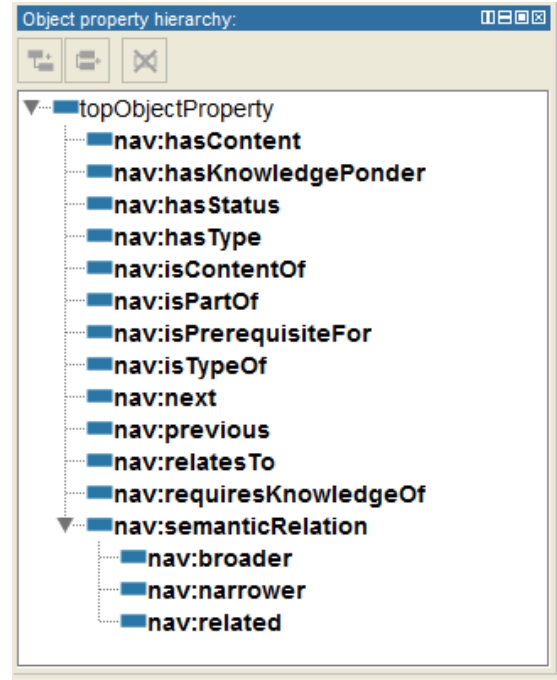

Figura 3.10: Propriedades da Ontologia Onto-Navigation.

Tabela 3.5: Descrição das relações da ontologia OnTO-NAVIGATion

\begin{tabular}{|c|c|c|}
\hline Relação & Domain & Range \\
\hline nav:hasContent & nav:ConceptualNode & nav:Content \\
\hline nav:hasKnowledgePonder & nav:Content & \\
\hline nav:hasStatus & nav:Content & nav:Action \\
\hline hasType & nav:MediaType & \\
\hline nav:isContentOf & nav:Content & nav:ConceptualNode \\
\hline nav:isPartOf & nav:Action, nav:ConceptualNode & nav:Content \\
\hline nav:isPrerequisiteFor & nav:ConceptualNode & nav:ConceptualNode \\
\hline nav:isTypeOf & nav:MediaType & nav:Content \\
\hline nav:next & nav:ConceptualNode & \\
\hline nav:hasStatus & nav:Content & nav:Action \\
\hline nav:previous & nav:ConceptualNode & \\
\hline nav:relatesTo & nav:ConceptualNode & \\
\hline nav:requiresKnowledgeOf & nav:ConceptualNode & nav:ConceptualNode \\
\hline nav:semanticRelation & nav:Content & nav:Content \\
\hline
\end{tabular}

\subsection{Considerações Finais}

Neste capítulo foram apresentadas as ontologias Onto-ImACID, OnTo-Domain, Onto-Usermodel e Onto-Navigation. Essas ontologias são importadas para uma ontologia global ou de integração - ONTOTOLEARNER, com o objetivo de promover a personalização da apresentação do conteúdo de acordo com a abordagem $\mathcal{I M A}-\mathcal{C L D}$ e com base no modelo do usuário.

O conjunto de ontologias propostas, associado ao mapeamento das relações e das regras de inferência, proporciona a construção da personalização. As características e os passos necessários para o mapeamento e instanciação das ontologias na ONTOTOLEARNER são discutidos no Capítulo 4. 
CAPÍTULO 3. UM CONJUNTO DE ONTOLOGIAS PARA PERSONALIZAÇÃO 


\section{OntoToLearner - Uma Ontologia de Integração para Personalização}

\subsection{Considerações Iniciais}

Conforme discutido no capítulo anterior, as ontologias OnTo-Imacid, Onto-Domain, Onto-UserModel e Onto-NAvigation foram propostas tendo como objetivo proporcionar a personalização do conteúdo de acordo com o perfil do usuário e com a abordagem $\mathcal{A L M}$ - CID. A partir das ontologias definidas foi construída uma ontologia de integração, denominada ONTOTOLEARNER, sobre a qual foi realizado o mapeamento e a instanciação das propriedades e dos indivíduos.

Além do conjunto de ontologias, consultas e regras de inferência são construídas e executadas na estrutura da ONTOTOLEARNER, mantendo as especificidades ontologias originais, isto é, as mesmas não são alteradas com as inserções de propriedades e/ou objetos. Dessa forma, procura-se garantir: (i) a integridade das ontologias; (ii) a estruturação do conteúdo de acordo com a abordagem $\mathcal{A} \mathcal{I} M-\mathcal{C I D}$; e (iii) a generalidade da ontologia de domínio.

Neste capítulo são discutidos os passos de desenvolvimento do mapeamento das relações, a criação das consultas e das regras de inferência, a instanciação das ontologias e os resultados obtidos. Na Seção 4.2 é apresentado o processo de composição da ontologia global. Na Seção 4.3 são descritos o mapeamento entre as ontologias e a instanciação dos 
conceitos. Por fim, na Seção 4.4 um exemplo de uso da Onto ToLearner é apresentado, com consultas e inferências para a visualização da personalização do conteúdo.

\subsection{Processo de Composição da OntoToLearner}

A Ontotolearner é formada pela importação das ontologias desenvolvidas neste trabalho. Trata-se de uma ontologia na linguagem OWL que possui uma estrutura formada pelas ontologias Onto-Imacid, Onto-Domain, Onto-UserModel e ONTO-NAVIGATION, na qual são inseridas as propriedades e são instanciados os usuários e o domínio de conhecimento, gerando assim a adaptação do ambiente para proporcionar a personalização do apresentação do conteúdo ao usuário. Na Figura 4.1 é ilustrada a composição da ontologia ONTOTOLEARNER.

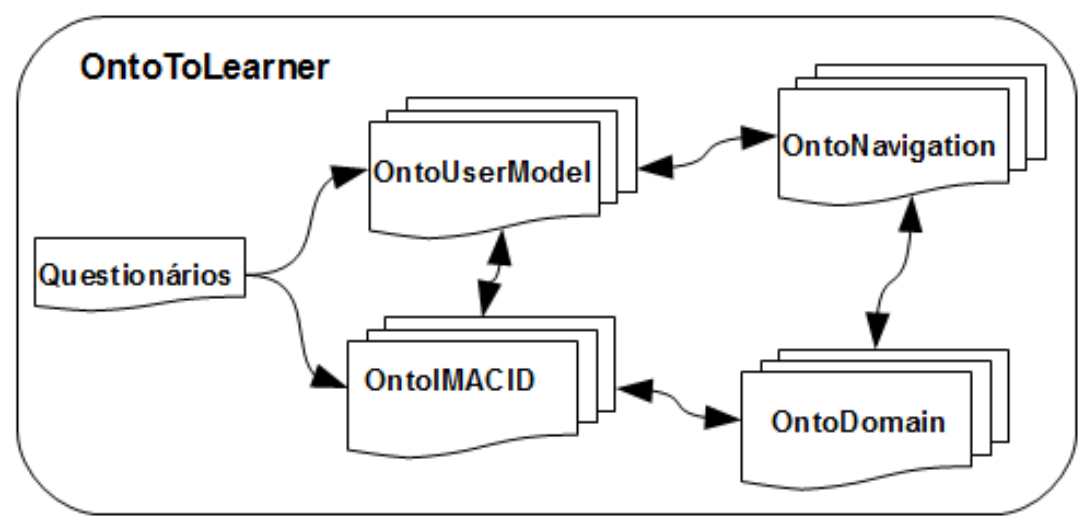

Figura 4.1: Composição da ontologia OnTOToLeARner.

A OntoToLearner é composta pelo conjunto de ontologias, pelo mapeamento estabelecido de acordo com os objetivos de adaptação e as regras de inferência. Na Figura 4.1 as setas entre as ontologias representam a comunicação entre as mesmas, via instanciação por meio de questionários e mapeamento de propriedades entre elas.

A fim de permitir a comunicação entre as ontologias propostas, foi feito o mapeamento entre as propriedades das mesmas, o qual foi construído na OnTOTOLEARNER. Foram consideradas relações genéricas a fim de instanciar os conceitos segundo a abordagem IMA-CID e personalizar os conteúdos educacionais da ONTO-DOMAIN para cada usuário, de acordo com a Onto-UserModel e a Onto-Navigation. Ressalta-se que a estrutura das ontologias foi mantida.

Além disso, foi utilizada a técnica de mapeamento entre ontologia global integrada, isto é, a ONTOTOLEARNER, e ontologias locais. As relações para o mapeamento são feitas na ontologia de integração, envolvendo as propriedades e os conceitos das ontologias. Um exemplo de mapeamento é a associação de forma direta entre propriedades de diferentes ontologias em uma mesma relação mapeada. 


\section{CAPÍTULO 4. ONTOTOLEARNER - UMA ONTOLOGIA DE INTEGRAÇÃO}

PARA PERSONALIZAÇÃO

A associação entre as propriedades pode ser feita pela máquina de inferência e/ou pelo autor do conteúdo, dependendo da ontologia e do tipo de instanciação. Um caso específico é a instanciação das relações entre a ONTO-IMACID e a ONTO-Domain, que são feitas pelo autor do conteúdo, pois ele quem conhece o conteúdo e sabe associar o domínio com a abordagem $\mathcal{I M A}-\mathcal{C I D}$, de acordo com as suas definições e metas para a aprendizagem do aluno. É importante observar que o papel do autor do conteúdo é indispensável, até mesmo para que as inferências aconteçam, visto que, o mapeamento inicial e as definições relacionadas ao domínio e à abordagem aplicada são feitas pelo instrutor.

Na Figura 4.2 é apresentada uma visão mais detalhada do processo de composição da OntoTolearner. São apresentadas as ontologias e os componentes diretamente relacionados. Os questionários são utilizados para instanciar a ONTO-UsERMODEL e a Onto-Domain. A Onto-Imacid será instanciada, como exemplificado anteriormente, por intermédio do autor do conteúdo, que irá associar as propriedades definidas aos conceitos da ONTO-Domain de acordo com o perfil do usuário, fazendo o mapeamento entre o domínio de conteúdo e a abordagem $\mathcal{A L M}$-CLDD. Além disso, em todas essas ações são levadas em consideração as características de navegação, as quais são pré-definidas pelo autor do conteúdo. Estas são associadas ao modelo do usuário para gerar a granularidade do conteúdo, bem como ao domínio do conteúdo para buscar os tipos de mídia e as relações de precedência entre os conceitos a serem apresentados.

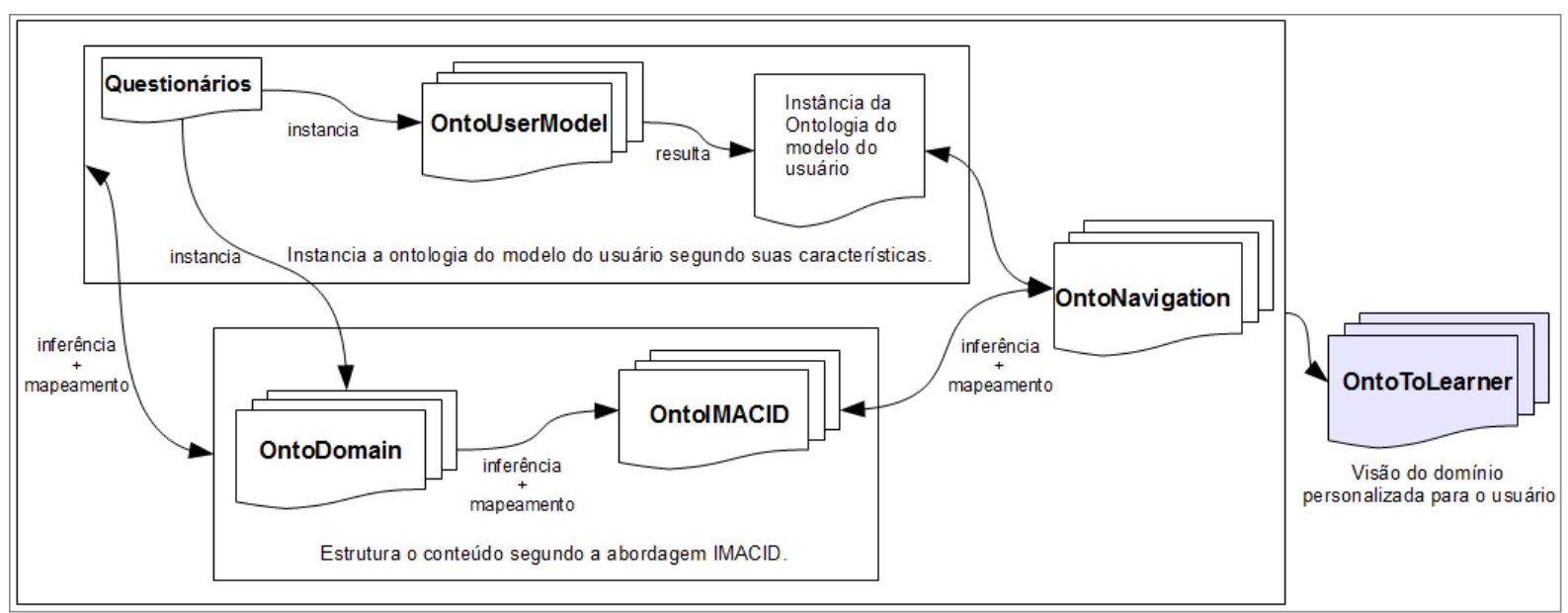

Figura 4.2: Processo para a geração da ontologia de integração OnToToLEARner.

O mapeamento foi feito na ONTOTOLEARNER por meio da identificação das propriedades que são necessárias para a associação dos conceitos, com a finalidade de proporcionar maior manutenibilidade das regras e das associações e para manter a integridade original do conjunto das ontologias. Em decorrência dessas características, pode-se verificar os termos inferência e mapeamento em vários pontos da Figura 4.2. Além 

disso, a ONTOTOLEARNER pode ser instanciada para vários usuários, possibilitando a criação de cenários de aprendizagem personalizados para cada aluno.

Deve-se observar que o processo de composição da ontologia de integração, apresentado de maneira fragmentada, acontece na máquina de inferência de forma simultânea. Em outras palavras, após a instanciação dos conceitos pelos questionários e pelo autor do conteúdo, as propriedades e os conceitos são instanciados ao mesmo tempo pelo reasoner da Protégé, de acordo com a ordem e as características estabelecidas nas consultas e regras de inferência definidas.

Nas próximas seções são discutidos de forma mais detalhada o processo de instanciação para cada ontologia, bem como os mapeamentos, consultas e regras de inferência relacionados.

\subsection{Mapeamento e Instanciação das Ontologias}

A partir do desenvolvimento das ontologias e da integração das mesmas na ONTOTOLEARNER foram elaborados os mapeamentos entre as propriedades a fim de estabelecer os vínculos entre os conceitos e as instâncias dos conceitos do conjunto de ontologias.

O processo de mapeamento é iniciado ao analisar as definições e características das ontologias, levando em consideração as necessidades para a estruturação da ontologia do domínio segundo a abordagem $\mathcal{I M A}-\mathcal{C I D}$ e as diretrizes da navegação e do perfil do usuário. Criam-se propriedades que formalizam e associam os conceitos do domínio e identificam-se regras genéricas para a associação dos conceitos.

O mapeamento na ontologia de integração permite que sejam encontradas as correspondências e as similaridades entre as classes ou conceitos de maneira otimizada, ao utilizar a máquina de inferência na Protégé. Vale ressaltar que, embora as ontologias sejam diferentes, estas são consistentes entre si e têm objetos e propriedades que se inter-relacionam, gerando o conteúdo personalizado para cada usuário de acordo com as regras construídas.

Para as propriedades definidas no mapeamento da ONTOTOLEARNER são modeladas consultas a fim de identificar os objetos instanciados. Dessa forma, atua-se diretamente na construção da personalização e na estruturação do conteúdo. Tais consultas, quando escritas e executadas na máquina de inferência, retornam indivíduos e classes (ou conceitos) relacionados de acordo com as propriedades referidas.

A inferência pode ser caracterizada como a capacidade de identificar raciocínios implícitos entre as propriedades definidas nas ontologias. Neste trabalho, a inferência é 
feita pelo reasoner da Protégé, a partir das combinações das propriedades nas consultas. Isso favorece a personalização da apresentação do conteúdo para o usuário pois, a partir de suas características e dos conceitos instanciados, as associações podem ser feitas de maneira direta pela máquina de inferência.

Na sequência é descrito o processo de instanciação para cada ontologia na ONTOTOLEARNER.

\subsubsection{Instanciação da Onto-Imacid}

Para a instanciação da ONTO-IMACID foram criadas propriedades na ONTOTOLEARner que correspondem aos conceitos da ontologia, as quais são diretamente associadas às propriedades da ontologia da $\mathcal{A L M}$ - CID , propiciando a inferência de relações implícitas identificadas pelo reasoner. Esse procedimento possibilita que o domínio seja instanciado na ontologia global sem que a ONTO-IMACID seja alterada, mantendo assim as características originais da ontologia.

O autor do conteúdo é responsável por associar as relações às instâncias do domínio, tendo papel fundamental para estruturar e relacionar o conteúdo. A instanciação ocorre por meio da associação das propriedades da ontologia OnTOTOLEARNER, relacionando a abordagem $\mathcal{A L M}$ - CID aos indivíduos da ONTO-DomAIn. As propriedades estabelecidas na ontologia global para a ONTO-IMACID podem ser vistas na Figura 4.3.

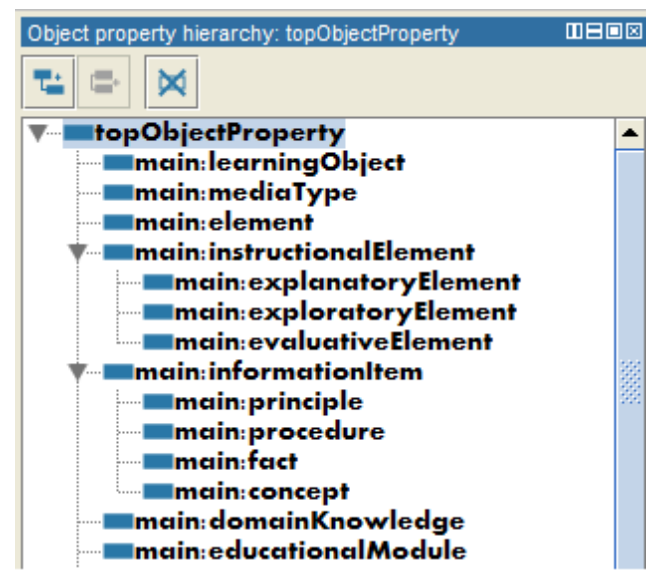

Figura 4.3: OnTO-IMACID: propriedades criadas na OnTOTOLEARnER.

Na Figura 4.3 são descritas as propriedades construídas e que são utilizadas ao associar os indivíduos da ONTO-Domain à abordagem $\mathcal{A}$ IM - CID. Além de manter a integridade da ONTO-IMACID, a criação de propriedades facilita o reúso das classes e das relações, visto que uma propriedade pode ser associada diversas vezes, para domínios e usuários diferentes. Um exemplo de propriedade utilizada é a main : concept que é associada a um indivíduo classificado como conceito na ontologia de domínio, como mostrado na Figura 
4.4. Ao relacionar o indivíduo d:processoAPF da ontologia de domínio à propriedade main: concept, a máquina de inferência verifica as relações e infere que este indivíduo faz parte da classe conceito da ONTO-IMACID (imacid:Concept).

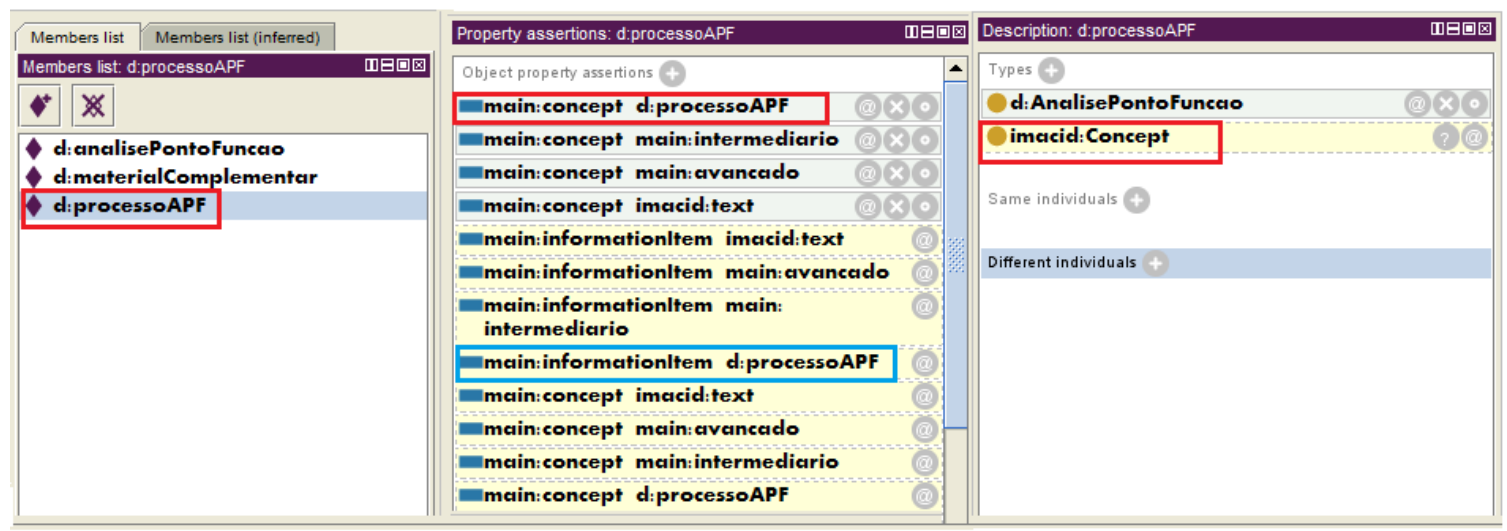

Figura 4.4: Exemplo da instância d:processoAPF associada à ONTOTOLEARNER.

Pode-se observar outra inferência pelo reasoner na Figura 4.4; trata-se da propriedade main:informationItem (destacada pelo retângulo azul), que implica em dizer que o indivíduo d:processoAPF é um item de informação. Esta relação é inferida, pois a propriedade main:concept é uma sub-propriedade de main:informationItem, já que, em conformidade com a abordagem $\mathcal{A L M}$ - CID, sabe-se que um conceito é um item de informação. Essas relações modeladas na ontologia, mesmo que de maneira indireta, são conhecidas pela máquina de inferência e são apresentadas para a instância em questão, ao iniciar o reasoner.

O procedimento de associar as instâncias da ontologia de domínio às propriedades referentes à ONTO-IMACID é feito para todos os indivíduos da ONTO-Domain pelo instrutor. Após a estruturação do conteúdo segundo a abordagem $\mathcal{A} \mathcal{L} M-\mathcal{C I D}$, a instanciação do conteúdo e a execução das inferências, a ONTOTOLEARnER promove a personalização do conteúdo com base no perfil do usuário.

\subsubsection{Instanciação da Onto-Domain}

No contexto deste projeto, a OnTO-Domain foi desenvolvida e instanciada no domínio de Análise de Ponto de Função, como foi descrito na Seção 3.2.2. A Onto-Domain é composta por aproximadamente 120 indivíduos ou instâncias (a maioria do tipo texto), tais conceitos foram extraídos de livros e materiais correlatos.

A instanciação da Onto-Domain, assim como sua construção, é dependente do autor do conteúdo. Espera-se que ao criar ou inserir a ontologia de domínio na OnTOTOLEARNER sejam instanciados os conceitos do domínio, para que posteriormente 


\section{CAPÍTULO 4. ONTOTOLEARNER - UMA ONTOLOGIA DE INTEGRAÇÃO}

PARA PERSONALIZAÇÃO

estes sejam associados à ONTO-IMACID. Neste projeto, a instanciação é feita na ferramenta Protégé, criando os indivíduos para cada conceito e inserindo suas propriedades associadas e seus dados (texto, imagem, link, etc.).

O conteúdo relacionado à APF pode ser dividido em cinco grandes partes, como apresenta a Figura 4.5. Foram estipulados alguns caminhos de apresentação do conteúdo, levando em consideração o possível conhecimento e aptidão do usuário ou aprendiz. O primeiro perfil representa um aprendiz que tem pouco conhecimento, para o qual o conteúdo será apresentado de forma mais resumida, a fim de possibilitar uma maior fixação dos conceitos. Para o segundo perfil, tem-se um aprendiz que já apresenta algum conhecimento do conteúdo; dessa forma, parte dos conceitos são mais detalhados. Por fim, para o terceiro perfil, considerando-se um usuário que tem um conhecimento mais amplo e mais experiência no domínio de APF; para este, a granularidade dos conceitos é maior, a fim de que o conhecimento seja mais detalhado.

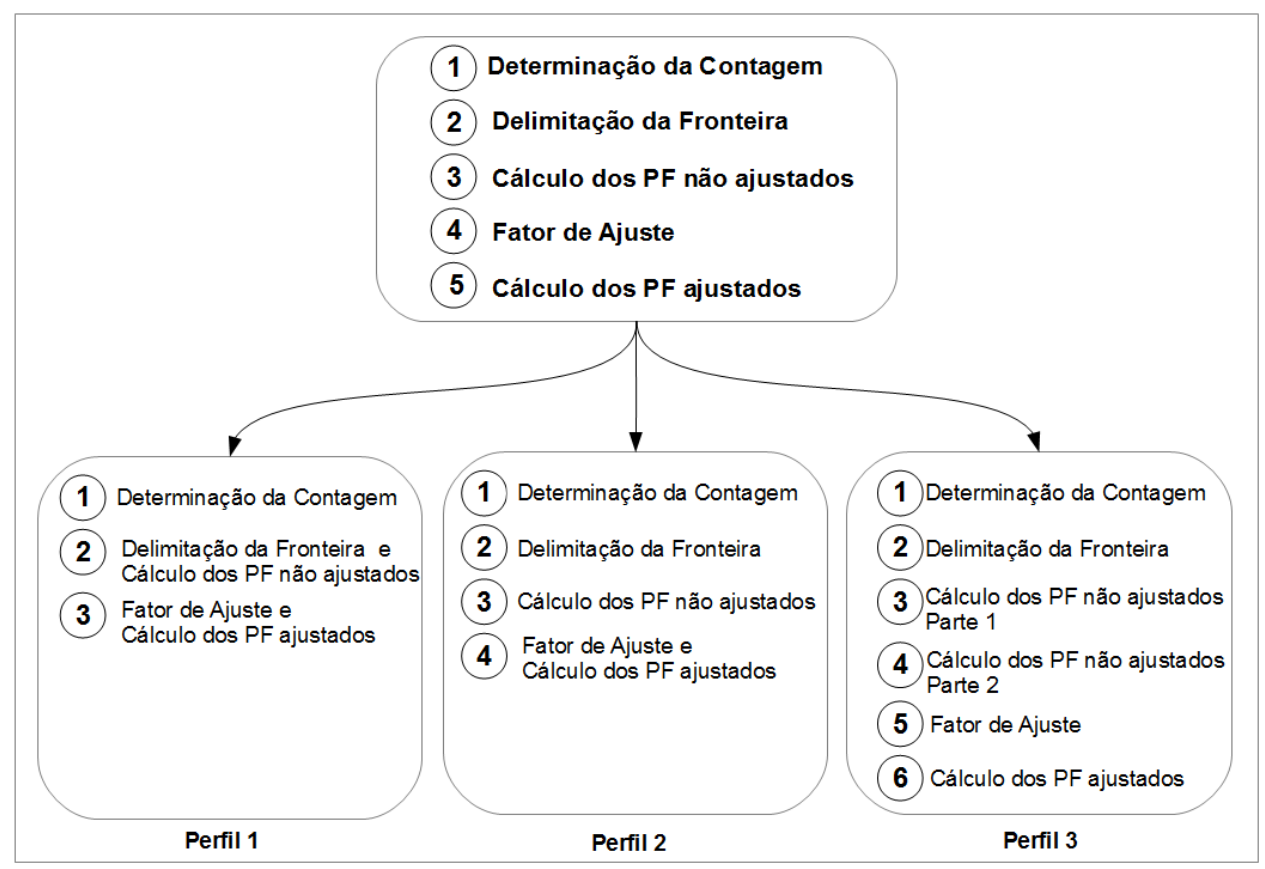

Figura 4.5: Possibilidades de apresentação do conteúdo para a OnTO-Domain.

As possibilidades de apresentação do conteúdo ou granularidade do conteúdo são importantes para instanciar a ontologia do modelo do usuário de acordo com o conhecimento e experiências que o mesmo possui. Além disso, também são relevantes para instanciar parte dos conceitos da ontologia de navegação. Neste trabalho, são definidos três perfis para o nível do conhecimento do usuário: (i) perfil 1: básico; (ii) perfil 2: intermediário; e perfil 3: avançado.

Para a definição do nível de conhecimento do usuário no domínio de APF, que está diretamente relacionado ao conceito user:Knowledge da ONTO-UsERMODEL, a 
instanciação é feita a partir das respostas dos usuários no questionário referente a este domínio. O questionário foi criado com base em questões referentes a provas e aulas, sendo respondido, em sua maioria, por pessoas certificadas em Análise de Ponto de Função. O questionário pode ser consultado no Apêndice C.

A classificação do nível de conhecimento dos usuários é feita de acordo com o resultado obtido no questionário. Os dados da categorização dos níveis são sumarizados na Tabela 4.1 .

Tabela 4.1: Nível de conhecimento para o domínio dos usuários

\begin{tabular}{l|l|l}
\hline \hline Usuário & Acertos & Nível \\
\hline Usuário $A$ & 7 & Básico $(1-7)$ \\
\hline Usuário $B$ & 10 & Intermediário $(8-10)$ \\
\hline Usuário $C$ & 14 & Avançado $(11-15)$ \\
\hline \hline
\end{tabular}

A título de ilustração, neste trabalho foram apresentados cenários de aprendizagem para três usuários (A, B e C), os quais têm, respectivamente, níveis de conhecimento básico, intermediário e avançado, como apresentado na Tabela 4.1. Com isso, pode-se visualizar as diferenças de comportamento na ONTOTOLEARNER, bem como a personalização do conteúdo e de sua apresentação segundo o conhecimento dos usuários.

Por fim, vale destacar que a ontologia de domínio também se relaciona com a ontologia Onto-Navigation. Nesse sentido, é necessário que o autor do conteúdo explicite as relações de precedência entre os conceitos, se estas existirem. Caso contrário, o mapeamento entre as ontologias não será capaz de identificar exceções a respeito da representação do conteúdo, segundo as necessidades do autor. Essas questões são mostradas e discutidas na Seção 4.3.4.

\subsubsection{Instanciação da Onto-UserModel}

A instanciação da ONTO-UserModel pode ocorrer de três maneiras: (i) pelo usuário, por meio do preenchimento de questionários; (ii) pelo autor do conteúdo, ao definir as metas e as atividades do usuário; e (iii) pelo sistema, por meio da extração de informações do usuário e do ambiente (como desempenho, feedback, configuração do ambiente). Esses tipos de instanciação podem ser combinados ou não, ou ainda podem acontecer simultaneamente, dependendo do tipo de conceito e dos objetivo envolvidos.

O questionário exposto no Apêndice A possui questões que ao serem respondidas pelos usuários permitem a instanciação das características referentes à identificação (user:Identification), preferências (user:Preference), traços individuais (user:IndividualTraits), estilo cognitivo (user:CognitiveStyle), estado afetivo 


\section{CAPÍTULO 4. ONTOTOLEARNER - UMA ONTOLOGIA DE INTEGRAÇÃO}

PARA PERSONALIZAÇÃO

(user:AfectiveState), interesses (user:Interest) e competência (user:Competency).

As questões são compostas de duas alternativas e o tempo médio de resposta ficou entre dois e cinco minutos.

Há também um questionário referente ao estilo de aprendizagem dos alunos é exposto no Apêndice B, esse modelo é extraído das características definidas por Soloman e Felder (2001). O estilo de aprendizagem é calculado com base nas 44 respostas do aprendiz, retornando o estilo do usuário: sequencial ou global; visual ou verbal; sensitivo ou intuitivo; indutivo ou dedutivo; e ativo ou reflexivo. As questões são objetivas e têm duas opções, o tempo médio para responder às questões ficou entre 10 e 15 minutos. Vale ressaltar que esses questionários devem ser respondidos uma única vez ao longo do curso ou das aulas apresentadas sobre o domínio.

Para que as instâncias do usuário sejam associadas na ONTOToLEARNER às propriedades e aos conceitos das demais ontologias foram criadas instâncias genéricas que correspondem às possíveis respostas dos questionários. Na Figura 4.6 são apresentados alguns indivíduos que foram criados com este propósito. Podem-se observar, por exemplo, as instâncias userp: Reservado e userp:Verbal que descrevem respectivamente os traços pessoais e o estilo de aprendizagem de um usuário, as quais podem ser associados aos demais conceitos que formam o perfil de um ou mais usuários instanciados na ontologia.

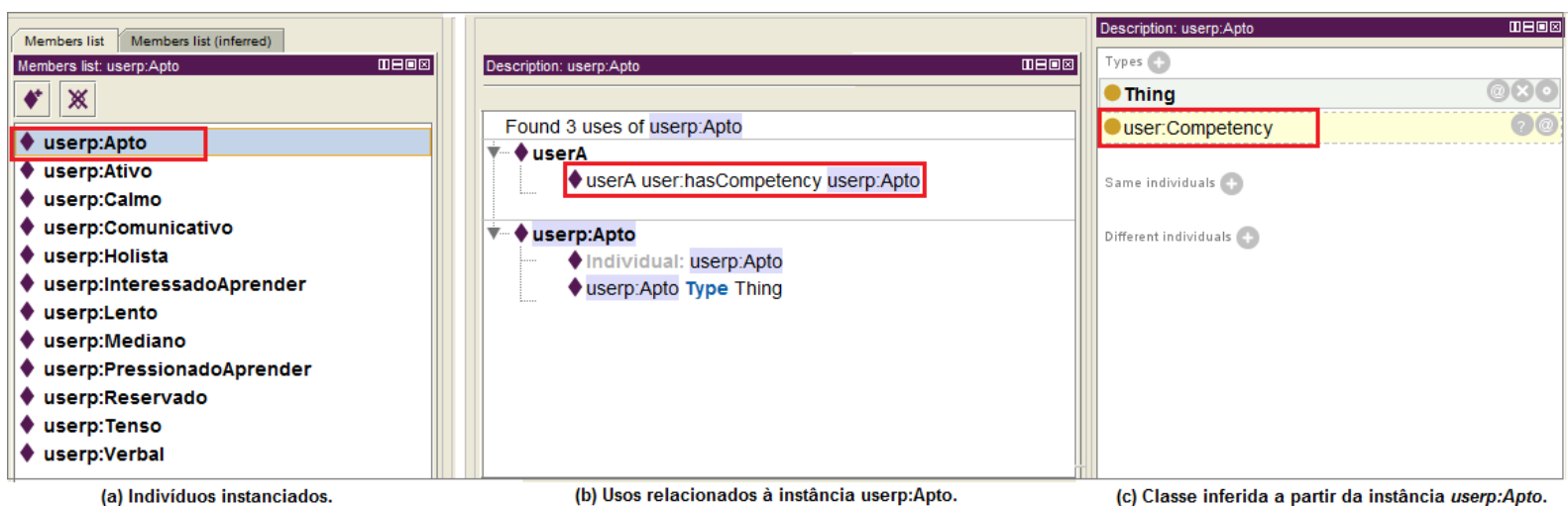

Figura 4.6: Exemplo de uma instância associada à ONTO-UsERMODEL.

$\mathrm{Na}$ Figura 4.6.a estão os indivíduos criados com base nas possíveis respostas para o questionário das características relacionadas aos traços pessoais dos usuários. Esses indivíduos são relacionados aos conceitos da ontologia ONTO-UsERModEL tanto por meio das relações da ontologia de domínio como das relações estabelecidas na OntoToLearner. Na Figura 4.6.b é ilustrada a propriedade (user:hasCompetency) que é relacionada ao userA, que apresenta o perfil básico. Esta propriedade indica que o usuário userA se considera apto, isto é, possui habilidade e competência para aprender o conteúdo. Por fim, na Figura 4.6.c é exibida a classe inferida user : Competency, indicando que a instância user : Apto está relacionada à classe competência na ONTO-USERMODEL. 
É importante destacar a existência de instâncias que podem ser alteradas no decorrer das atividades do usuário. Tratam-se de conceitos que podem ser atualizados de acordo com o andamento de um curso. Por exemplo, o conhecimento (user:Knowledge), a competência (user:Competency) e o background (user:Background) são características que podem ser modificadas em conformidade com os resultados obtidos pelo usuário.

A criação das instâncias referentes aos conceitos da Onto-UserModel, e que formam o perfil do usuário, é essencial para a inserção das características dos usuários na OntoToLearner, proporcionando que as propriedades da ontologia do modelo do usuário sejam utilizadas para vários perfis e usuários na ontologia global. Além disso, o autor do conteúdo pode inserir novos indivíduos, associações e até mesmo propriedades, caso seja necessário, na ontologia global.

Nesta seção foram apresentados os passos necessários para instanciar os usuários, a fim de implementar características e propriedades definidas nas ontologias. Dessa forma, pode-se visualizar os resultados da personalização e estruturação do conteúdo, de acordo com cada perfil de usuário, como será visto na Seção 4.4.

\subsubsection{Instanciação da Onto-Navigation}

A Onto-Navigation é responsável por associar os conteúdos do domínio às características do perfil do usuário, com o intuito de fornecer diferentes apresentações e granularidades do conteúdo. Como visto na instanciação da Onto-Domain (Seção 4.3.2), o autor do conteúdo deve especificar as precedências entre os conceitos, caso seja necessário, para que o mapeamento entre as propriedades e instâncias tenha as associações de acordo com as pré-definições para estruturar os objetos de aprendizagem.

A instanciação da ontologia de navegação está diretamente relacionada ao domínio e às definições estabelecidas pelo autor do conteúdo. Neste caso, não são criados indivíduos relacionados somente à ONTO-NAVIGATION; pelo contrário, utilizam-se os conceitos e as propriedades da ontologia que são associados às propriedades da ONTOTOLEARnER e aos indivíduos da Onto-Domain.

Um exemplo de associação de uma propriedade da OnTO-NAVIGATION pode ser visto na Figura 4.7, na qual o indivíduo d:analisePontoFuncao é associado à propriedade nav: isPrerequisiteFor e ao indivíduo d:materialComplementar. Essa relação implica em dizer que a instância d:analisePontoFuncao é pré-requisito para que o conteúdo da instância d:materialComplementar seja apresentado.

Na Figura 4.7.a é ilustrado o indivíduo d:analisePontoFuncao (da Onto-Domain), que é relacionado à propriedade nav:isPrerequisiteFor da ontologia de navegação. Na Figura 4.7.b são vistas as propriedades referentes ao indivíduo, tanto as que foram 

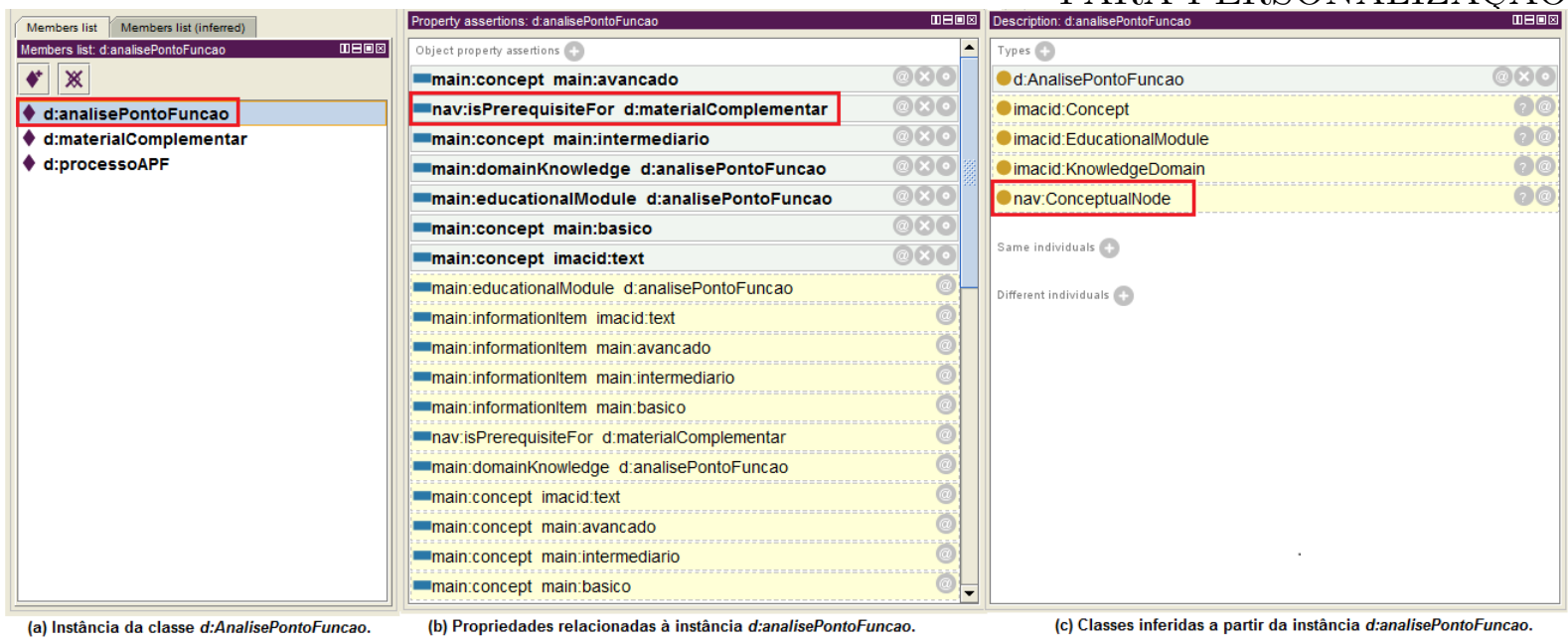

Figura 4.7: Exemplo de uma instância associada à Onto-Navigation.

definidas como as que são inferidas pelo reasoner. Por fim, na Figura 4.7.c estão as classes inferidas a partir das relações estabelecidas para a instância d:analisePontoFuncao.

O autor do conteúdo pode relacionar ou não a precedência dos conceitos para a forma de apresentação aos usuários, dependendo das especificidades do domínio e das metas existentes para cada conteúdo. Nesse sentido, tem-se: (i) a possibilidade de instanciar vários caminhos de aprendizagem de acordo com o perfil do usuário, sem a restrição de conteúdo; ou (ii) a construção de restrições que devem ser observadas ao apresentar o conteúdo. Pode-se dizer então, que a Onto-NAvigation cobre as características do modelo didático da abordagem $\mathcal{A} \mathcal{L} \mathcal{C}$ - CID , pois, para o primeiro caso pode ser feita uma analogia com o modelo didático da abordagem que tem apoio à especificação aberta, e o segundo caso pode ser comparado à especificação fechada.

Além disso, a navegação pode ser diretamente influenciada pelas características do usuário. Um usuário que apresenta pouco conhecimento em um domínio terá uma sequência de aulas diferente do usuário que possui mais conhecimento e experiência. Nesse sentido, a ONTO-NAVIGATION auxilia na criação da granularidade do conteúdo, por meio do uso e das associações entre as propriedades na ontologia ONTOTOLEARNER.

Ao associar um indivíduo da Onto-Domain a uma propriedade da Onto-Navigation, a máquina de inferência encontra os relacionamentos e a lógica de associação implícitas, retornando as inferências entre os conceitos, indivíduos e propriedades na OntoToLearner. Dessa forma, as consultas podem ser geradas sem a necessidade da instanciação manual de todas as ontologias, pois os resultados são obtidos nas consultas, por meio da construção das associações. Este fato permite, de maneira otimizada, a visualização das relações e da comunicação entre as ontologias, admitindo também a criação de diversas consultas de acordo com o domínio. 


\subsection{Exemplo de Instanciação}

Nesta seção será apresentado um exemplo construído na ONTOTOLEARNER a fim de apresentar a instanciação das ontologias e dos usuários para o curso de Análise de Ponto de Função. O curso é formado pelo conteúdo da ontologia de domínio, o qual é composto pelos objetos de aprendizagem e/ou módulos educacionais.

Os perfis dos usuários foram instanciados a partir das respostas enviadas aos questionários e do estabelecimento das relações entre as propriedades das ontologias na OntoTolearner, como exposto nas seções anteriores. Na Figura 4.8 são exibidas as características para os usuários criados - userA, userB e userC respectivamente.

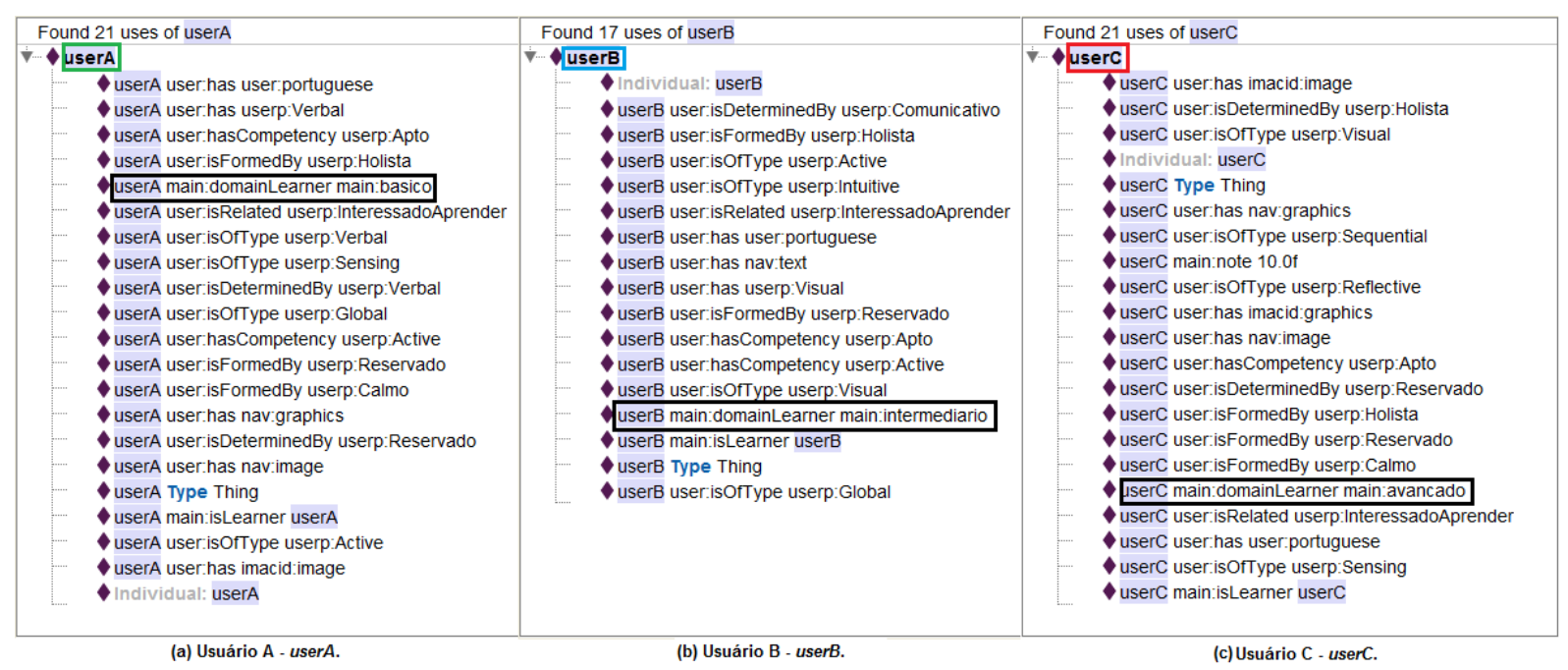

Figura 4.8: Propriedades e suas instâncias para os usuários userA, userB e userC.

Foram escolhidos três usuários com características diferentes, referentes ao estilo de aprendizagem e ao nível de conhecimento, a fim de consultar diferentes visões e apresentação do conteúdo. Tais diferenças podem ser observadas por meio da propriedade main:domainLerner, a qual indica que os usuários userA, userB e userC têm o nível de conhecimento avaliado em básico, intermediário e avançado, respectivamente. Pode-se notar, também, as diferenças entre os estilos cognitivos dos usuários (user:isOfType), sendo: o userA do tipo verbal, sensitivo, global e ativo; o userB do tipo intuitivo, visual, global e ativo; e o userC do tipo sequencial, visual, reflexivo e sensitivo.

Para a instanciação e execução do exemplo foram criados alguns indivíduos que simbolizam as possibilidades padrão para instanciar as classes na ontologia. Os indivíduos que são designados pelo prefixo userp são padrões de respostas dos questionários e que representam os tipos de características relacionadas aos usuários, tais como: userp:Apto, userp:Verbal, userp:Reservado, userp:Calmo, userp:Holista, entre outras. 
Vale ressaltar que as associações das propriedades nos indivíduos referem-se aos conceitos do modelo do usuário, tais como: preferências (user:portuguese, imacid:graphics), competência (user:Apto), estilo cognitivo (userp:Verbal), interesses (userp:InteressadoAprender), estilo de aprendizagem (userp:Verbal, userp:Sensing, userp:Global, userp:Active) e estado afetivo (userp:Calmo).

Percebe-se ainda que as propriedades, em sua maioria, instanciam classes da Onto-UserModel; outras, porém, instanciam as classes da OnTO-Imacid (imacid:graphics) e da Onto-NAVigation (nav:graphics). Há, também, propriedades globais na ONTOTOLEARNER que são formadas por conceitos das diferentes ontologias, a fim de facilitar a generalização e composição das relações. Estas possuem o prefixo main como forma de identificação. No exemplo duas propriedades foram utilizadas: (i) main:domainLearner: designa o nível de conhecimento do usuário para o domínio correspondente; e (ii) main: isLearner: indica que o indivíduo em questão é um aluno.

A partir da instanciação dos usuários, a máquina de inferência consegue extrair informações e características implícitas, que vão além das associações estabelecidas pelo instrutor do conteúdo devido ao apoio das propriedades definidas e das inferências geradas. Na próxima seção são apresentados os resultados obtidos nas consultas, para a personalização de acordo com o perfil do usuário e as regras de inferência extraídas.

\subsubsection{Geração de Consultas e Visualização da Personalização}

As consultas são implementadas utilizando a ferramenta Protégé, por meio de uma sintaxe simples, porém eficiente ao extrair as inferências entre os elementos da OntoToLearner. Ao longo do trabalho foram feitas várias consultas: (i) para extrair elementos da ONTO-IMACID; (ii) para verificar as instâncias da ONTO-DomAIn; (iii) para relacionar os conceitos com o usuário na ONTO-USERMODEL; (iv) para verificar as características de navegação na Onto-Navigation. Além disso, também foram elaboradas consultas complexas, envolvendo várias classes das ontologias na OntoToLeAner, a fim de obter resultados mais completos e envolvendo um número maior de variáveis.

A título de ilustração, na Figura 4.9 é apresentada uma consulta simples que busca os alunos instanciados na ontologia do modelo do usuário. Estes são identificados pela propriedade (main:isLearner) na ONTOTOLEANER, os quais são instâncias da classe user:Role.

Considerando que o conceito é um item de informação, para identificar os conceitos que devem ser vistos pelos usuários, de acordo com o nível de conhecimento de cada um, é necessário verificar os itens de informação na ontologia OntoDomain. Além 


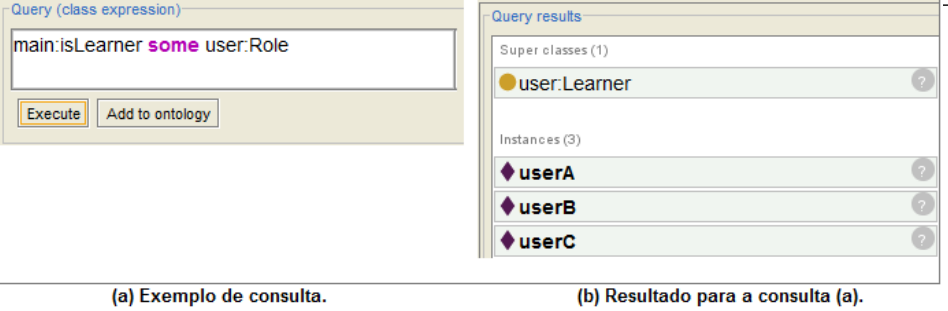

Figura 4.9: Consulta que retorna os usuários instanciados no curso.

disso, é preciso identificar os alunos de acordo com o nível de conhecimento, por meio da propriedade main: domainLearner que pode ser do tipo básico, intermediário ou avançado.

Na Figura 4.10 são apresentadas as consultas construídas para cada nível de conhecimento definido pelo instrutor do conteúdo. As palavras coloridas na consulta são palavras reservadas da sintaxe; as demais palavras são propriedades, classes e/ou indivíduos da OnToToLEANER.

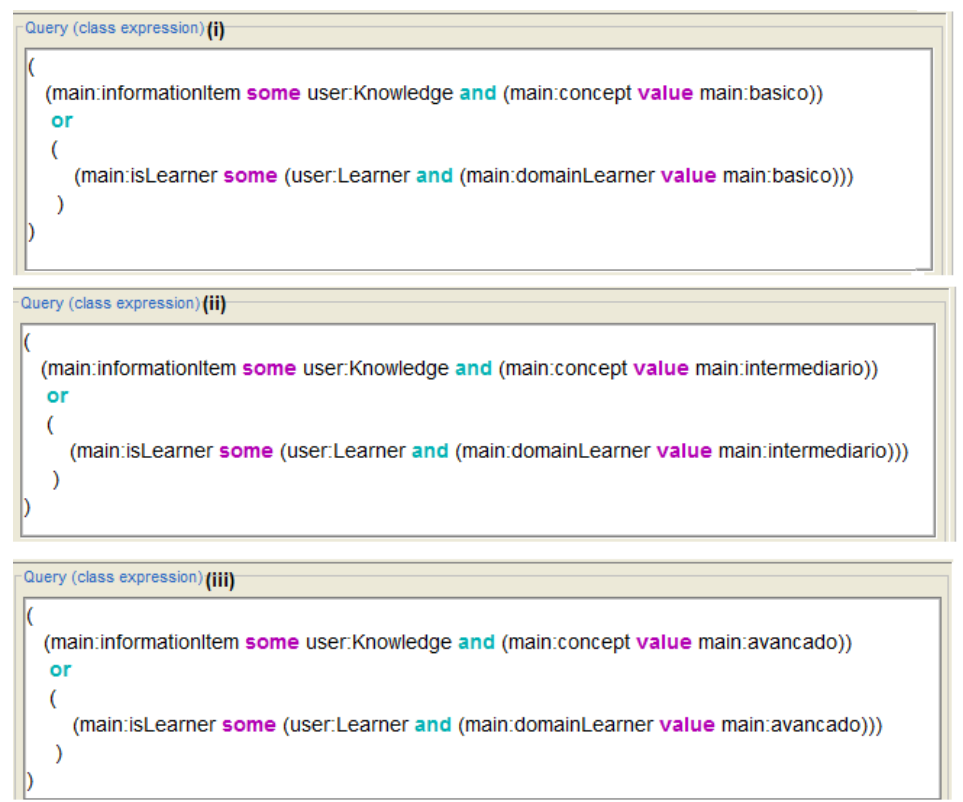

Figura 4.10: Consultas que retornam os usuários instanciados no curso de acordo com o perfil de usuário.

A diferença entre as três consultas apresentadas na Figura 4.10 refere-se à classificação estipulada pelo autor do conteúdo, para cada conceito ou objeto de aprendizagem, associado ao nível de conhecimento do domínio de cada aluno (propriedade main: domainLearner); de forma que, faz-se uma consulta para cada tipo de perfil definido. Este fato pode ser notado ao final de cada consulta, em que os indivíduos main: basico, main:intermediario e main:avancado diferenciam os tipos de usuários existentes na ONTOTOLEARNER.

Após a execução de cada consulta, o conteúdo é apresentado de acordo com o nível de conhecimento em questão (básico, intermediário ou avançado). Os objetos 
de aprendizagem são vistos no formato de indivíduos na ONTOTOLEARNER, conforme ilustrado na Figura 4.11.

\begin{tabular}{|c|c|c|c|c|}
\hline \multicolumn{2}{|l|}{ Query results } & Query results & \multicolumn{2}{|l|}{ Query results } \\
\hline Super classes (1) & & Super classes (1) & Super classes (1) & \\
\hline Thing & (2) & Thing & Thing & (2) \\
\hline Instances (11) & & Instances (16) & Instances (23) & \\
\hline d:projetoMelhoria & 2 & d:determinacaoContagem & d:determinacaoContagem & (2) \\
\hline d:analisePontoFuncao & (2) & d:tiposDados & d:tiposDados & (3) \\
\hline d:determinacaoContagem & 2 & d:fatorAjuste & d:complexidadeFuncionalEE & (3) \\
\hline$\checkmark$ usera & (2) & userB & $\checkmark$ d:fatorAjuste & (2) \\
\hline$\checkmark$ d:fatorAjuste & (2) & $\checkmark$ d:calculoPfajustados & userc & (3) \\
\hline$\checkmark$ d:delimitacaofronteira & (2) & $\checkmark$ d:se & d:calculoPfajustados & (3) \\
\hline d:calculoPfajustados & 2 & $\checkmark$ d:aie & $\checkmark$ d:se & $(2)$ \\
\hline$\checkmark$ d:formulaPFA & 2 & d:formulaPFA-Baseline & $\checkmark$ d:aie & (3) \\
\hline d:baseline & 2 & $\$$ d:ali & d:projetoDesenvolvimento & (2) \\
\hline d:projetoDesenvolvimento & (2) & d:formulaPFA-ProjetoMelhoria & d:materialComplementar & (2) \\
\hline d:calculoPFNaoAjustados & (3) & $\checkmark$ d:ce & d:formulaPFA-Baseline & (2) \\
\hline & & $\checkmark$ d:formulaPFA-ProjetoDesenvolvimento & $\downarrow$ d:ali & (3) \\
\hline & & d:analisePontoFuncao & d:formulaPFA-ProjetoMelhoria & (2) \\
\hline & & $\checkmark$ d:calculoPfNaoAjustados & d:projetoMelhoria & $(3)$ \\
\hline & & $\checkmark$ d:fronteira & $\checkmark$ d:ce & (2) \\
\hline & & d:processoAPF & d:formulaPFA-ProjetoDesenvolvimento & (3) \\
\hline & & & d:analisePontoFuncao & (2) \\
\hline & & & d:baseline & (2) \\
\hline & & & d:calculoPFNaoAjustados & (2) \\
\hline & & & d:complexidadeFuncionalALleAIE & (2) \\
\hline & & & d:fronteira & (2) \\
\hline & & & d:processoAPF & (2) \\
\hline & & & $\checkmark$ d:complexidadeFuncionalSEeCE & (2) \\
\hline
\end{tabular}

Figura 4.11: Instâncias que devem ser apresentadas para cada perfil de usuário.

Conforme descrito na instanciação da OnTo-Domain (Seção 4.3.2), o conteúdo apresenta três visões sobre a Análise de Ponto de Função, uma para cada tipo de nível de conhecimento. Essa fragmentação do conteúdo pode ser definida como a granularidade do conhecimento que deve ser ensinado ao aluno. A granularidade é ilustrada na Figura 4.11, em que para cada usuário e nível correspondente são expostos tipos e quantidades diferentes de objetos de aprendizagem.

Para todos os perfis considerados, os cinco grandes tópicos de ensino da ontologia de domínio para APF são cobertos: (i) determinação da contagem; (ii) delimitação da fronteira; (iii) cálculo dos pontos de função não ajustados; (iv) fator de ajuste; e (v) cálculo dos pontos de função ajustados. Essa sequência de conteúdo acontece, de maneira mais detalhada ou não, em todos os níveis de conhecimento de acordo com o perfil do usuário. As instâncias destes conceitos são: d:determinacaoContagem, d:delimitacaoFronteira, d:fatorAjuste, d:calculoPFNaoAjustados e d:calculoPFAjustados. Vale destacar, ainda, que o conceito inicial sobre o domínio também é apresentado para todos os usuários, por meio da instância d:analisePontoFuncao. 
Ainda de acordo com a Figura 4.11, tem-se que para o nível básico são expostos 10 indivíduos; para o nível intermediário 15 indivíduos; e para o nível avançado 22 indivíduos. Essa configuração deve-se à escolha do instrutor do conteúdo em aumentar a granularidade de conteúdo de acordo com a experiência e a maturidade do aluno no domínio envolvido. Contudo, essa estratégia pode ser alterada pelo autor na instanciação da ontologia Onto-Domain. Além disso, também se pode criar mais perfis para os usuários. Logo, além da OnTOTOLEARnER possibilitar a inserção de qualquer domínio de conhecimento, tem-se a possibilidade de estruturar as especificidades do conteúdo de acordo com o curso e com os objetivos do instrutor, tendo ainda o apoio dos recursos de modelagem propiciados pela abordagem $\mathcal{A}$ IM $-\mathcal{C I D}$.

A diferença da granularidade de conteúdo é um aspecto importante da personalização neste trabalho. Outro aspecto refere-se à forma de apresentação do conhecimento de acordo com o estilo de aprendizagem do usuário e de suas características pessoais, que são extraídas na ONTO-UserModel. Este segundo aspecto da personalização é feito a partir do conjunto de resultados retornado da primeira consulta apresentada (discutida anteriormente na Figura 4.10). De modo geral, faz-se um filtro em conformidade com o estilo de aprendizagem do aluno e suas preferências de mídia. Na Figura 4.12 são exibidas as consultas que retornam os conteúdos de acordo com o nível de conhecimento do aluno e com o tipo de mídia envolvido.

Ao executar a consulta da Figura 4.12 as características do estilo de aprendizagem do aluno são identificadas pela máquina de inferência, que faz as associações entre os itens de informação (imacid:InformationItem), as mídias dos conceitos (main:hasMediaOf), o estilo de aprendizagem (user:LearningStyle) e o domínio de conhecimento do aluno (main:domainLearner). Dessa forma, caso um objeto de aprendizagem esteja disponível no formato de imagem e o aluno seja classificado como visual, este objeto de aprendizagem será exibido ao aluno no formato de imagem.

Em cada perfil são feitas combinações de relações e conceitos para obter o conteúdo de acordo com as preferências do aluno. Pode-se notar, na Figura 4.12, que para os perfis básico e intermediário foram consultados conceitos do tipo "texto" e para o estilo de aprendizagem do tipo "verbal". Já para o perfil avançado foram consultados conceitos do tipo "imagem" e do estilo de aprendizagem caracterizado como "visual". Estes são exemplos de combinações que podem ser pesquisadas na OnTOTOLEARNER, as quais podem ser alteradas em função das necessidades do autor do conteúdo. Ao executar as consultas são exibidos os objetos de aprendizagem que satisfazem às condições estabelecidas, disponibilizando ao aluno o conteúdo de acordo com o seu conhecimento e sua preferência de mídia. Na Figura 4.13 são ilustrados os conceitos correspondentes para as consultas definidas. 
(imacid:Informationltem and main:hasMediaOf value imacid:text) and (main: concept value main:basico]

or (user: LearningStyle and user:has value userp:Verbal)

[main: isLearner some user: Learner] and main: domainLearner value main:basico

(a) Consulta executada para o usuário nível básico e do tipo verbal.

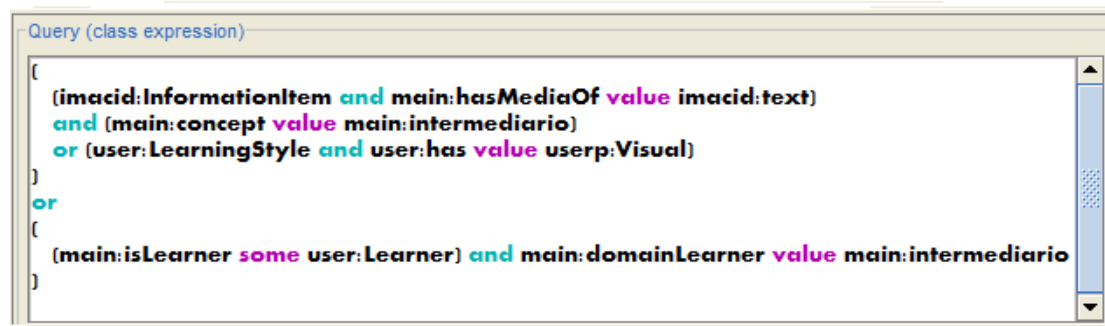

(b) Consulta executada para o usuário nivel intermediário e do tipo visual.

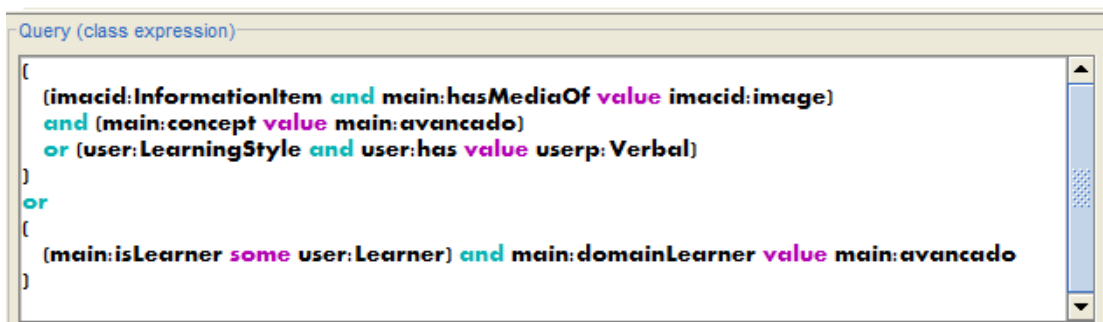

(c) Consulta executada para o usuário nível avançado e do tipo verbal.

Figura 4.12: Consultas estabelecidas de acordo com os estilos de aprendizagem dos usuários.

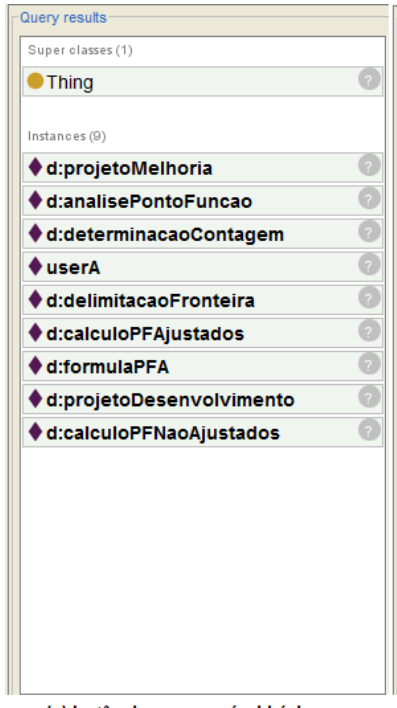

(a) Instâncias para o nivel básico.

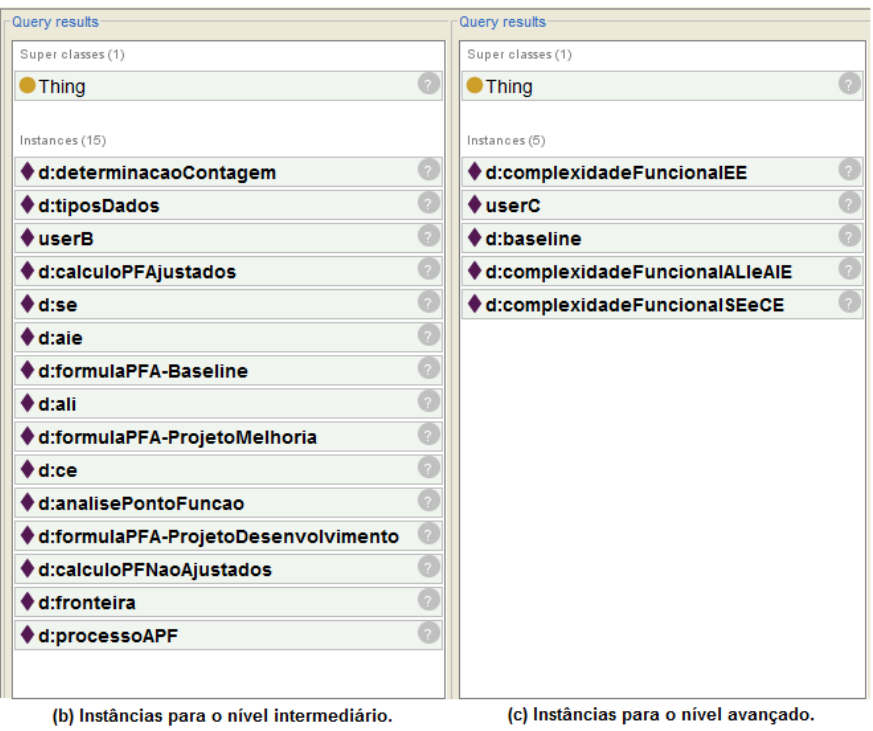

(c) Instâncias para o nível avançado.

Figura 4.13: Instâncias dos conceitos para cada perfil de usuário de acordo com o estilo de aprendizagem.

Nota-se na Figura 4.13 que os resultados diferem para cada perfil de usuário, em conformidade com a consulta executada. Para o nível básico foram encontradas 08 instâncias do tipo texto que devem ser apresentadas ao userA classificado como verbal; 
para o nível intermediário foram identificados 14 instâncias do tipo texto para o userB, que tem o estilo de aprendizagem definido como visual. Nesse caso, as consultas retornam os indivíduos que são do tipo texto, visto que, se não houver instâncias do tipo imagem, mesmo que o usuário seja visual o conteúdo será apresentado no formato de texto, seguindo as definições para o nível de conhecimento em questão. Por fim, para o nível avançado são apresentados 04 indivíduos do tipo imagem para o userC que é classificado como verbal.

Tais resultados mostram que a partir de um conjunto de objetos de aprendizagem são anexadas informações dos conceitos instanciados na ONTO-USERMODEL, para cada perfil e respectivo usuário, propiciando a apresentação do conteúdo no formato de mídia de preferência do aluno.

Um outro tipo de consulta feita na ONTOTOLEARNER refere-se à pesquisa das precedências e pré-requisitos na ordem de apresentação dos objetos de aprendizagem. Caso um objeto de aprendizagem seja associado às propriedades da OnTONAVIGATion, o conteúdo é apresentado ao aluno obedecendo as especificações do instrutor. Dessa forma, dentro do conjunto de objetos de aprendizagem para um determinado aluno, é feita a análise dos elementos de navegação entre os conceitos, para que as definições entre os conceitos permaneçam consistentes.

Além disso, conforme observado anteriormente, existem conceitos dos perfis dos alunos que serão alterados no decorrer das atividades do curso. Ao finalizar cada atividade, o usuário é convidado a fazer uma avaliação ou dar uma opinião a respeito do módulo ensinado, como forma de feedback para o professor. Dessa maneira, são atualizados conceitos como: user:Background, user:Competency, user:Performance e user:Knowledge. Essa atualização pode ser feita com base no envolvimento do aluno; pelo próprio professor, que indica as alterações necessárias; e/ou de forma automática, por meio de relações entre as propriedades instanciadas na ONTOTOLEARNER.

Vale ressaltar que essas consultas originam as regras que compõem a OnTOTOLEARNER, segundo os perfis dos alunos, as quais que podem ser escritas em linguagens específicas (como SWRL e SPARQL). No entanto, neste trabalho as regras foram definidas em nível conceitual, a fim de que possam ser escritas de acordo com a aplicação das ontologias.

O exemplo de integração desenvolvido teve como objetivo evidenciar e demonstrar os resultados obtidos na integração das ontologias na OntoToLEARnER. Em síntese, a personalização do conteúdo pode ser vista com a exposição de diferentes granularidades de objetos de aprendizagem; bem como, por meio das características de navegação e do perfil do usuário associadas.

A OntoToLearner servirá como base para o desenvolvimento de uma aplicação web para disponibilizar de forma automática e intuitiva a construção da personalização do 
conteúdo, de acordo com o modelo do usuário e segundo as características da abordagem $\mathcal{A L M}-\mathcal{C I D}$. As ontologias serão o núcleo da aplicação e serão transparentes para os usuários, não havendo a necessidade de que o instrutor tenha conhecimento no domínio de ontologias ou na ferramenta Protégé.

\subsection{Considerações Finais}

Neste capítulo foi abordada a construção e instanciação da ontologia de integração Ontotolearner. Apresentou-se a composição da ontologia global, bem como o processo para integração e mapeamento das relações das ontologias ONTO-IMACID, Onto-Domain, Onto-Usermodel e Onto-Navigation. Também foram detalhados os mecanismos de instanciação e criação de propriedades em cada ontologia e na ONTOTOLEARnER, com exemplos e descrições para a construção da personalização.

Além disso, foi descrito um exemplo de instanciação da OnToToLEARner, apresentando os resultados para o conteúdo e os perfis dos usuários instanciados. Os resultados foram obtidos por meio das consultas executadas nesta ontologia, ilustrando a utilização da ontologia de integração na personalização do conteúdo e de sua apresentação para o usuário em função de suas características extraídas da ONTO-USERMODEL.

A seguir são sumarizadas as vantagens, limitações e contribuições do trabalho realizado, bem como as principais perspectivas de pesquisa a serem exploradas em trabalhos futuros. 
CAPÍTULO 4. ONTOTOLEARNER - UMA ONTOLOGIA DE INTEGRAÇÃO

PARA PERSONALIZAÇÃO 


\subsection{Visão Geral}

No contexto de ensino e aprendizagem, o desenvolvimento de conteúdos educacionais e a adoção de mecanismos de modelagem representam importantes fatores a serem considerados. Tais mecanismos auxiliam o autor na definição e estruturação dos principais conceitos e relacionamentos associados ao domínio de conhecimento em questão, de forma a facilitar a padronização e reutilização do conteúdo.

Nesse sentido, diversas aplicações com base em ontologias têm sido utilizadas tanto para modelar domínios educacionais como para construir; organizar e atualizar objetos de aprendizagem, perfis de aluno; garantir a formalização, compartilhamento e reúso do conhecimento; navegação e apresentação do conteúdo e caminhos de aprendizagem, entre outras (Gaeta et al., 2009).

Além disso, a representação do conhecimento utilizando ontologias proporciona vantagens tais como definição formal do conhecimento, reusabilidade e interoperabilidade de informações. Facilidades como recuperação dos objetos de aprendizagem, reúso do conteúdo de aprendizagem e personalização do conteúdo a partir do desempenho do usuário podem ser identificadas na literatura (Arapi et al., 2008; Capuano et al., 2009; Gaeta et al., 2009; Jain e Pareek, 2010; Keleberda et al., 2006). 
Neste cenário, este projeto tem como principal objetivo o desenvolvimento e a utilização de ontologias, associando características de modelagem, especificamente os modelos da abordagem $\mathcal{A} \mathcal{L} \mathcal{M}$ - CIDD, na personalização de conteúdo.

No decorrer do trabalho foram desenvolvidas quatro ontologias com a finalidade de prover a personalização do conteúdo, estruturando-o de acordo com a abordagem $\mathcal{A L M}-\mathcal{C L D}$ e com base no perfil do usuário.

- Onto-Imacid: ontologia educacional com base nos modelos da $\mathcal{A} \mathcal{L} M-\mathcal{C D D}$, considerando os modelos conceitual e instrucional da abordagem.

- Onto-UserModel: ontologia do modelo do usuário, desenvolvida para estabelecer as características e preferências do usuário.

- Onto-Navigation: ontologia de navegação, desenvolvida para prover a dissociação das regras de apresentação do domínio.

- Onto-Domain: ontologia de domínio, desenvolvida para instanciar a ontologia da $\mathcal{A I M}-\mathcal{C I D}$ e associar as demais ontologias.

Além disso, considerando o conjunto de ontologias propostas foi construída a OntoToLEARner, uma ontologia global ou de integração, na qual são inseridos o mapeamento entre as relações das ontologias e as regras de inferência para gerar a personalização de forma automática (por meio do reasoner da Protégé). Vale destacar que a decisão de integrar as ontologias em uma ontologia global foi considerada e implementada devido à facilidade para garantir a integridade das ontologias originais, propiciando maior manutenibilidade durante a execução das consultas.

A fim de ilustrar a aplicação da OnTOTOLEARnER, as ontologias foram instanciadas abordando o domínio de Análise de Ponto de Função, levando em consideração a instanciação de três usuários com diferentes níveis de conhecimento. Dessa forma, mostrou-se a diferença da granularidade de conteúdo para cada usuário, de acordo com o nível de conhecimento dos alunos, as relações estabelecidas pelo autor do conteúdo e as inferências entre os conceitos das ontologias.

\subsection{Contribuições}

Como principais contribuições de pesquisa, podem-se destacar os seguintes fatores:

- Proposta de um conjunto das ontologias - Onto-Imacid, Onto-Domain, Onto-Usermodel e Onto-Navigation na OntoToLearner - definidas para personalização do conteúdo. 
- Integração das ontologias propostas em uma ontologia global - ONTOTOLEARNER.

- Estruturação do conteúdo em conformidade com os modelos conceitual e instrucional da abordagem $\mathcal{A} \mathcal{L} \mathcal{M}-\mathcal{C I D}$, por meio da OnTO-ImACID. Ressalta-se que esta ontologia também pode ser utilizada como apoio ao desenvolvimento de ferramentas relacionadas à abordagem de modelagem.

- Definição da granularidade de conteúdo, de acordo com o perfil do usuário e as propriedades definidas na ONTOTOLEARNER, para o domínio instanciado na OnTO-DOMAIN.

- Construção de consultas e regras na OntoToLeARner que atuam na personalização do conteúdo de acordo com as especificações do autor na Onto-Domain.

- Generalidade na inserção do domínio de conteúdo na ontologia Onto-Domain, visto que pode-se inserir qualquer domínio de conhecimento, para que o mesmo seja estruturado na ONTO-IMACID.

- Estabelecimento de diferentes visões do conteúdo, por meio das regras de precedência entre os objetos de aprendizagem instanciados na ONTO-NAVIGATION.

- Compartilhamento e reutilização de ontologias no desenvolvimento da Onto-UserModel, a qual poderá ser reutilizada em aplicações compatíveis com suas definições.

Além disso, outra contribuição refere-se ao fato de que as ontologias podem ser utilizadas separadamente. Aspectos como modelagem de conteúdo, navegação e definição da granularidade do conteúdo e personalização de acordo com o perfil do usuário podem ser abordados de forma individual.

\subsection{Trabalhos Futuros}

Visando dar continuidade à pesquisa desenvolvida, destacam-se os seguintes trabalhos futuros:

- Desenvolvimento de uma aplicação para automatizar o processo de personalização na OntoToLearner. Criar um software ou uma aplicação web em que o conjunto de ontologias seja transparente e, a partir de uma interface amigável e intuitiva, o instrutor possa inserir o conteúdo de uma maneira automática ou mais 
usual, não necessariamente utilizando a ferramenta Protégé. Dessa maneira, o aluno ou usuário terá a possibilidade de visualizar os objetos de aprendizagem no tipo de apresentação de acordo com suas preferências (texto, vídeo, imagem ou animação, por exemplo).

- Construção das regras de inferência em SWRL ou SPARQL para a OntoToLearner. Para que as regras conceituais, definidas por meio das consultas, sejam formalizadas e utilizadas em outros projetos é necessário que se desenvolvam regras de inferência em uma linguagem específica, tal como SWRL, SPARQL ou outra linguagem de construção de regras, a fim de aumentar o reúso e a aplicação dos conceitos de personalização em aplicações correlatas.

- Gerar o perfil do usuário a partir de técnicas de mineração de dados e/ou agentes. A utilização de técnicas de mineração de dados e de extração automática da informação são muito comuns na área de inteligência artificial, e também são aplicadas no campo de desenvolvimento de tecnologias para ensino e aprendizagem. Especificamente, para a modelagem de perfil do usuário, existem diversas abordagens que constroem a personalização do conteúdo com base em resultados obtidos automaticamente, seja por meio de agentes ou por meio de mineração da informação. Nesse sentido, pode-se desenvolver um trabalho em que as informações dos perfis dos usuários sejam extraídas de forma automática ao instanciar a ONTO-USERMOdel na ONTOTOLEARNER.

- Integração da OntoToLeaner em ambientes virtuais de aprendizagem. Investigar e promover a integração da personalização de conteúdo, com base em ontologias, especificamente a OnTOTOLEANER, em ambientes de ensino e aprendizagem. Objetiva-se assim, prover o desenvolvimento de ambientes mais efetivos e interessantes, que sejam adaptativos e mais próximos do usuário, levando em consideração as preferências e traços de cada indivíduo. Ambientes de ensino, tais como Moodle e Sakai, podem ser utilizados para a integração do conjunto de ontologias, com o intuito de personalizar o conteúdo para o aluno de acordo com a base de informações de cada ambiente para seus alunos. 


\section{Referências Bibliográficas}

ADL, A. D. L. I. Scorm specifications. Http://www.adlnet.org/, 2006.

Ahn, J.; Brusilovsky, P. Can concept-based user modeling improve adaptive visualization? In: 18th Conference User Modelong, Adaptation and Personalization UMAP, 2010, p. 4-15.

Arapi, P.; Moumoutzis, N.; Mylonakis, M.; Theodorakis, G.; Christodoulakis, S. A pedagogy-driven personalization framework to support automatic construction of adaptive learning experiences, v. 4823 de Lecture Notes in Computer Science Springer Berlin / Heidelberg, p. 55-65, 2008.

Baldoni, M.; Baroglio, C.; Henze, N. Personalization for the semantic web. In: LNCS Tutorial in Reasoning Web., Springer, 2005, p. 173-212.

Barbosa, E. F. Uma contribuição ao processo de desenvolvimento e modelagem de módulos educacionais. Tese de Doutoramento, ICMC-USP, São Carlos, SP, 2004.

Barbosa, E. F.; Maldonado, J. C. An integrated content modeling approach for educational modules. In: International Conference on Education for the 21st Century. IFIP 19th World Computer Congress., Santiago, Chile, 2006a, p. 17-26.

Barbosa, E. F.; Maldonado, J. C. An integrated content modeling approach for educational modules. In: IFIP International Conference on Education for the 21st Century, Santiago, Chile: Springer, 2006b, p. 17-26.

Barbosa, E. F.; Maldonado, J. C. An integrated content modeling approach for educational modules. In: IFIP 19th World Computer Congress - International Conference on Education for the 21st Century, Santiago, Chile, 2006c, p. 17-26. 
Barbosa, E. F.; Maldonado, J. C. Towards the establishment of a standard process for developing educational modules. In: 36th Annual Frontiers in Education Conference (FIE 2006), San Diego, CA, 2006d.

Barbosa, E. F.; Maldonado, J. C. Collaborative development of educational modules: a need for lifelong learning. In: Magoulas, G. D., ed. E-Infrastructures and Technologies for Lifelong Learning: Next Generation Environments, London, UK: IGI Global, p. 175-211, 2011a.

Barbosa, E. F.; Maldonado, J. C. Towards the establishment of ima-cid: An integrated modeling approach for developing educational modules. Journal of the Brazilian Computer Society (Impresso), 2011b, p. 207-239.

Borges, V. A. ; BARBOSA, E. F. 7th international workshop on ontologies and semantic web for e-learning (swel 2009). Brighton (UK), 2009, p. 71-75.

Borges, V. A. Uma contribuição à modelagem e à geração automática de conteúdos educacionais. Dissertação de Mestrado, São Carlos/SP, Brasil, 2010.

Borst, W. N. Construction of engineering ontologies for knowledge sharing and reuse. Tese de Doutoramento, Enschede, 1997.

Brusilovsky, P. Methods and techniques of adaptive hypermedia. User Modeling and User-Adapted Interaction, v. 6, p. 87-129, 10.1007/BF00143964, 1996.

Brusilovsky, P.; Peylo, C. Adaptive and intelligent web-based educational systems. Int. J. Artif. Intell. Ed., v. 13, p. 159-172, 2003.

Brusilovsky, P.; Wade, V. P.; Conlan, O. From learning objects to adaptive content services for e- learning. International Conference on Intelligent Agent MultiAgent Systems (2009), p. 1-19, 2009.

Capuano, N.; Dell'Angelo, L.; Orciuoli, F.; Miranda, S.; Zurolo, F. Ontology extraction from existing educational content to improve personalized e-learning experiences. In: IEEE International Conference on Semantic Computing, 2009. ICSC '09., 2009, p. 577 -582 .

Carlos Eduardo Vazquez, Guilherme Siqueira Simões, R. M. A. Análise de pontos de função. US: Ed. Érica, 2003.

Chi, Y.-L.; Lee, H.-M. Building conceptual knowledge for managing learning paths in e-learning. In: Lang, J.; Lin, F.; Wang, J., eds. Knowledge Science, Engineering 
and Management, v. 4092 de Lecture Notes in Computer Science, Springer Berlin / Heidelberg, p. 66-77, 2006.

Choi, N.; Song, I.-Y.; Han, H. A survey on ontology mapping. SIGMOD Rec., v. 35, p. 34-41, 2006.

Corcho, O.; Fernández-López, M.; Gómez-Pérez, A. Ontological engineering: Principles, methods, tools and languages. In: Calero, C.; Ruiz, F.; Piattini, M., eds. Ontologies for Software Engineering and Software Technology, Springer-Verlag, p. 1-48, 2006.

Corte, C. K. D.; Barbosa, E. F.; Maldonado, J. C. Estabelecimento de mecanismos de apoio ao ensino integrado de fundamentos de programação e teste de software. CD-ROM., 2006.

Costa, T. S. P.; Gusmão, C. M. G. Definição de ontologia para identificação de riscos de projetos de software. Niterói - RJ - Brasil: Seminário de Pesquisa em Ontologia no Brasil, 2008.

Dean, M.; Schreiber, G. Owl web ontology language reference. 2004.

Devedžic, V. Semantic web and education. US: Springer US, 2006.

Gaeta, M.; Orciuoli, F.; Ritrovato, P. Advanced ontology management system for personalised e-learning. Know.-Based Syst., v. 22, p. 292-301, 2009.

Gasparini, I.; Lichtnow, D.; Pimenta, M.; de Oliveira, J. Quality ontology for recommendation in an adaptive educational system. Intelligent Networking and Collaborative Systems, 2009. INCOS '09. International Conference on, p. 329 -334, 2009.

Gómez-Pérez, A.; Corcho, O.; Fernandez-Lopez, M. Ontological engineering: with examples from the areas of knowledge management, e-commerce and the semantic web. 1st. ed. Springer, 2004.

Gomez-Perez, A.; Corcho-Garcia, O.; Fernandez-Lopez, M. Ontological engineering. Secaucus, NJ, USA: Springer-Verlag New York, Inc., 2004.

Gruber, T. R. Towards principles for the design of ontologies used for knowledge sharing. Int. Journal Human-Computer Studies, v. 43, n. 5/6, 1995.

Guarino, N. Formal ontology in information systems. Trento, Italy: First International Conference on Formal Ontology in Information Systems (FOIS 98), 1998, p. 443-456. 
Heiyanthuduwage, S.; Karunaratne, D. A learner oriented ontology to make effective learning management systems. In: 1st International Conference on Digital Information Management, 2006, 2007, p. $476-481$.

Hooijmaijers, D.; Stumptner, M. Improving integration with subjective combining of ontology mappings. In: Proceedings of the 17th international conference on Foundations of intelligent systems, ISMIS'08, Berlin, Heidelberg: Springer-Verlag, 2008, p. 552-562 (ISMIS'08, ).

Horrocks, I.; Patel-Schneider, P. F.; Boley, H.; Tabet, S.; Grosof, B.; Dean, M. SWRL: A semantic web rule language combining owl and ruleml. Último acesso 20/03/2012, 2004.

Disponível em http://www.w3.org/Submission/SWRL/

IEEE IEEE standard for developing software life cycle processes. IEEE Computer Society, 1996, p. 33-40.

IEEE-LTSC Public and private information (PAPI) for learners (PAPI learner). no. p1484.2.1. 2001.

IMS Learner information package specification: IMS/GLC. 2001.

Isaac, A.; Phipps, J.; Rubin, D. SKOS use cases and requirements. Último acesso em: 21/03/2012, 2007.

Disponível em http://www.w3.org/TR/2007/WD-skos-ucr-20070516/

Jain, S.; Pareek, J. Automatic identification of granularity level of learning document. In: Technology for Education (T4E), 2010 International Conference on, 2010, p. 72 -75 .

Jing, Y.; Jeong, D.; Baik, D.-K. Sparql graph pattern rewriting for owl-dl inference query. In: Fourth International Conference on Networked Computing and Advanced Information Management, 2008. NCM '08., 2008, p. 675 -680.

Jovanovic, J.; D., G.; V., D. Automating semantic annotation to enable learning content adaptation. Lecture Notes in Computer Science (including subseries Lecture Notes in Artificial Intelligence and Lecture Notes in Bioinformatics), v. 4018 LNCS, p. 151-160, 2006a.

Jovanovic, J.; Gasevic, D.; Devedzic, V. Ontology based automatic annotation of learning content. International Journal on Semantic Web and Information Systems, v. 2, p. 91-119, 2006b. 
Keleberda, I.; Repka, V.; Biletskiy, Y. Building learner's ontologies to assist personalized search of learning objects. In: ICEC '06: Proceedings of the 8th international conference on Electronic commerce, New York, NY, USA: ACM, 2006, p. 569-573.

Knutov, E.; De Bra, P.; Pechenizkiy, M. Ah 12 years later: a comprehensive survey of adaptive hypermedia methods and techniques. New Rev. Hypermedia Multimedia, v. 15, p. 5-38, 2009.

Lassila, O.; Mcguinness, D. The role of frame-based representation on the semantic web. Relatório Técnico, Knowledge Systems, Laboratory. Stanford University, Stanford, California, 2001.

Marietto, M. B.; David, N.; Sichman, J. S.; Coelho, H. Requirements analysis of agent-based simulation platforms: state of the art and new prospects. MABS'02, Berlin, Heidelberg: Springer-Verlag, 2002, p. 125-141 (MABS'02, ).

Merrill, M. D. Component display theory. In: Instructional Design Theories and Models: An Overview of their Current States, Hillsdale, NJ: Lawrence Erlbaum, 1983.

Mizoguchi, R. Part 2: Ontology development, tools and languages. 2003.

Mizoguchi, R.; Vanwelkenhuysen, J.; Ikeda, M. Task ontology for reuse of problem solving knowledge. Amsterdam: IOS Press, 1995.

Moro, R.; Falbo, R. A. Avaliação e melhoria de processos de software: Conceituação e definição de um processo para apoiar a sua automatização. Ouro Preto - MG: VIII Simpósio Brasileiro de Qualidade de Software, Concurso de Teses e Dissertações em Qualidade de Software, 2009, p. 406-420.

Neches, R.; Fikes, R. E.; Finin, T.; Gruber, T. R.; Senator, T.; Swartout, W. R. Enabling technology for knowledge sharing, p. 36-56. 1991.

Novak, J. D. Concept mapping: A useful tool for science education. Journal of Research in Science Teaching, v. 27, p. 937-949, 1990.

Soloman, B. A.; Felder, R. M. Index of learning styles questionnaire. Http://www.engr.ncsu.edu/learningstyles/ilsweb.html [26/01/2012], 2001.

Sosnovsky, S.; Dicheva, D. Ontological technologies for user modelling. Int. J. Metadata Semant. Ontologies, v. 5, p. 32-71, 2010.

Turine, M. A. S.; Oliveira, M. C. F.; Masiero, P. C. Designing structured hypertext with HMBS. In: VIII International ACM Hypertext Conference (Hypertext 97), Southampton, UK, 1997, p. 241-256. 
Uschold, M.; Gruninger, M. Ontologies: Principles, methods and applications. Knowledge Engineering Review, 1996.

Verbert, K.; Klerkx, J.; Meire, M.; Najjar, J.; Duval, E. Towards a global component architecture for learning objects: An ontology based approach. In: WOSE: Workshop on Ontologies, Semantics, and E-learning, Springer Verlag, 2004.

Vesin, B.; Ivanovic, M.; Klasnja-Milicevic, A.; Budimac, Z. Rule-based reasoning for altering pattern navigation in programming tutoring system. In: 2011 15th International Conference on System Theory, Control and Computing (ICSTCC), 2011, p. $1-6$.

Wang, H. C.; Hsu, C. W. Teaching-materia design center: An ontology-based system for customizing reusable e-materials. Computers Education, v. 46, n. 4, p. 458-470, times Cited: 7, 2006.

Wang, Q.; na Sui, A.; bin Wang, Y. Knowledge representation and reasoning of cataloging based on domain ontology and rule. In: International Conference on Management and Service Science, 2009. MASS '09., 2009, p. 1 -4.

Wiley, D. A. Learning objects and instructional theory. In: Reigeluth, C. M.; Carr-Chellman, A. A., eds. Instructional-Design Theories and Models, Volume III: Building a Common Knowledge Base, Lawrence Erlbaum, p. 349-364, 2009.

$\mathrm{Xu}, \mathrm{T}$; $\mathrm{Xu}, \mathrm{T}$. An approach for ontology mapping based on semantic and structural information in ontologies. In: 2010 International Conference on Information Management, Innovation Management and Industrial Engineering (ICIII), 2010, p. 636 -639 .

Zheng, C.; Shen, Y.-P.; Mei, L. Ontology mapping based on structures and instances. In: 2010 International Conference on Machine Learning and Cybernetics (ICMLC), 2010 , p. $460-465$. 
Este questionário é composto por questões básicas a respeito das preferências, interesses e competências que serão informadas diretamente pelo usuário, sendo utilizado para instanciar parte do perfil do usuário na ontologia OntoUserModel. As questões são apresentadas a seguir:

1. Informações básicas a seu respeito:
(a) Nome:
(b) E-mail:
(c) Idade:

2. Você prefere quais tipos de mídia para visualizar um conteúdo
(a) texto
(b) imagem e/ou gráfico
(c) vídeo
(d) áudio

3. Você prefere que o conteúdo seja apresentado em
(a) inglês
(b) português

4. Você tende a ser uma pessoa mais
(a) reservada, quieta
(b) expansiva, comunicativa 
5. Você tende a organizar o conteúdo
(a) por partes ou de maneira geral
(b) por reflexões e imagens, por meio do raciocínio
6. Você tende a ser uma pessoa mais
(a) tranquila, paciente e bem-humorada
(b) nervosa, tensa e facilmente fica mal-humorada

7. Você tende a fazer um curso, uma atividade
(a) principalmente por interesse pessoal
(b) principalmente por obrigações curriculares

8. Você se considera uma pessoa
(a) apta e tem facilidade para aprender
(b) mediana e tem dificuldade para aprender
9. Você é mais inclinado a ser
(a) lento e gradativo no aprendizado
(b) ativo e global no aprendizado 
Questionário para calcular o índice de estilo de aprendizagem (Index of Learning Styles), proposto por Soloman e Felder (2001).

1. Eu compreendo melhor alguma coisa depois de
(a) experimentar
(b) refletir sobre ela

2. Eu me considero

(a) realista

(b) inovador(a)

3. Quando penso sobre o que fiz ontem, é mais provável que aflorem
(a) figuras
(b) palavras
4. Eu tendo a

(a) compreender os detalhes de um assunto, mas a estrutura geral pode ficar imprecisa

(b) compreender a estrutura geral de um assunto, mas os detalhes podem ficar imprecisos

5. Quando estou aprendendo algum assunto novo, me ajuda
(a) falar sobre ele
(b) refletir sobre ele 
6. Se eu fosse um(a) professor(a), eu preferiria ensinar uma disciplina
(a) que trate com fatos e situações reais
(b) que trate com ideias e teorias

7. Eu prefiro obter novas informações através de

(a) figuras, diagramas, gráficos ou mapas

(b) instruções escritas ou informações verbais

\section{Quando eu compreendo}

(a) todas as partes, consigo entender o todo

(b) o todo, consigo ver como as partes se encaixam

9. Em um grupo de estudo, trabalhando um material difícil, eu provavelmente
(a) tomo a iniciativa e contribuo com ideias
(b) assumo uma posição discreta e escuto

10. Acho mais fácil
(a) aprender fatos
(b) aprender conceitos

11. Em um livro com uma porção de figuras e desenhos, eu provavelmente
(a) observo as figuras e desenhos cuidadosamente
(b) atento para o texto escrito

\section{Quando resolvo problemas de matemática, eu}

(a) usualmente trabalho de maneira a resolver uma etapa de cada vez

(b) freqüentemente antevejo as soluções, mas tenho que me esforçar muito para conceber as etapas para chegar a elas

\section{Nas disciplinas que cursei eu}
(a) em geral fiz amizade com muitos dos colegas
(b) raramente fiz amizade com muitos dos colegas

\section{Em literatura de não-ficção, eu prefiro}

(a) algo que me ensine fatos novos ou me indique como fazer alguma coisa

(b) algo que me apresente novas ideias para pensar

\section{Eu gosto de professores}

(a) que colocam uma porção de diagramas no quadro

(b) que gastam bastante tempo explicando

\section{Quando estou analisando uma estória ou novela eu}

(a) penso nos incidentes e tento colocá-los juntos para identificar os temas

(b) tenho consciência dos temas quando termino a leitura e então tenho que voltar atrás para encontrar os incidentes que os confirmem 
17. Quando inicio a resolução de um problema para casa, normalmente eu

(a) começo a trabalhar imediatamente na solução

(b) primeiro tento compreender completamente o problema

18. Prefiro a ideia do

(a) certo

(b) teórico

19. Relembro melhor

(a) o que vejo

(b) o que ouço

20. É mais importante para mim que o professor

(a) apresente a matéria em etapas seqüenciais claras

(b) apresente um quadro geral e relacione a matéria com outros assuntos

21. Eu prefiro estudar

(a) em grupo

(b) sozinho(a)

22. Eu costumo ser considerado(a)

(a) cuidadoso(a) cm os detalhes do meu trabalho

(b) criativo(a) na maneira de realizar meu trabalho

23. Quando busco uma orientação para chegar a um lugar desconhecido, eu prefiro
(a) um mapa
(b) instruções por escrito

\section{Eu aprendo}

(a) num ritmo bastante regular. Se estudar pesado, eu "chego lá"

(b) em saltos. Fico totalmente confuso(a) por algum tempo, e então, repentinamente eu tenho um "estalo"

\section{Eu prefiro primeiro}

(a) experimentar as coisas

(b) pensar sobre como é que eu vou fazer

26. Quando estou lendo como lazer, eu prefiro escritores que

(a) explicitem claramente o que querem dizer

(b) dizem as coisas de maneira criativa, interessante

27. Quando vejo um diagrama ou esquema em uma aula, relembro mais facilmente
(a) a figura
(b) o que o professor disse a respeito dela 
28. Quando considero um conjunto de informações, provavelmente eu
(a) presto mais atenção nos detalhes e não percebo o quadro geral
(b) procuro compreender o quadro geral antes de atentar para os detalhes

29. Relembro mais facilmente

(a) algo que fiz

(b) algo sobre o que pensei bastante

30. Quando tenho uma tarefa para executar, eu prefiro

(a) dominar uma maneira para execução da tarefa

(b) encontrar novas maneiras para execução da tarefa

31. Quando alguém está me mostrando dados, eu prefiro

(a) diagramas ou gráficos

(b) texto sumarizando os resultados

32. Quando escrevo um texto, eu prefiro trabalhar (pensar a respeito ou escrever)

(a) a parte inicial do texto e avançar ordenadamente

(b) diferentes partes do texto e ordená-las depois

33. Quando tenho que trabalhar em um projeto em grupo, eu prefiro que se faça primeiro

(a) um debate (brainstorming) em grupo, onde todos contribuem com ideias

(b) um brainstorming individual, seguido de reunião do grupo para comparar as ideias

34. Considero um elogio chamar alguém de
(a) sensível
(b) imaginativo

35. Das pessoas que conheço em uma festa, provavelmente eu me recordo melhor

(a) de suas aparências

(b) do que elas disseram sobre si mesmas

36. Quando estou aprendendo um assunto novo, eu prefiro

(a) concentrar-me no assunto, aprendendo o máximo possível

(b) tentar estabelecer conexões entre o assunto e outros com ele relacionados

37. Mais provavelmente sou considerado(a)
(a) expansivo(a)
(b) reservado(a)

38. Prefiro disciplinas que enfatizam
(a) material concreto (fatos, dados)
(b) material abstrato (conceitos, teorias) 
39. Para entretenimento, eu prefiro
(a) assistir televisão
(b) ler um livro

40. Alguns professores iniciam suas preleções com um resumo do que irão cobrir. Tais resumos são
(a) de alguma utilidade para mim
(b) muito úteis para mim

41. A ideia de fazer o trabalho de casa em grupo, com a mesma nota para todos do grupo
(a) me agrada
(b) não me agrada

42. Quando estou fazendo cálculos longos

(a) tendo a repetir todos os passos e conferir meu trabalho cuidadosamente

(b) acho cansativo conferir meu trabalho e tenho que me esforçar para fazê-lo

43. Tendo a descrever os lugares onde estive
(a) com facilidade e com bom detalhamento
(b) com dificuldade e sem detalhamento

44. Quando estou resolvendo problemas em grupo, mais provavelmente eu

(a) penso nas etapas do processo de solução

(b) penso nas possíveis consequiências, ou sobre as aplicações da solução para uma ampla faixa de áreas. 
APÊNDICE B. QUESTIONÁRIO SOBRE ESTILO DE APRENDIZAGEM 


$\bar{c}$

\section{Questionário sobre APF}

Este questionário foi aplicado aos usuários para a identificação do nível de conhecimento em Análise de Pontos de Função. As questões abaixo apresentam diferentes graus de complexidade, tendo sido atribuídos pesos para classificação do nível de conhecimento (básico, intermediário e avançado), bem como o número de acertos do usuário para efetuar o resultado da classificação.

\section{Questão 01}

A APF auxilia a compreender e agir sobre problemas típicos de gerenciamento de projetos, tais como baixos custos, atrasos no pagamento, insatisfação do usuário e produtividade de desenvolvedores, bem como sobre as dificuldades de medição do progresso do projeto.

( ) Certo

( ) Errado

\section{Questão 02}

Análise por pontos de função executa a medição do software determinando a quantidade de funcionalidades que o software fornece ao usuário baseado principalmente na arquitetura lógica.

( ) Certo

( ) Errado

\section{Questão 03}

O objetivo da análise por pontos de função é medir as funcionalidades que o usuário requisita e recebe e, também, medir o desenvolvimento e manutenção do software com 
dependência na implementação utilizada pela empresa.

( ) Certo
( ) Errado

\section{Questão 04}

O processo de contagem dos pontos de função deve ser simples o suficiente para minimizar a sobrecarga do processo de medida e consistente dentre os vários projetos e organizações.
( ) Certo
( ) Errado

\section{Questão 05}

Se duas aplicações mantiverem o mesmo arquivo lógico interno, então esse arquivo será contado apenas na aplicação que detém o arquivo físico.
( ) Certo
( ) Errado

Questão 06 A identificação do propósito da contagem determina o que se pretende atingir com a contagem que será feita e qual o problema que se pretende resolver com ela.
( ) Certo
( ) Errado

Questão 07 Determinação do tipo de contagem: composta por três tipos de contagem, sendo um deles, o projeto de desenvolvimento, que mede todas as funções que o projeto entregará e eventuais funções de conversão de dados.
( ) Certo
( ) Errado

Questão 08 Cálculo do fator de ajuste representa a influência de requisitos técnicos e de qualidade no tamanho do software.
( ) Certo
( ) Errado

Questão 09 O cálculo dos pontos de função ajustados consiste basicamente em multiplicar o fator de ajuste pelos pontos de função não ajustados.
( ) Certo
( ) Errado

\section{Questão 10}

Uma consulta que possua contador incrementado é considerada uma saída externa.
( ) Certo
( ) Errado

\section{Questão 11}

A precisão de estimativas de tamanho, que depende de informações que nem sempre estão disponíveis no início dos projetos, auxilia a discussão de contratos ou determinação da 
viabilidade do projeto em termos da análise de custos e benefícios.

( ) Certo
( ) Errado

\section{Questão 12}

$\mathrm{Na} \mathrm{APF}$, a precisão da estimativa melhora à medida que se obtém mais informações da análise e do projeto de sistemas. Assim, é possível estimar o tamanho do software continuamente ao longo do processo de desenvolvimento do projeto. No método backfiring, o número de pontos de função de uma aplicação é derivado a partir de seu tamanho físico, que é assumido linear entre os tamanhos funcional e físico.
( ) Certo
( ) Errado

\section{Questão 13}

A APF considera mais importante o número de linhas de código do que as funcionalidades criadas.
( ) Certo
( ) Errado

\section{Questão 14}

A APF pode ser aplicada antes do código ser escrito, baseando-se na descrição arquitetural do projeto.
( ) Certo
( ) Errado

\section{Questão 15}

De acordo com o manual de contagem de pontos de função, consulta externa é um processo elementar que envia dados ou informações de controle para fora da fronteira, sendo considerada componente funcional básico.
( ) Certo
( ) Errado 